The University of Southern Mississippi

The Aquila Digital Community

Dissertations

Summer 2019

\title{
Enablers and Barriers Influencing African American \\ Administrators' Career Advancement at Predominantly White Institutions of Higher Learning
}

Larry Webster

University of Southern Mississippi

Follow this and additional works at: https://aquila.usm.edu/dissertations

Part of the Educational Leadership Commons, and the Organization Development Commons

\section{Recommended Citation}

Webster, Larry, "Enablers and Barriers Influencing African American Administrators' Career Advancement at Predominantly White Institutions of Higher Learning" (2019). Dissertations. 1696.

https://aquila.usm.edu/dissertations/1696

This Dissertation is brought to you for free and open access by The Aquila Digital Community. It has been accepted for inclusion in Dissertations by an authorized administrator of The Aquila Digital Community. For more information, please contact Joshua.Cromwell@usm.edu. 
ENABLERS AND BARRIERS INFLUENCING AFRICAN AMERICAN

ADMINISTRATORS' CAREER ADVANCEMENT AT

PREDOMINANTLY WHITE INSTITUTIONS

OF HIGHER LEARNING

by

Larry Cal Webster, Jr.

\begin{abstract}
A Dissertation
Submitted to the Graduate School, the College of Arts and Sciences

and the School of Interdisciplinary Studies and Professional Development at The University of Southern Mississippi

in Partial Fulfillment of the Requirements

for the Degree of Doctor of Philosophy
\end{abstract}

Approved by:

Dr. H. Quincy Brown, Committee Chair

Dr. Heather M. Annulis

Dr. Cyndi H. Gaudet

Dr. Dale L. Lunsford

Dr. H. Quincy Brown

Committee Chair
Dr. Cyndi H. Gaudet

School Director
Dr. Karen S. Coats

Dean of the Graduate School

August 2019 


\section{COPYRIGHT BY}

Larry Cal Webster, Jr.

2019

Published by the Graduate School

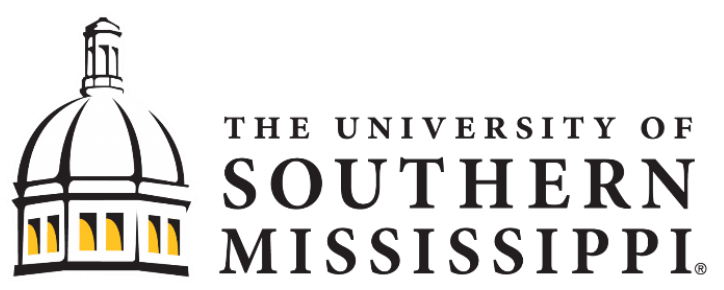




\begin{abstract}
Many Predominantly White Institutions (PWIs) of higher learning do not have enough African Americans to lead their institutions in curriculum development, mentoring, recruitment, and governance (Reyes \& Rios, 2005). Previous studies have attributed the modest representation of African American administrators to systemic barriers impeding the recruitment and advancement of African Americans at PWIs of higher learning (Jones, 2007; Perna, Gerald, Baum, \& Milem, 2007). Ideally, the administrative leadership at PWIs of higher learning would adequately represent-ethnically and racially_ - its student population (Higgs, 2014). Levin, Walker, Haberler, and JacksonBoothby (2013) suggest minimal progress in hiring African American administrators at PWIs of higher learning has been made, failing to keep pace with the increasing number of African American students matriculating at those institutions. Therefore, the purpose of this study was to explore and identify enablers and barriers contributing to African Americans' career advancement into administrative positions at PWIs of higher learning. This study's design was qualitative phenomenological. The results of this study derived from the analysis of the participants' demographic information and interview transcripts. The analysis yielded 23 emergent themes clustered into seven of the eight overall themes regarding the enablers and barriers influencing the career advancement of African Americans at public two and four-year PWIs in Mississippi. The findings from the study suggest the creation of a state and national mentoring program in addition to hiring strategies aimed at growing the pipeline of potential African American administrators could lead to PWIs having a workforce that adequately represents its student population. Consequently, increasing African American representation throughout various levels of
\end{abstract}


the institution (e.g., faculty, staff, support staff, administration), which could increase PWIs ability to recruit, retain and graduate more African American students. 


\section{ACKNOWLEDGMENTS}

First and foremost, I would like to give honor and praise to my Lord and Savior Jesus Christ, through whom all of my blessings flow and to God Almighty for giving me the strength and courage to complete this journey. For without His grace and mercy, I would not have persevered.

I want to express my sincere gratitude to a few individuals who had a significant impact on my development — first, Dr. Quincy Brown, my committee chair. At the beginning of this journey, I never imagined selecting you as my chair. Not because of anything you said or did but because of your stern look and the stories I heard before taking your classes. However, I am so glad I did, and even more grateful you accepted. Thank you, Sir, for your guidance, mentorship, and most of all your friendship. You made what was once thought, by me, to be the impossible, possible. You have inspired me and motivated me in more ways than I can explain, and I am forever grateful. To my committee members: Dr. Annulis, Dr. Gaudet, and Dr. Lunsford, there were so many times throughout this process I thought I was not going to make it. I felt like an imposter, who was not smart enough or worthy of such an honor but at various points throughout this program, each one of you said something or made a gesture that gave me the belief that I could be successful. I am forever thankful. To Suzy Robinson and Robin Johnson, thank you for taking care of all of our needs during in-person and registration. Your work behind the scenes made it easy for us to focus on just being doctoral students, which was hard enough. 
To my ride or die partner in crime, my sister from another mother and father, Valeria Williams. Thank you, for keeping your promise to enroll in the program. We have been on one heck of a ride these past three years, and I don't know if I would have been successful without you. Thanks for always answering the phone, regardless of what time I called. Throughout this process, you have motivated me, pushed me, and been one of my biggest cheerleaders. Thanks for being a constant in my life for the past 26 years. We are forever the number 11, and you will always be my little sister.

To my children, Branden, Ebonee, and Larry Caleb, thank you for being so unselfish. Over the last four years, I have missed some major events and milestones in your life, and I have taken time away from you all that we cannot get back, and for that, I do apologize. I love you all more than life itself, and for your sacrifices, I am eternally grateful.

To my beautiful wife, Michelle, your sacrifice throughout this process has been immeasurable. We knew this journey would be a difficult one, but I don't think either of us really knew what was to come. We started this journey only a year after being married, and a year later, we were expecting a new addition to the family. You immediately were thrust into the throes of having to take care of two teenagers and a newborn, while I was indulged in all things school and work related. You are my superhero and the wind beneath my wings. Thanks for loving me unconditionally.

Last, but not least, I want to thank my mother, who has always supported me and challenged me to do more. You never stopped believing in me, even during times when I did not believe in myself. When it seemed like the world was against me and the streets 
were calling me, you prayed for me, and I am thankful that God heard your prayers and answered them. Thank you for teaching me how to get up when I fall down. 


\section{DEDICATION}

I want to dedicate this research posthumously to my grandmother Almeta "Toot" Rhodes. In spite of having only a third-grade education, she instilled in me the importance of having a college education. It was because of her that I enrolled and because I was afraid of disappointing her that I finished. She sacrificed so much for me so that I could have this opportunity. Thank you, grandma, for the tough love, the stories, and all of the life lessons. Your legacy will live on in my children.

To my children Branden, Ebonee, and Larry Caleb you all are and will continue to be a part of what motivates me to succeed. Let this research serve as a testament that if you put your mind to it, work hard, and pray, the impossible is possible. Remember, no one but you can determine your future.

Lastly, I dedicate this dissertation to all of the African American youth who come from where I came from. No, not geographically, but from a space and a place where it seems as if all odds are against you. Put your faith in God, and understand your beginning does not determine your ending. Keep pressing onward and upward toward the light. 


\section{TABLE OF CONTENTS}

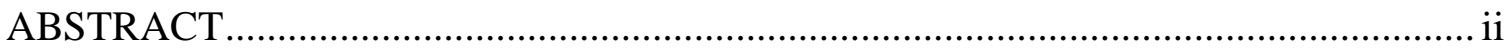

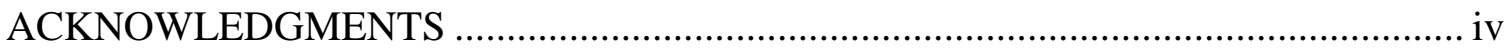

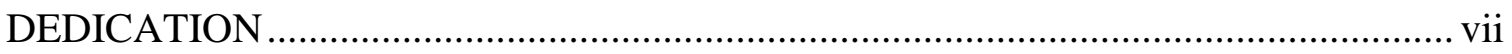

LIST OF TABLES ...................................................................................... xiii

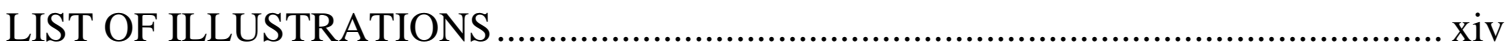

LIST OF ABBREVIATIONS .........................................................................

CHAPTER I - INTRODUCTION .................................................................... 1

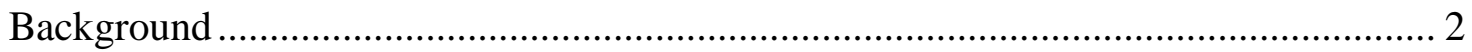

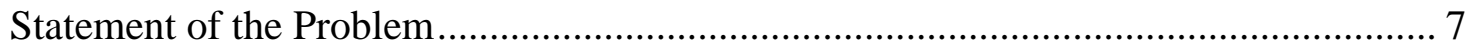

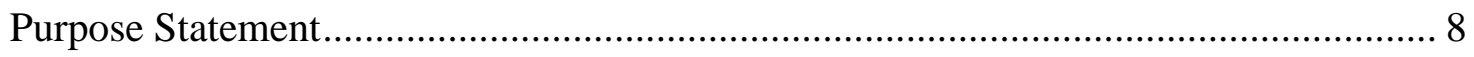

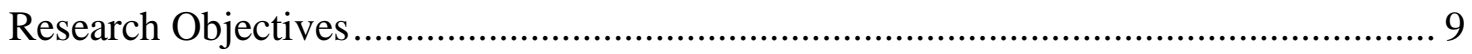

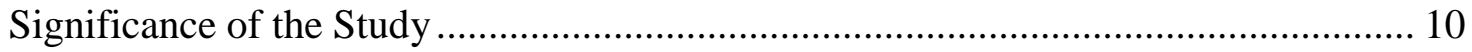

Conceptual Framework ................................................................................ 10

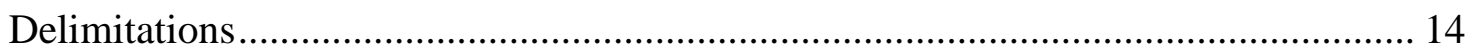

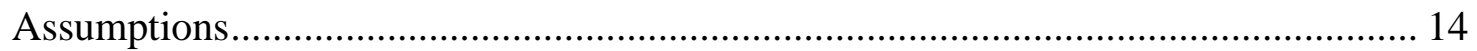

Definition of Terms........................................................................................... 15

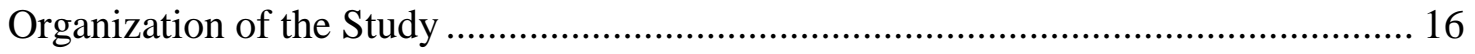

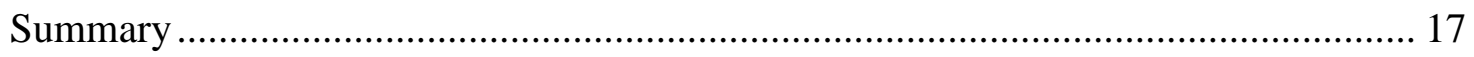

CHAPTER II - LITERATURE REVIEW ….................................................... 18

Historical Perspective on Race and Education ...................................................... 18

viii 
Civil Rights Act of 1964

Affirmative Action

Adams v. Richardson 1972 24

The United States v. Fordice 1992 _.................................................................... 25

Historically Black Colleges and Universities (HBCUs) ................................... 26

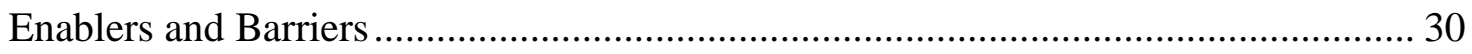

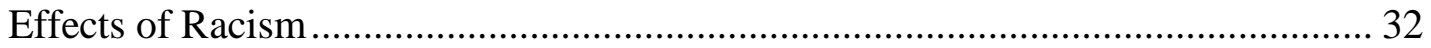

Perspective on Advancement Opportunities .................................................... 36

Development and Advancement Strategies ..................................................... 39

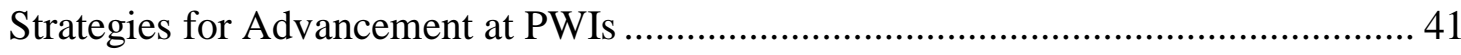

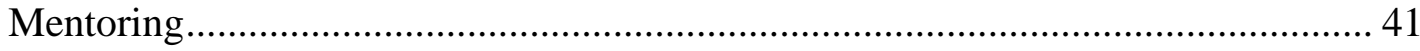

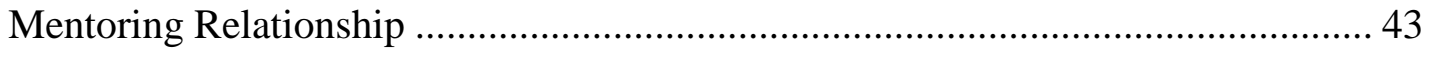

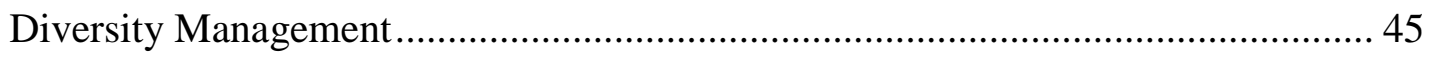

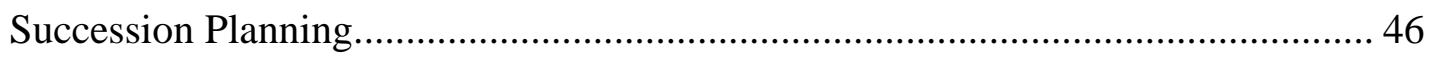

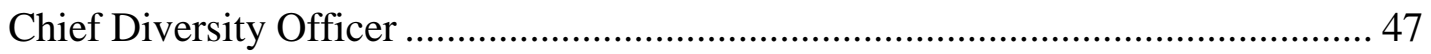

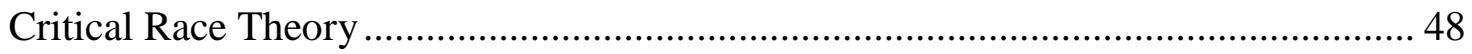

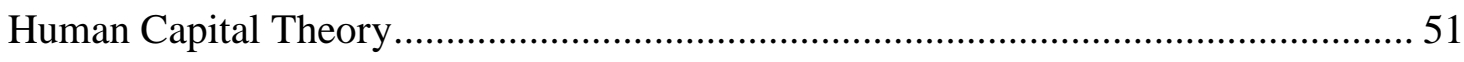

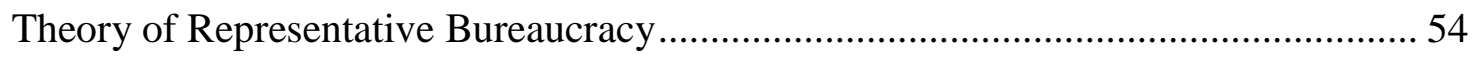

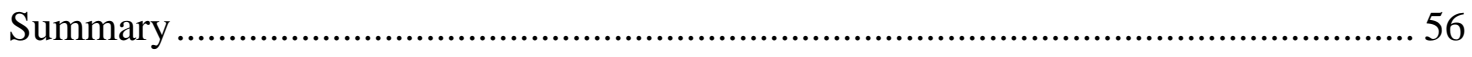

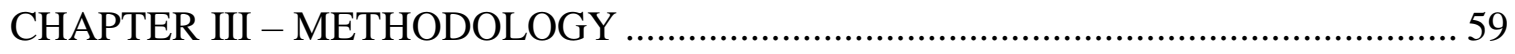




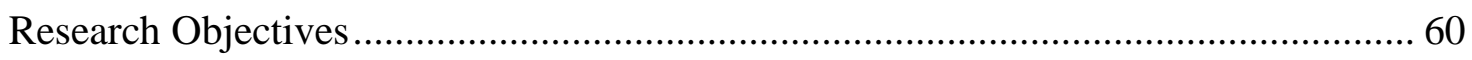

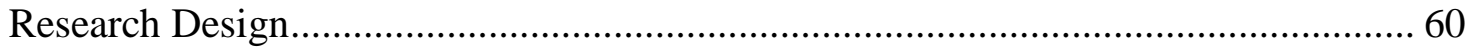

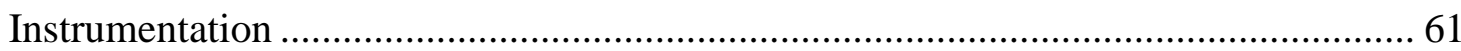

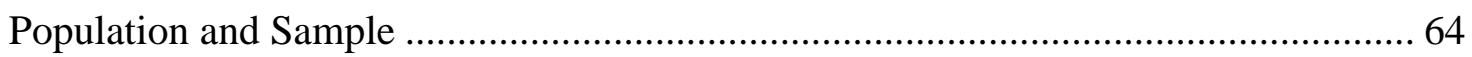

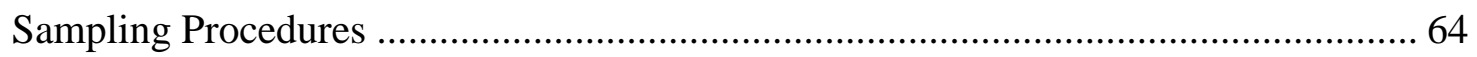

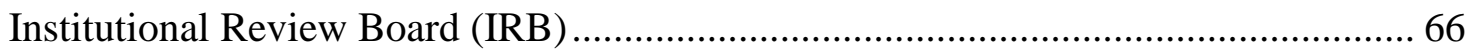

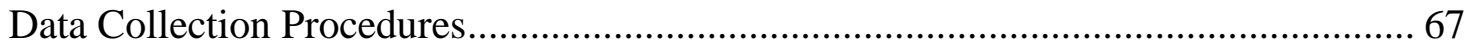

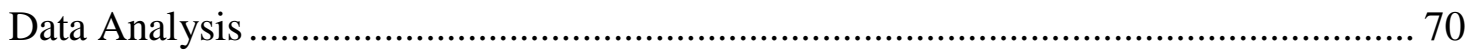

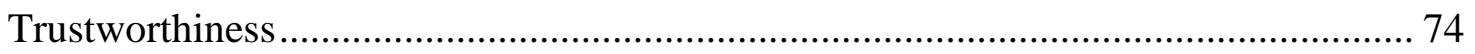

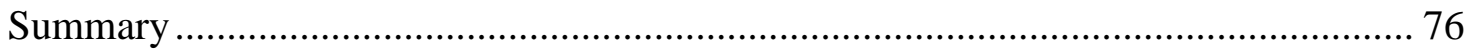

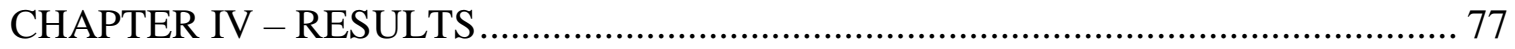

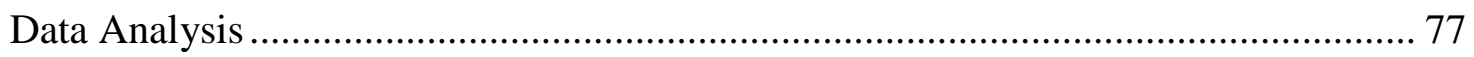

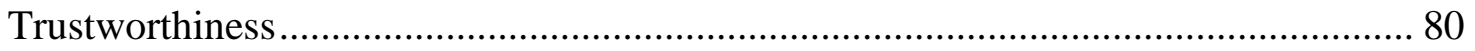

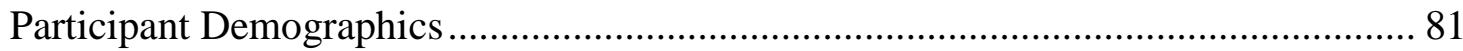

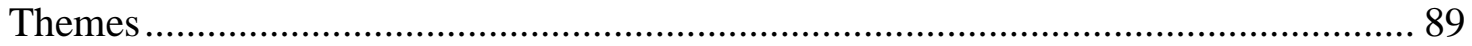

Themes Associated with Internal and External Enablers ........................................ 89

Themes Associated with Internal and External Barriers........................................ 105

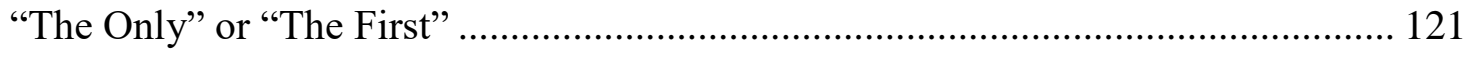

Perspectives Toward Advancement Opportunities ................................................ 124

Strategies Addressing Racial Diversity ........................................................ 126 
Research Objectives and Theme Correlation

Summary

CHAPTER V - CONCLUSION

Summary of the Study

Summary of Results

Findings, Conclusions, and Recommendations 134

Implications of Limitations. 141

Recommendations for Further Research 142

Discussion 143

Summary 144

APPENDIX A - IRB Approval Letter. 146

APPENDIX B - Initial Email to Participants 147

APPENDIX C - Consent Form 148

APPENDIX D - Initial Email to Referred Participants ................................................... 150

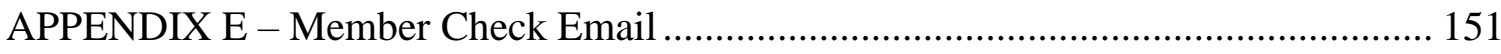

APPENDIX F - One-on-One Interview Protocol....................................................... 152

APPENDIX G - One-on-One Interview Questions................................................... 155

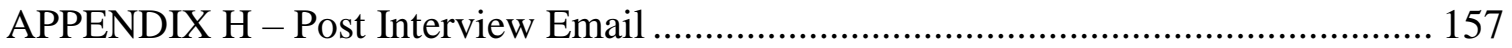

APPENDIX J - Focus Group Demographic Form ....................................................... 159

APPENDIX K - Focus Group Protocol.......................................................................... 160

APPENDIX L - Focus Group Interview Questions ………………………………...... 162 
APPENDIX M - Transcript Analysis Exerpt ........................................................ 164

APPENDIX N - Coding Board ......................................................................... 165

APPENDIX O - Emergent Theme Matrix ............................................................. 166

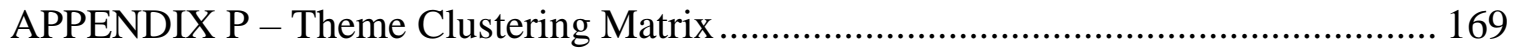

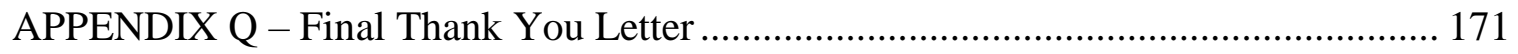

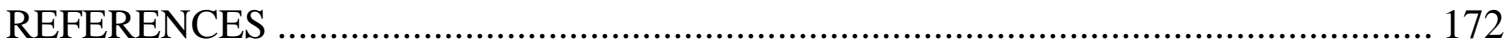




\section{LIST OF TABLES}

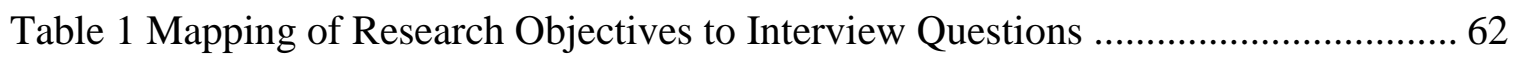

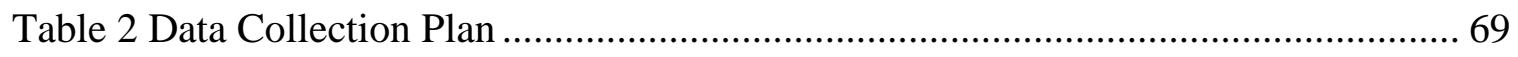

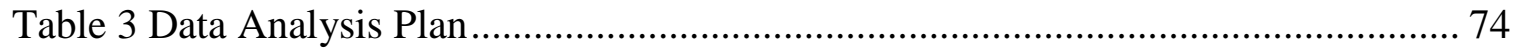

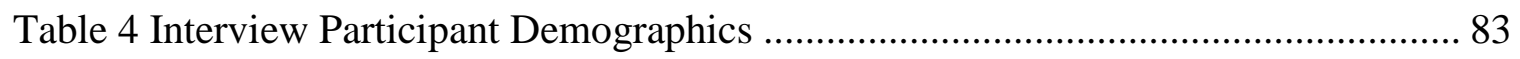

Table 5 Focus Group Participant Demographics ..................................................... 87

Table 6 Research Objectives and Theme Correlation.............................................. 131 


\section{LIST OF ILLUSTRATIONS}

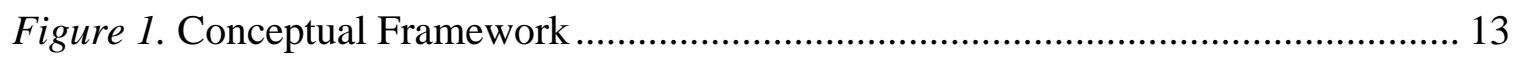

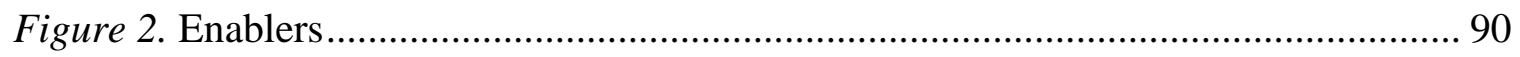

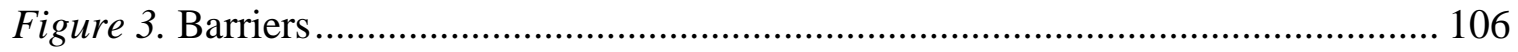

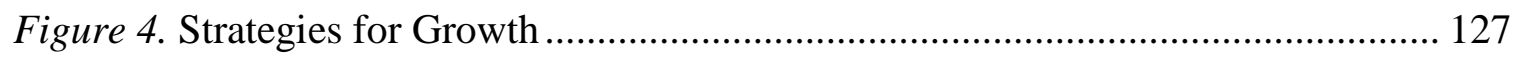




\section{LIST OF ABBREVIATIONS}

$A A C C$

$A C E$

CAOs

CEOs

$C R T$

ERA

HBCUs

$H C T$

$H E W$

IRB

NCES

PWIs
American Association of Community Colleges

American Council on Education

Chief Academic Officers

Chief Executive Officers

Critical Race Theory

Engagement, Retention, and Advancement

Historically Black Colleges and Universities

Human Capital Theory

Health, Education, and Welfare

Institutional Review Board

National Center for Education Statistics

Predominantly White Institutions 


\section{CHAPTER I - INTRODUCTION}

Predominantly White Institutions (PWIs) of higher learning must employ knowledgeable and competent administrators in the ever-evolving environment of higher education (Bisbee, 2007; Turner \& Grauerholz, 2017). With the increasing growth, in the United States, of racial and ethnic minorities' matriculation into college, PWIs of higher learning must pursue ways to diversify their administration to equip all students with the skills needed to live and compete in a global society (Creighton, 2007). Betts, Urias, Chavez, and Betts (2009) and Whittaker, Montgomery, and Acosta (2015) suggest the more diverse PWIs of higher learning faculty, staff, and student body become, the need to develop a more diverse pool of upper-level administrators to lead increases.

Reyes and Rios (2005) suggest many PWIs of higher learning do not have adequate African American representation to lead their institutions in curriculum development, mentoring, recruitment, and governance. However, Martin (2014) along with Perna, Gerald, Baum, and Milem (2007) attribute the modest representation of African American administrators and faculty members to systemic barriers impeding the recruitment, advancement, and tenure of African Americans at PWIs of higher learning. As society searches for ways to cultivate a culturally and socially sensitive environment that produces success for all people, educational institutions, especially PWIs, must understand the barriers African Americans encounter (Dockery, 2015).

According to Spearman and Harrison (2010), having someone of the same race and the same gender as a role model within the organization or institution is more influential than having someone of the opposite race or gender as a role model. Turrentine and Conely (2001) suggest students from all backgrounds benefit from faculty 
and staff diversity because students witness different role models, as well as an environment reflective of the workforce students will enter. Bollinger (2007) suggests exposure to diverse perspectives in the classroom prepares students to become citizens and leaders in a diverse society. Furthermore, previous studies suggest the underrepresentation of role models of the same race, in academic settings, might impede African Americans and other minorities' professional progress (Spearman \& Harrison, 2010). Chen and Hamilton (2015) referenced a study conducted by Tinto (1975), which explains how the dynamics between students and educational institutions could significantly impact a student's decision to persist or drop out of college. Kelly, Gayles, and Williams (2017) contend the lack of African American representation at PWIs could lead to racial tension and protest by African American students and faculty. The remaining sections of Chapter I include background information, a statement of the problem, the purpose statement, research objectives, significance of the study, the conceptual framework, limitations, delimitations, assumptions, organization of the study, the definition of terms, and a chapter summary.

\section{Background}

To comprehend how the leadership at PWIs of higher learning has advanced for African American administrators, an examination of the history of African Americans and their plight in the U.S. educational system follows (Higgs, 2014). Since the origin of higher education in America, women and minorities have encountered discriminatory practices (Beckwith, Carter, \& Peters, 2016). Caplow and McGee (2001) maintain that race-based discrimination seems absolute in higher education and no major PWIs of 
higher learning employ more than a token representation of African American faculty members.

Before the 1960s, the minimal representation of African American administrators and faculty members at PWIs was due to deliberate discriminatory practices (Jackson, 1991). The minimal representation of African Americans in administration in higher education dates back to the Brown v. the Board of Education 1954 ruling (Brown, 2007). Leading up to the ruling of Brown v. the Board of Education, the majority of African American college students attended historically Black colleges and universities (HBCUs) due to a segregated educational system (Brown, 2007). Brown (2007) suggests after the Brown v. the Board of Education decision, African Americans lost administrative positions at HBCUs. Due to the significant decrease in African American students' matriculation at HBCUs and noticeable growth in their matriculation in desegregated colleges, the diversity gap in higher education leadership positions expanded (Brown, 2007).

From early accounts, affirmative action was enacted to eradicate racial barriers prohibiting access to disenfranchised groups (Jones, 2007). African Americans have since made marginal advancements in accumulating notable educational accomplishments such as earning high school diplomas, achieving higher education matriculation, filling faculty and staff positions, receiving promotions, and earning senior-level administration appointments (Jones, 2007). Although the objectives of affirmative action have positive intent, the structural and political changes pertaining to employment, advancement, and promotion opportunities often come at the expense of the 
minority hires having to endure and adjust to institutions' political landscape. (Alger, 2000).

Previous studies and reports support the notion of progress in higher education, but Jones (2007) calls for greater action in improving the representation of African Americans and women in positions such as chief academic officers (CAOs), vice presidents, deans, and directors. Several studies suggest the pathway to president positions at institutions of higher learning is through CAO positions (Valburn, 2018; Vaughn, 1996). However, Jackson and O’Cullaghan (2009b) contend students and faculty diversity rate at PWIs are not representative of the population change in America. For example, in 2006, racial minorities held $13.6 \%$ of college CEO positions (King \& Gomez, 2008), and according to the National Center for Education Statatics (2008), racial minorities held only $16 \%$ of faculty positions. Jackson and O'Cullaghan (2009b) contend students of color during the same timeframe represented $31 \%$ of the total student body. A study conducted by Jackson and O'Cullaghan (2009) on full-time administrators in higher education indicated an increase in administrative positions of $51 \%$, and of those available openings, Caucasians filled $89.6 \%$ of the vacancies as compared to minorities who filled only $10.4 \%$ of the vacancies.

African Americans statistically lack representation in top policy and decisionmaking positions, except for positions traditionally designated for minorities (Brown, 2007). Likewise, women and people of color, especially African American administrators, are underrepresented in higher education (Alexander, 2010; Seltzer 2017). The Association of American Colleges and Universities (2017) report women in 1986 held about $9.5 \%$ of college president positions in the United States. Of the $9.5 \%$, African 
American women occupied about $3 \%$ of those positions. Data collected by the American Council on Education (ACE; 2017) show during the same period, females represented about $56 \%$ of the student population attending colleges and universities. Moreover, Whites represented $82.6 \%$ and Blacks totaled 10.5\%. In 2016, the ACE (2017) reports women representation increased to $31.1 \%$ while Black women representation remained static at approximately $8.1 \%$ of the total number of women serving as college presidents. Conversely, the enrollment of African American females in institutions of higher learning increased to $15.5 \%$ (ACE, 2017). The study also suggests ethnic and racial minorities account for less than a fifth of all college and university presidents. According to the Chronicle of Higher Education (2014), men in higher education administrative roles, in 2011, totaled 109,347. Only 8,638 (7.9\%) administrators were African American males.

The community college system has experienced significant growth in the matriculation of African American students, but the representation of African American faculty and administrators fails to keep pace (Fujii, 2014). The American Association of Community Colleges (2015) reports the racial demographics of community college presidents as follows: 81\% Caucasian; 8\% African American; 6\% Hispanic; $1 \%$ Asian Pacific, and 3\% American Indian. According to Fujii (2014), most community colleges' senior and mid-level administrators are promoted or hired from the faculty level; therefore, an increased level of African American representation at the administrative ranks is dependent on the progress of faculty diversity.

Prior studies indicate African American faculty members lack adequate representation, and when compared to their Caucasian counterparts, African Americans often have inferior academic standing and status at their institutions (Allen, Epps, 
Guillory, Suh, \& Bonous-Hammarth, 2000; Jackson, 2004; Jackson \& O’Callaghan, 2009a). The National Center for Education Statistics (NCES; 2016) reports full-time faculty members at community colleges and universities total 807,032 . Of the 575,657 (approximately 71\%) were Caucasian and 44,146 (approximately 5\%) were African American. When comparing full-time faculty members at community colleges and universities based on gender by race, Caucasian males accounted for 39\%, Caucasian females 33\%, African American males 2\% and African American females 3\%.

If the United States seeks to improve or maintain its global positions in production, innovation, and technology, Palmer, Davis, Moore, and Hilton (2010) propose success will derive from developing human capital, especially African Americans, through higher education. African Americans along with other racial minorities, from 2007-2008, represented 35\% of all students enrolled at two-year colleges across the United States (Fujimoto, 2012). Now, more than any other time in the history of the United States, a need exist to reduce the disparity of college access and degree attainment between African Americans and Caucasians (Wagner, 2006). Increasing access could help to ensure the United States has an adequate number of college-educated people to participate in the fast-paced and ever-growing knowledge-based economy (Wagner, 2006).

According to NCES (2016), the original source for data on U.S. colleges, universities, and technical and vocational institutions, the number of students enrolled at the 14 predominantly White public community colleges in Mississippi, in 2015-2016, totaled 69,125. African American students enrolled at those institutions totaled 25,506 (approximately 37\%). During that same time frame, Mississippi's five predominantly 
White public universities included a student population of (undergraduate) 54,595. Of the 54,595 approximately $21 \%(11,502)$ of the students were African American.

According to the Chronicle of Higher Education (2014), the national college completion rate for students who attended two-year public colleges at $150 \%$ time to complete was $19.4 \%$. In Mississippi, the completion rate was 24.2\%. However, the data from the report indicates a significant gap between the graduation rate of Caucasian and African American college students. Nationally, Caucasian students' completion rate at $150 \%$ (4 years) time to complete is $22.4 \%$ as compared to African American students at 18.9\% (The Chronicle of Higher Education, 2014). When examining two-year public institutions in Mississippi, the graduation rate for Caucasian students was $28.9 \%$ and for African American students $10.7 \%$. However, the graduation rate at public four-year institutions at a $150 \%$ time to complete (6 years) nationally was $57.6 \%$ compared to 49.8\% in Mississippi (The Chronicle of Higher Education, 2014). The data from the study also show when comparing Caucasian students and African American students' graduation rate at public four-year institutions at a $150 \%$ time to complete, nationally, Caucasian students had a $60.6 \%$ completion rate versus African American students who had a $40.3 \%$ completion rate. In Mississippi, Caucasian students had a completion rate of 58.8\% as compared to African American students who had a 36.5\% completion rate. Statement of the Problem

Ideally, the administrative leadership at PWIs of higher learning would adequately represent—ethnically and racially—its student population (Higgs, 2014). Levin, Walker, Haberler, and Jackson-Boothby (2013) suggest minimal progress in hiring African American administrators at PWIs of higher learning has been made, failing 
to keep pace with the increasing number of African American students matriculating at those institutions. According to the ACE (2013), the racial and ethnic demographics of senior leaders remain stagnant, and Africain Americans in Chief Academic Officer (CAO) positions dropped from $3.7 \%$ to $2.3 \%$. The reality is racial equality continues as a barrier confronting higher education (Jackson, 2001). Jackson (2001) also suggest mentoring, and leadership development opportunities for African Americans are essential to increasing African Americans representation in the higher education leadership pipeline. However, Ladson-Billings and Donner (2005) contend a barrier for African Americans could be the minimal effort from upper-level administration to push African Americans to seek senior-level leadership positions. Findings suggest African Americans struggle to become accepted into mainstream society (Rolle, Davis, \& Banning, 2000). If institutions of higher learning are committed to producing culturally proficient administrators, an increase in the representation of racially and socially diverse personnel within their institutions is required (Quezada \& Louque, 2004). The risk of not correcting the ethnic and racial gap existing in administration at PWIs is the continued lack of diversity within the various levels of the institutions (William, 2005), and the institutions' inability to recruit, retain, and graduate African American students (Robinson, Byrd, \& Bonner, 2013).

\section{Purpose Statement}

The purpose of this research is to explore and identify enablers and barriers contributing to African Americans' advancement into administrative positions at PWIs of higher learning. The study will also seek to investigate the phenomena contributing to 
understanding enablers and barriers African Americans encounter when trying to advance into administrative positions at PWIs of higher learning.

\section{Research Objectives}

A critical factor in completing a successful research project requires the researcher to develop a set of well-structured, clearly defined, and meaningful research objectives (Roberts, 2010). Likewise, research objectives set the parameters for what the researcher expects to achieve, driving various aspects of the methodology, i.e., design, data collection, and analysis (Creswell, 2013). Therefore, the following research objectives were developed to explore the enablers and barriers influencing African Americans' advancement at PWIs of higher learning.

RO1 - Describe the demographic characteristics of the participants, including their gender, work experience in higher education, years of experience in their current position, and degree attainment.

$R O 2$ - Explore and identify perceived enablers influencing the advancement of African Americans at PWIs of higher learning.

RO3 - Explore and identify perceived barriers influencing the advancement of African Americans at PWIs of higher learning.

RO4 - Explore African American administrators' perspective toward advancement opportunities for African Americans at PWIs of higher learning.

RO5 - Identify institutional strategies in place at PWIs of higher learning addressing racial diversity. 


\section{Significance of the Study}

Future African American administrators and institutions of higher learning can use the data collected as a resource to promote awareness and improve understanding for college and university administrators who are committed to bridging the racial diversity gap in higher education leadership. A review of the literature suggests only marginal gains in the advancement of African Americans into administrative positions at PWIs. (Perrakis, Campbell, \& Antonaros, 2009; Robinson-Neal, 2009). This research focuses on the perspectives and realizations of African American administrators regarding enablers and barriers influencing advancement into upper-level administrative positions in today's higher education environment.

This study represents an effort to inform African Americans who desire seniorlevel and mid-level administrator positions (e.g., chancellors, presidents, vice-presidents, deans, and directors) of the percieved internal and external enablers and barriers influencing advancement opportunities. Moreover, this information could be instrumental for institutions of higher learning serious about supporting the advancement of African Americans. The findings will add to the conversations pertaining to the development and implementation of strategies, which could lead to an increase in the recruitment and retention of African American administrators at PWIs of higher learning.

\section{Conceptual Framework}

According to Corbin and Strauss (2008), a conceptual framework can assist researchers in understanding which methodology is appropriate. Merriam (1998) describes a conceptual framework as an analytical instrument explained as an illustration and description serving as the platform and the structure of a study. A conceptual 
framework corresponds with theories, concepts, and terms from a specific area of literature. Within the conceptual framework (see Figure 1), three theories-critical race theory (CRT), human capital theory (HCT) and the theory of representative bureaucracy — are used to examine the impact of race and other internal and external factors as it relates to understanding the advancement of African Americans at PWIs.

Critical race theory, a social science theoretical framework originating from the critical theory, is intended to study race, laws, and power and their interrelationship with society and culture (Lynn, Benigno, Williams, Park, \& Michell, 2006). The CRT was used to identify perceived enablers and barriers influencing African Americans' ability to advance into higher education administration. According to Zamudio, Russell, Rios, and Bridgeman (2011), CRT contests the concept of meritocracy, which assumes all people have equal access to opportunity. Critical race theory, according to Parker and Villalpando (2007), provides opportunities for action to address the racial injustices in educational institutions. Applying CRT suggests race is the principal driver in Amerian culture (Blauner, 2001). Parker and Villalpando (2007) also assert CRT can be an important and invaluable lens through which to investigate and clarify educational institutions' managerial policies and procedures, and their relationship to racial injustice. CRT identifies racial and ethnic minorities as one of the primary factors in defining societal inequities (Lynn et al., 2006).

Human capital theory, according to Schultz (1981), suggests human capital consists of the knowledge, skills, and abilities — innate or acquired — that an employee brings to an organization. Becker (1993) adds that education and training, as a whole, advance human capital. Therefore, this researcher used the human capital theory as a 
lens through which to investigate the factors, informal and formal, influencing the career advancement of African Americans at PWIs.

According to Bradbury and Kellough (2008), the theory of representative bureaucracy posits to ensure the interest of all groups, in the decision-making process of a bureaucratic organization, organizations should reflect the people in terms of race, ethnicity, and sex. Meier and Smith (1994) also reference the importance of representation within the administration of public agencies. Selden (1998) suggests the theory of representative bureaucracy holds that passive representation leads to active representation.

Passive representation is the degree to which a government employs people of diverse demographic backgrounds, while active representation is the pursuit of policies echoing the interests and needs of those people (Selden, 1998). Meier and Smith (1994) state the representation of diverse employees increases the legitimacy of the organization, thereby, bringing about a feeling of inclusiveness at the upper levels of the organization. Bradbury and Kellough (2008) note research in the field of public administration is consistent with active representation and studies in the criminal justice field. Testing relationships between workforce demographics and government, at the individual level, were consistent with outcomes observed as actions by minorities or female public servants. Therefore, this researcher uses the theory of representative bureaucracy as a lens to identify and explore PWIs diversity and inclusion strategies and if they are passive or active institutions. 


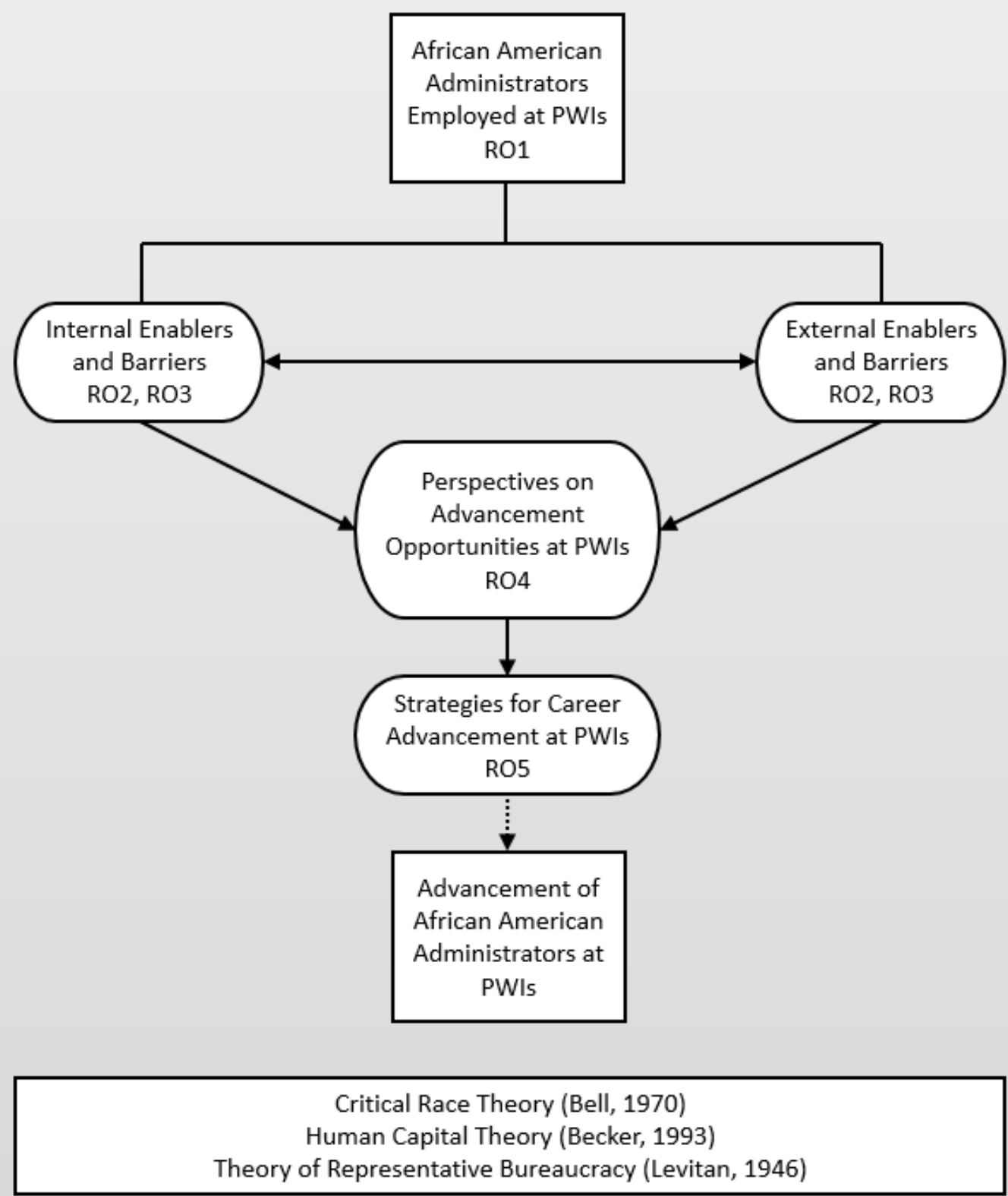

Figure 1. Conceptual Framework 


\section{Delimitations}

Roberts (2010) wrote delimitations inform the reader of how the scope of the study is condensed, what the researcher will include, and what will be left out. Roberts (2010) identifies delimitations as factors controlled by the researcher that may or will affect the study. Through snowball sampling, the current study will only focus on African American administrators currently employed at two and four-year public PWIs of higher learning in Mississippi. The researcher is aware of the possibility there may be enablers and barriers influencing advancement opportunities for African Americans at private PWIs. However, the researcher chose to focus this study on predominantly White, publicly funded, state institutions.

The current study will not include responses from professional staff, faculty, or support staff who are African American. The researcher acknowledges participation from African Americans who work in one or more of the positions previously mentioned may provide significant insight into possible enablers and barriers affecting African American advancement opportunities at PWIs. However, the focus of this study is on the formal and informal experiences of African American administrators at PWIs.

\section{Assumptions}

Assumptions are realities taken for granted but are understood as operational for the purpose of the study (Roberts, 2010). This research takes into account the following assumptions: (a) the participants' responses to the interview questions will be true and honest when sharing their perspective on the advancement of African Americans in higher education at PWIs; (b) all of the participants understand the nature of the study 
and the terminology used to obtain responses; and (c) the participants were not pressured or coerced into providing particular responses.

\section{Definition of Terms}

For the purpose of this study the following definitions will be used:

1. Active representation the association of rules echoing the interests and needs of the people (Selden, 1998).

2. Administrator(s) are referred to in this study as employees who work in higher education administration in one of three areas, academic affairs, students affairs or administrative affairs and whose job title is president, vice president, dean or director in their respective department (Wolfe, 2010).

3. Advancement refers to promotions taking place internally or externally with the overarching goal of retaining African Americans in the field of administration (Cleveland, 2004).

4. African American(s) throughout the history of the United States have been characterized by various terms such as Negro, Black, Colored, and Mulatto, which all came to represent people who had Black or African ancestry (Davis, 1991).

5. Critical Race Theory $(C R T)$ challenges the social processes existing within the traditional setting of societal institutions, which examine racism and power and their correlation to practices in institutions (Fujii, 2014).

6. Diversity, for the purpose of this research, pertains to race and ethnicity (Aguirre \& Martinez, 2006). 
7. Historically Black Colleges or Universities (HBCUs) according to the Higher Educations Act (1965), is defined as any nationally accredited Black college or university founded before 1964 whose primary goal in education is the education of African Americans.

8. Mentoring the practice whereby a senior or more experienced individual direct, coach, counsel, and assist a junior, younger, new, or less experienced employee (Dunbar \& Kinnersley 2011).

9. Passive representation is the degree to which a government employs people of diverse demographic backgrounds (Selden, 1998).

10. Predominantly White Institutions (PWIs) are colleges or universities in which the majority of the administration and faculty and/or student body population is predominantly White (Wahington \& Harvey, 1989).

11. Racial microaggression represents "stunning automatic acts of disregard stemming from the unconscious attitudes of White superiority constituting a verification of Black inferiority" (Davis, 1989, p. 1576).

12. Racism is a system bestowing privileges and power that are unearned on those identifying with the dominant group while discriminating against those identifying as people of color (Allen, 2001).

13. Token the perception of being hired because of race or gender to fill a quota mandated by affirmative action (Kanter, 1993).

Organization of the Study

The chapters in this study are organized as follows: Chapter I provides an overview of the study regarding the introduction, the background of the problem, 
statement of the problem, purpose statement, research questions, the significance of the study, conceptual framework, limitations, delimitations, assumptions, and definition of the terms. Chapter II will provide a thorough, systematic, and comprehensive view of scholarly literature and research relating to African Americans in higher education. Chapter III will explain the methodology used to conduct this qualitative study and the selection process. Chapter IV will provide an analysis and presentation of the themes and patterns emerging from the data. Chapter $\mathrm{V}$ will conclude with a summarization and discussion of the findings along with recommendations for future research.

\section{Summary}

A barrier still confronting higher education is racial equality (Jackson, 2001). If institutions of higher learning are serious about producing culturally proficient administrators, more specifically African Americans, they will need to increase the representation of racially and culturally diverse employees within their institutions (Quezada \& Louque, 2004). While the underrepresentation of African American administrators at PWIs of higher learning is not a new phenomenon, the increasing growth of racial and ethnic minorities' matriculation into PWIs demands that PWIs diversify administration if they are to equip all students to live and compete in a global society (Creighton, 2007). Moreover, current and future higher education administrators, regardless of racial identification may use the data collected from this study to promote awareness and develop an understanding of the enablers and barriers influencing the advancement of African Americans administrators at PWIs. 


\section{CHAPTER II - LITERATURE REVIEW}

The 1960s represented an era of change in the United States in which social and political policies deprived African Americans equal access to pursuing a post-secondary degree (Prendergast, 2002). African Americans' enrollment in PWIs of higher learning increased significantly after the 1954 decision by the U.S. Supreme Court in the case of Brown v. Board of Education of Topeka Kansas (Prendergast, 2002). The review of literature for this study provides a brief perspective on the history of race and education in America as well as the social and political legislation that presented barriers and opened doors of opportunities in higher education for African Americans. With educational opportunity at an all-time high, African Americans are still disproportionally represented in leadership positions at PWIs of higher learning (Evans \& Chun, 2007).

The purpose of this literature review is to provide the credibility required to justify conducting the study (Creswell, 2005). Chapter II literature review includes sections on the historical, political, and social changes affecting race and education in the United States. The review of literature provides insight on perceived internal and external enablers and barriers influencing African American administrators' career advancement at PWIs of higher learning.

Historical Perspective on Race and Education

To understand and overcome the current barriers and challenges in higher education faced by African American administrators, the historical journey of African Americans must be understood (Allen et al., 2000). African Americans in higher educations have continued to be affected by trends in higher education, which limits their access to opportunity; thereby, contributing to low representation of African Americans 
employed in leadership positions in higher education (Marable, 2008). Despite constitutional advancements, lawmakers have passed legislation suppressing African Americans and other marginalized groups (Lopez, 2006). For many African American students and other disadvantaged students, the passing of the Higher Education Act of 1965 made education more accessible (Ria \& Critzer, 2000). However, the Supreme Court case Brown v. Board of Education of Topeka in 1954 is arguably the most renowned piece of academic legislation to date (McNeal, 2009)

In the years leading into, and the subsequent years following the Revolutionary War, the majority of post-secondary institutions in the United States embraced social norm of racial exclusion and the idea of Africain Americans not being educable at the college level (Slater, 1994). African Americans were considered academically challenged, mediocre, and unworthy of being educated (Slater, 1994). It was not until nearly 200 years after the establishment of Harvard University (1896), the first institution of higher learning in the United States, before an African American would earn a college degree from an American university (Slater, 1994). Dreading educating slaves would defy the slave system, the White majority legislated laws making it a crime to teach slaves to read and write (Barrows, 1836). Slaves who pursued educational obtainment endured mental and corporal punishment from their owners (Harris, 1992).

With the general notion that African American slaves were intellectually inferior and incapable of earning a college degree, in the early 1800s, a few African Americans were allowed to enroll in certain colleges and universities (Slater, 1994). In 1883, Alexander Lucius Twilight graduated from Middlebury College in Vermont making him the first African American to earn a degree from a college in the United States. Edward 
Jones and John Russwurm soon followed Alexander Lucius Twilight, graduating from Amherst and Bowdoin three years later (Slater,1994). Founded in 1833, Oberlin Collegiate Institute became the first institution of higher learning to publicly adopt policies admitting African American students (Rudolph, 1990). In 1862, Mary Jane Patterson earned a college degree, making her the first African American woman to do so (Slater, 1994).

In an effort to maintain White superiority and privilege throughout the 18th and 19th century, the federal government, judicial, legislative, and executive branches continued imposing and passing acts and policies based on misguided beliefs (Prendergast, 2002). One such illustration was the 1896 Plessy v. Ferguson court decision, which upheld the separate but equal racial segregation laws for public facilities (Byrd-Chichester, 2000). Prendergast (2002) suggests changes for African Americans, socially and politically, as it related to restrictions prohibiting them from pursuing higher education did not come about until 1960. However, it was the Brown v. Board of Education of Topeka Kansas case in 1954 which produced the first victory regarding education for African Americans in which the U. S. Supreme Courts acknowledged segregation laws as being unconstitutional (Rolle, Davies, \& Banning, 2000). It took almost eighteen years after 1954 ruling in the Brown v. Board of Education of Topeka Kansas before enrollment for African American students nearly doubled at colleges and universities, leading to a record number of African American students graduating from PWIs of higher learning in the United States (Rolle et al., 2000).

The Civil Rights Act of 1964 coupled with federal legislation produced by President Kennedy and President Johnson were instrumental in generating political 
victories for African Americans (DeSousa, 2001). According to Williams (2001), it was the civil rights moment and the enactment of federal legislation, not the essence of equality and justice within the academic institutions, which led to the desegregation of post-secondary institutions. These victories forced integration, allowing African Americans greater access into PWIs of higher learning, which had long denied African Americans access because of the color of their skin (Williams, 2001). Byrd-Chichester (2000) suggests the involvement of the federal courts mandating PWIs of higher learning to grant access to African Americans met enormous resistance, especially in southern states like Mississippi and Alabama.

Civil Rights Act of 1964

According to Rosenberg (2004), the Civil Rights Act of 1964 is the most significant and influential anti-discrimination regulation ever passed by the U.S. Congress. First proposed by President Kennedy, the Civil Rights Act of 1964 received stiff resistance from southern members of Congress but was eventually passed by Congress under the leadership of President Lydon B. Johnson (Stefkovich \& Leas, 1994). Prior to the legislation of the Civil Rights Act of 1964 employers were allowed to pay African Americans less than their Caucasian counterparts for the same work, often refusing to promote African Americans who were sometimes better qualified (Stefkovich \& Leas, 1994).

The Civil Rights Act of 1964 authorized equal opportunity in public higher education by directing the eradication of racial discrimination. A critical underpinning of the Civil Rights Act of 1964 was,

to enforce the constitutional rights to vote, to confer jurisdiction upon the district 
courts of the United States to provide injunctive relief against discrimination to public accommodations, to authorize the Attorney General to institute suits to protect constitutional rights in public facilities and public education, to extend the Commission on Civil Rights, to prevent discrimination in federally assisted programs, to establish a Commission on Equal Employment Opportunity, and for other purposes. (Civil Rights Act of 1964)

The year following the legislation of the Civil Rights Act of 1964, Congress passed the Voting Rights Act of 1965 (Rosenberg, 2004).

\section{Affirmative Action}

Jim Crow laws in part were the impetus for affirmative action and were viewed as the laws of the land in the south and their neighboring states (Allen et al., 2000). Jim Crow was a racial caste system which forced racial segregation in the south dating from 1877 , end of Reconstruction, to the 1950 s, which begin the civil rights movement (Allen et al., 2000a). In an attempt to address America's soiled past, slavery and "Jim Crowism," President Lyndon B. Johnson signed an executive order in 1965 mandating affirmative action (Allen et al., 2000). The main reason for affirmative action was to eliminate biased barriers and prevent access and equal participation to underrepresented people of color and women (Allen, Teranishi, \& Dinwiddie, 2000). Coined by President Kennedy, and signed into Executive Order "affirmative action" was instituted to force federal contractors to take a more aggressive approach to ensure contractors employ minority applicants and treat them fairly without regards to race, color, creed, or national origin (Grahm, 1992). Marable (1996) contends affirmative action was never a law, nor was it developed logically to address societal discrimination and institutional racism. 
Affirmative action, however, was a sequence of presidential executive orders, governmental programs, and civil right laws aimed at addressing the awarding of federal licenses and contracts (Marable, 1996).

Between 1970 and 1977, approximately five years after the executive order mandating affirmative action, enrollment for African Americans in higher education increased from 522,000 to 1.1 million (Rolle et al., 2000). Glazer (2000) suggests African American students, from 1970 to 1977 represented approximately 6\% of the student population in PWIs would probably be less than $2 \%$ if it were not for affirmative action, which would consequently lead to fewer African American professionals. Eastland (1997) suggests in its infancy stages, affirmative action's purpose was to combat the effects of discrimination against African Americans, but in the early 1970s, it was expanded to include women and other disenfranchised groups. Over the years advocates for affirmative action have inferred additional rationalization such as attaining diversity and overcoming underrepresentation of minority groups (Eastland, 1997).

Individuals in opposition of affirmative action, view it as a political privilege claimed by ethnic minorities, which sometimes produce problems in society because it conflicts with the principles of fairness and equal opportunity for all American citizens (Birch, 2007). Birch (2007) differentiate between affirmative action and positive discrimination suggesting affirmative action measures are intentional actions by organizations, companies, or employers. Conversely, positive discrimination has to do with numerical quotas and are typically directed by legal regulations. Birch (2007) also contends both are problematic because they are viewed as negatively impacting members 
of the dominant group who may be more qualified or better credentialed but likely passed over for a post at a university for a minority candidate who is appointed.

Affirmative action is a process built on the premise members of the minority group meet the minimum qualifications, but opposer of affirmative action conjecture that it brings into question the whole notion of fairness and the possibility of reverse discrimination (Birch, 2007). According to Birch (2007), policies adopted through affirmative action measures are not consistent, and decisions made were circumstantial depending on locale. Since the beginning of desegregation, many methods have been used to obtain levels of diversity in higher education; however, progress towards advancement has been slow (Jackson, 2004). Even with the inception of programs like affirmative action, which was embraced and supported by the federal government, African Americans continue to advance at a disproportionate rate (Wahington \& Harvey, 1989). Meier (1975) notes affirmative action programs were mistaken for quota systems due to misinterpretation and the policies becoming controversial and viewed as flawed (Kaplin \& Lee, 1995). Futhermore, Birch (2007) suggests the establishment of affirmative action measures were to be short-term solution to assimilate minority group members into educational and workplace institutions, but in turn, became very controversial and intense whenever discussions of undoing affirmative action take place.

\section{Adams v. Richardson 1972}

In January 1969 the federal department of Health, Education, Welfare (HEW), investigated the state of Louisiana higher education system and determined the state of Louisiana to be in violation of operating a racially segregated system, which was a breach of Title VI of the Civil Rights Act of 1964 (Stefkovich \& Leas, 1994). According to 
Egerton (1974), between January 1969 and February 1970, HEW found nine other states, Mississippi, Arkansas, Flordia, North Carolina, Pennsylvania, Georgia, Oklahoma, Maryland, and Virginia were also in violation of Title VI of the Civil Rights Act of 1964. Due to the findings, HEW requested each of the ten states to submit a desegregation plan. In 1972, due to HEW failure to stop disbursing funds to the ten states found to have been still operating a segregated higher education system, the National Association for the Advancement of Colored People (NAACP) sued HEW in the landmark case known as Adams v. Richardson 1972 (Egerton, 1974). The presiding judge, John Pratt ruled in favor of the NAACP and in doing so required HEW to develop a more rigorous set of guidelines for North Carolina and the nine other states charged with not having a desegregation plan for higher education (Egerton, 1974).

The United States v. Fordice 1992

The United States v. Fordice 1992 was a groundbreaking decision regarding affirmative action policies in post-secondary education (Sum, Light, \& King, 2004). According to Hebel (2001), the Supreme Court concluded Mississippi needed to reform its so-called unbiased method to higher education in order to nullify the continued afflictions of desegregation. One goal of a previous 500 million dollar settlement was for HBCUs to enroll "other race" students. In the ruling, the court acknowledged the state as having continued a pattern of unequal resource distribution, thereby contributing to the ongoing disadvantages of three Mississippi HBCUs (Sum et al., 2004). Thus the prior court's settlement of 500 million dollars negotiated with the state under Fordice, in part, was contingent upon three public HBCUs, Mississippi Valley State University, Jackson State University, and Alcorn State University, ability to recruit, enroll, and 
retain "other race" students (Sum et al., 2004). The Supreme Court in determining its ruling defined success as it related to the HBCUs ability to recruit, enroll, and retain other race students as the enrollment of nonblack students at a rate of $10 \%$ of the total student body for three consecutive years (Sum et al., 2004). According to Sum et al. (2004), each HBCU would receive a substantial monetary award. In awarding the monetary rewards through the court settlement, the court's objective was to reduce or even diminish the racially segregated enrollment patterns which had soiled Mississippi's institution of higher learning post-secondary system (Hebel, 2001).

\section{Historically Black Colleges and Universities (HBCUs)}

Higher education for African Americans was not a typical expectation, so they were systematically omitted from the PWIs of higher learning (Wilson, 1998). The creation of HBCUs and their educational mission resembled the institutional and cultural views held by Caucasians about African Americans in the United States during the nineteenth century ("The tradition of," 1997). HBCUs were created to eradicate the hostile effects stemming from slavery, as well as the long-standing legal sanctions of discrimination against U.S. citizens of African descent (Humphrey, 2006). At the time it was unbelievable to Caucasians that African Americans were capable and competent enough to study in fields requiring a higher level of thinking, such as business, chemistry, physics, or philosophy, which caused some uncertainty about the real purpose and future of HBCUs (LeMelle, 2002). Richard Humphreys, a Quaker philanthropist, donate onetenth of his estate to establish the first HBCU, Cheyney University of Pennsylvania (formerly called the Institute for Colored Youth ), in 1837 (Tomar, 2018). Lincoln University of Pennsylvania founded in 1854 was the first HBCU to grant degrees in the 
United States; however, the first HBCU to be owned and run by African Americans, Wilberforce University, was founded in 1856 (Tomar, 2018).

HBCUs are the only institution in the United States created for the sole purpose of educating African Americans (Gasman \& Abiola, 2016). Before the Civil Rights movement of the 1960s, African Americans - if they wanted to attend college-were only allowed to enroll in HBCUs, which were typical underfunded and substandard (Byrd-Chichester, 2000). The funding to the support development and operation of most of the HBCUs, in the beginning, came from the federal government's Freedmen's Bureau, White abolitionist missionaries, who wanted to bring religion to Blacks, and philanthropist from the north who wanted Blacks for industrial enterprise (Gasman \& Tudico, 2009).

In the beginning, HBCUs were more industrialized with a mission and vision of training African Americans to improve themselves just enough to earn a living (ByrdChichester, 2000). By 1936, more than $80 \%$ of the African Americans earning a PhD worked at three of the HBCUs: Howard, Fisk, and Atlanta (Beilke, 1997; Washington, \& Harvey, 1989). Ballard (1973) maintains prior to employing Allison Davis (University of Chicago) in 1941, almost no PWIs of higher learning in the United States would acknowledge the idea of an African American having enough intellect to be a professor at their institution. In 1947 only 78 African Americans out of 3,000, identifying their profession as being a college professor, had ever taught at a White college or university, and for those who had it was only as a part-time lecturer (Ballard, 1973).

HBCUs, as currently defined by the Higher Education Act of 1965, is "any established Black college or university that was established prior 1964 whose principal 
mission was and is the education of Black Americans" ( Humphreys, 2006, p. 1). The majority of the HBCUs established reside in economically deprived areas or neighborhoods with the economic activities of the institution being paramount for the area (Humphreys, 2006). By definition, 105 accredited HBCU institutions are operating in the 50 states, and the District of Columbia, with the majority of them residing in the South and 101 of them being Title IV institutions (schools or institutions that process U.S. federal student aid).

Literature indicates when measuring outcomes such as growth and development, i.e., cognitive development, academic achievement, educational aspiration, and occupational aspiration, HBCUs outperform PWIs (Allen, 1992; Fleming; 1984). Studies support the fact PWIs have a higher overall graduation rate when it comes to African American undergraduate students (Chronicle of Higher Education 2014). However, a technical report published by Humphreys (2006) produced results indicating HBCUs produce more African American graduates, who come from low-income households. According to Humphreys (2006) report, statistics produced by the Federal government indicate individuals whose household income rank in the top quartile of Americans is eight times more likely to earn a college degree than individuals whose household ranks in the lowest quartile. Humphreys (2006) report also compared the completion rates for institutions whose pell grant recipients make up more than $40 \%$ of their student body population. The findings from the report show, on average, HBCUs graduate African American students at a rate of $37.8 \%$ compared to $32 \%$ for PWIs of higher learning. Furthermore, the study found almost half of the nation's HBCUs have a freshman enrollment in which $25 \%$ of their students are from low-income households, while PWIs 
freshmen enrollment of African Americans who come from low-income homes was approximately $1 \%$.

The positive impact of HBCUs' long-standing relevance on African American students has been well documented (Allen, Jewell, Griffin \& Wolf, 2007; Fries-Britt \& Turner, 2002; Palmer, 2008; Palmer, Davis, \& Maramba, 2011; Palmer \& Gasman 2008). HBCUs were created - to offer African Americans access to a post-secondary education - when PWIs prevented them from enrolling (Allen et al., 2007). Reports now indicate a steady decline in the number of African Americans matriculating at HBCUs and a constant rise in their matriculation at PWIs of higher learning (Allen et al., 2007). The passing of acts like the Civil Rights Act of 1964 and the implementation of policies and programs such as affirmative action and federal aid programs in conjunction with the decisions from historical court cases like Adams v. Richardson 1972, Brown v. Board of Education 1954, and the United States v. Fordice 1992 have been instrumental in contributing to the shift in matriculation patterns among African American students (Allen et al., 2007).

Studies aimed at showcasing the relevance of HBCUs indicate while HBCUs only make up less than $3 \%$ of all institutions of higher learning, they matriculate $16 \%$ of all African Americans enrolled in college, and graduate 20\% of all African Americans enrolled in college at the undergraduate level (Allen et al., 2007). Research also indicates African American students who have had the HBCU experience tend to pursue degrees and professional certification beyond a bachelor's degree (Brown, Richard, \& Donahoo, 2004). In addition, Gasman et al. (2007) suggest HBCUs prepare most of America's 
African American leaders to undertake careers in science, medicine, mathematics, and engineering related fields.

\section{Enablers and Barriers}

Educational institutions like many other organizations and companies in the United States still have forms of racism and discrimination embedded in them (LadsonBillings, 1998). Race and racism at their core are attached to American culture, and neither are inseparable (Chesler, Lewis \& Crowfoot, 2005). It is the perspective of some that educational establishments are the primary setting in which racism occurs; thereby, having a significant effect on all involved (Lynn \& Adams, 2002), reflecting our perception of humanity (Burke, Cropper, \& Harrison, 2000). African Americans' anxiety and distress in pursuing upper-level administrative positions are in part due to their experiences and societal practices (King \& Watts, 2004). According to King and Watts (2004), African Americans have identified concerns of retaliation as a primary purpose of why advancement into upper-level leadership positions have been slow in the academy.

Kanter (1993) as well as King and Whatts (2004) agree employers tend to pursue and hire individuals who fit into the institutional culture - typically based on PWIs standard. Therefore, it is not unusual for African Americans to conform and assimilate into the environment around them - "to go along to get along"- to keep from being discounted (King \& Whatts, 2004). In efforts to maintain or reach a preferred level of organizational efficiency, employers tend to evaluate potential employees on what Carbado and Gylati (2003) call organizational fit screening. African Americans in their desire to obtain employment may feel pressured to acquiesce and mimic the behaviors of their White counterparts (Kanter, 1993). Alterations of behavior may come in the form 
of professional dress or the trends of the majority; furthermore, Kanter (1993) contends there are circumstances in which African Americans alter their tone and dialect when in the company of their White counterparts to keep from being categorized or looked upon as being unintelligent or uneducated. Holmes (2003) reference such categorizations made based upon racial stereotypes have limited career advancement opportunities for African Americans.

In a study conducted by Rolle, Davis, and Banning (2000) findings suggest African Americans struggle to become accepted into mainstream society. Additional findings reflect the idea of African American administrators feeling apprehensive about not measuring up and having to validate their ability to lead within organizations, continuously. Ladson-Billings and Donner (2005) suggest African American administrators felt as if they were regularly required to legitimize their leadership abilities. Harvey (1999) suggest minimal efforts from upper management were being put forth to push African Americans to seek senior-level leadership positions, because of the perception African Americans lack the requisite skills needed to be successful. Since only a limited number of African American administrators earn promotions into seniorlevel management, the privileged few are regularly referred to as the Black token due to the perception they were hired to fill quotas mandated by affirmative actions (Kanter, 1993). The theory of tokenism derived from the involvement of women in maledominated workplaces and was also used to describe other minority groups (Kanter, 1993). Racial tokenism derived from Kanter's original theory, referring to African Americans assuming high profile positions to be an authority on all issues related to African Americans. Kanter (1993) contends tokenism is an ethnic barrier causing 
African Americans to wonder if their advancement took place if an effort to have them be the envy of other African Americans. Jackson and O'Callaghan (2009b) suggest organizational or institutional barriers can lead to African Americans becoming discouraged and in essence causing them not to pursue upper-level positions.

\section{Effects of Racism}

Racism in the form of Jim Crow was relevant in the United States until the mid1960s after which it began to lose momentum due to the national attention of the Civil Rights Movement (Lords, 2002). Thomas Rice, a noted entertainer of the 1830s, was credited with popularizing the Jim Crow character which depicted African Americans as lethargic, unintelligent, and inhuman. The depiction of African Americans as irrational and uneducated was commonplace (Lords, 2002). Sears, Van Laar, Carrillo, and Kosterman (1997) termed this form of racism as old-fashion racism.

Allen (2001) posit racism as a system bestowing unearned privileges and power to individuals identifying with the dominant group while discriminating against individuals identifying as people of color. Jones (2007) maintains racism is multifaceted and categorized as individual racism, institutional racism, and cultural racism (Jones, 2007). Individual racism occurs when African Americans encounter racial discrimination on a personal level (Jones, 2007). Institutional racism, Jones (2007) suggests, occurs when African Americans encounter discrimination through the enactment of policies within an institution or organization prohibiting them from equal involvement and benefits accessible to their White counterparts. Lastly, cultural racism occurs when the dominant group's cultural practices are regarded as superior to least dominant group (Jones, 2007). 
Before the 1960s, to be overtly prejudiced or racist was not considered shameful or uncommon within White America (Brief \& Hayes, 1997). Brief et al. (1997) asserts the idea of a new form of racism in which racist now recognize racism as being unacceptable, but yet their attitudes toward African Americans are still negative. They now view the advancements made by African Americans as not of their own merit. For people of African ancestry, racism in the United States was harsh and treacherous, while the acts are different, the repercussions are just as harmful (Feagin \& Sikes, 1994).

Racism as noted by Constantine, Smith, Redington, and Owens (2008), is not the same as the deliberate acts experienced by African Americans before the Civil Rights era. However, the constant reality of racial inequity continues to permeate through the behaviors and attitudes of members from the dominant group who believe racism is no longer prevalent or a thing of the past (Constantine et al., 2008). This subtle form of unfair prejudice as noted by Bonilla-Silva (2003) denotes colorblind racism. According to Bonilla-Silva (2003), colorblind racism is the belief by White America that the thought of race is irrelevant. Colorblind racism is so embedded in the fabric of most institutions in America, including the educational institutions, most members of the dominant race are unaware of their racial prejudice and the role in which their attitudes contribute to the marginalization of African Americans (Sue, 2013). The original intent behind the idea of colorblindness was to fight against and reduce discrimination and prejudice within organizations and institutions (Sue, 2013). Several studies suggest colorblind protocols often have adverse effects, resulting in increased racial inequities and biases (Apfelbaum, Sommer, \& Norton, 2008). 
Purdie-Vaughns, Steele, Davis, Ditlman, and Crosby (2008) maintain organizations embracing the colorblind philosophy, unconsciously promoted unfair practices, which leads to interpersonal discrimination within organizations. Various studies have concluded strategic colorblindness accidentally amplifies biases toward African Americans (Apfelbaum et al., 2008). Apfelbaum et al. (2008) constructed the phrase strategic colorblindness and suggest it is another mechanism or façade in which the dominant group appear nonprejudiced or pretend not to see differences as it relates to race. Colorblind racism includes delicate forms of racial microaggressions, which are often viewed by the dominant group as insignificant (Pierce, Carew, Pierce-Gonzalez, \& Willis, 1977).

Racial microaggression is "stunning automatic acts of disregard stemming from the unconscious attitudes of White superiority which constitute a verification of Black inferiority" (Davis, 1989, p. 1576). Sue (2013) suggests acts of racial microaggression are committed by Whites, unconsciously, who are unaware of or do not comprehend the implications of their actions. Microaggression presents itself in three forms as noted by Sue et al. (2007), microinsults, microinvalidations, and microassaults. Microinsults are when an individual's racial, cultural, and heritage are articulated in a delicate yet condescending manner, for example, a White person suggesting a Black person obtained employment because of affirmative action (Sue et al., 2007). Sue et al. (2007) describe microinvalidations as the exchanges between Whites and Blacks in which the experience and authenticity of the exchange are diminished. Exchanges such as "I do not see you as Black" or "I am not prejudiced, when I see people I do not see color" suggest the overarching message race is not relevant (Sue, Capodilupo, \& Holder, 2008). 
Microassaults are intended to hurt the victim through overt interactions deemed racist (Sue et al., 2007). Microassaults encompass the use of racial language or nonverbal gestures such as tending to a White customer before a Black customer who was first in line.

The idea of racial microaggressions to most Caucasians come off as trite or insignificant (Davis, 1989). Findings from previous studies suggest Whites more often than not, see racial microaggression actions as a simple misunderstanding, but the effects are very damaging to the targeted individual (Davis, 1989; Sue et al., 2008). Within the educational institutions, on various levels, racial microaggression has created injustices and biases for African Americans (Steele, 2003). Previous studies have reported how many Black students in classroom setting have experienced acts of microaggression from White classmates and teachers which minimized, nullified, or excluded their contribution in school activities (Sue et al., 2007). African American men and women historically have faced barriers different from their Caucasian counterparts (Cornileus, 2012).

Findings from previous studies suggest a contributing factor to leadership access faced by African Americans is the shortage of African Americans enrolled in and having earned graduate and postgraduate degrees (Jackson, 2004). Moreover, numerous studies attribute the lack of African Americans within the educational pipeline for leadership positions to their low representation in graduate programs (Abrahams \& Jacobs, 2006; Brown, 2005; Holmes, 2004; Jackson, 2004). The NCES (2013, 2014, 2015) data on enrollment in graduate programs by race indicate, while degree attainment for African Americans has improved, it is still significantly lower than Caucasians and Asian Americans. According to the survey on earned doctorates (National Sciences 
Foundation, 2015), there was a total of 52,760 doctoral degree recipients. African Americans accounted for 2,652 degrees, Caucasians, 27,865 degrees; Asian Americans, 13,432 degrees; and Hispanics or Latinos Americans, 3,067.

\section{Perspective on Advancement Opportunities}

In a search to understand African American administrators perceived experiences at PWIs of higher learning, Rolle et al. (2002) used purposeful random sample to conduct a qualitative study in which they interviewed two chancellors and six college presidents, all African American. The findings from the study centered around three questions:

1. What experiences led you to a career in administration work in a predominantly White institution?

2. What is your experience today as an African American administrator working in a predominantly White institution?

3. What advice would you give future African Americans who may be seeking leadership in a predominantly White institution? (Rolle et al., 2002, p. 82)

According to Rolle et al. (2000), the results from their study suggest the most significant attribute in their career mobility was their race. The participants acknowledge political savvy, leadership qualities, and excellent communication skills as essential but not as important as race.

Jackson and O' Callaghan (2009) conducted a study to validate the minimal representation of African Americans in positions of leadership in post-secondary institutions. Jackson and O'Callaghan's study was a descriptive analysis of full-time administrators at institutions of higher learning spanning 22 years. Their results revealed in 2003 there was a 51\% increase in administrative positions. However, African 
Americans and other minority ethnic groups were underrepresented when it came to filling those administrative positions. Racial minorities accounted for a combined total of $10.39 \%$ of the total hired; Caucasian represented $89.61 \%$ of the total hired.

Perrakis et al. (2009) conducted a quantitative study examining campus administration. Findings from the study showed institutional diversity affected the level of satisfaction for Chief Executive Officers (CEOs). The CEOs who participated in the study represented both two and four-year institutions, 33 from community colleges and 81 from universities (Perrakis et al., 2009). Perrakis et al. (2009) established two null hypotheses: the first hypothesis stated "there would be no correlation between CEOs' satisfaction with their role and campus diversity, and the second stated that there would be no correlation between CEOs' satisfaction with their role and administrative diversity" (p. 13). The findings from the Perrakis et al. (2009) study concluded CEOs did not think diversity within the institutions was essential when it came to the level of satisfaction they encountered at work. Likewise, their finding revealed a need to grow a more diverse pool of applicants within the pipeline for administrative positions. The results of the study also indicated a need for further research to substantiate the hypotheses (Perrakis et al., 2009). While diversity was not a requirement for the CEOs' satisfaction, they believed diversity should be a priority for their institution (Perrakis et al., 2009).

Holmes (2004) conducted a mixed method study which was twofold. The first was to determine the level of influence past experiences had on the careers of African American presidents. Secondly, to collect and present data reinforcing the developments in higher education in an attempt to create a comprehensive portfolio of African American college presidents. Included in the study were three African American females 
and three African American males between the ages of 55 and 64, employed at two-year, four-year, and graduate institutions. One significant theme Holmes (2004) identified revealed all of the research participants started as faculty members before moving into administrative positions. The finding was significant because it addressed the issue of African Americans' access to the leadership pipeline in higher education. Results from the study suggest understanding the continued inadequate representation of African Americans in president positions, a review of colleges and universities' governing board is relevant since most board members would prefer to maintain their homogenous culture (Holmes, 2004).

Fujimoto (2012) conducted a case study at a community college in the midwest. The goal of the investigation was to gain an understanding of why the college had difficulties increasing the racial demographics of its faculty. The impetus for the study was the rapid growth in student diversity, the shortage in faculty diversity, and several vacant faculty positions at the college (Fujimoto, 2012). Fujimoto research focused on racial demographics, ethical issues, job screening, recruitment strategies, and the hiring practices of the college. The findings from the study, in relations to the college's ethics and hiring practices, revealed that the job announcements were not advertised in a manner to attract a more diverse pool of applicants (Fujimoto, 2012). However, because of counter discrimination accusations made by Caucasian applicants, the college's employment processes were highly centralized (Fujimoto, 2012). With regards to employment practices, the findings revealed the college used the preferred requirements for the screening process for vacant faculty positions instead of the minimum 
requirements which would have increased the pool of qualified applicants of color, instead of eliminating them from being eligible (Fujimoto, 2012).

\section{Development and Advancement Strategies}

Jerlando Jackson introduced the Engagement, Retention, and Advancement model (ERA) for African Americans administrators in higher education (Cleveland, 2004). In applying the ERA model to the development of African American administrators, Jackson emphasized the need for African American administrators to connect with the community. In doing so, Jackson contends the connection will contribute in creating a strong rapport between the African American community and his or her institution of higher learning (Cleveland, 2004). Jackson's ERA model focuses on three critical areas of importance, engagement, retention, and advancement (Cleveland, 2004). Jackson alludes to the possible appeal, during the engagement stage, and the idea of African American administrators having the opportunity to be more involved in a plethora of leadership opportunities at their educational institution. The leadership opportunities are believed to be critical in grooming African American administrators for advancement within their educational institutions (Cleveland, 2004).

Jackson identifies two essential components of engagement: mentoring and professional development (Cleveland, 2004). He suggests formal mentoring shows the institutions are providing the needed opportunities for African American administrators to obtain professional development and that institutions are serious about the retention of African American administrators (Cleveland, 2004). If the mentoring process is to be successful, the mentoring relationship should be a process in which one or more experienced administrators are paired with an African American to provide guidance and 
career advice (Cleveland, 2004). The idea of mentoring taking place in both a formal and informal capacity can provide valuable insight into the politics of the institution and the overall campus culture for African American administrators (Cleveland, 2004). The second component of the engagement, in-service professional development, is critical to the continued progression of African American administrators because it allows them to build on and add to the skills specific to his or her profession. "For professional development to be useful, it should be aligned with the administrator's position and should be developed specifically for African Americans" (Cleveland, 2004, p 218). Jackson's next phase in the ERA model is advancement (Cleveland, 2004). This phase he suggests is critical in the retention and upward mobility of African American administrators within institutions of higher learning. Jackson posits professional release time, professional development funds, and beyond-diversity experience are three vital components (Cleveland, 2004). Jackson also contends African American administrators' should be encouraged and supported by their institutions to participate in national organizations and attend national conferences geared toward professional development, in which he suggests indicates colleges and universities are serious about retaining and advancing African American administrators (Cleveland, 2004). Another component of advancement according to Jackson has to do with allowing African American administrators the opportunity to advance beyond experiences and positions connected to diversity and inclusion (Cleveland, 2004). Moving beyond diversity and inclusion experiences afford African American administrators the opportunity to develop a holistic perspective of the college in which they are employed (Cleveland, 2004). 
Within the ERA model, Jackson presents an outcome phase which has two components, retention and career advancement (Cleveland, 2004). Regarding retention, Jackson uses it in the context of retaining African American administrators at a rate equal to or greater than their Caucasian counterparts at PWIs (Cleveland, 2004). Career advancement refers to promotions taking place either internally or externally with the overarching goal of retaining African Americans in the field of administration (Cleveland, 2004). Cleveland (2004) suggests the “central focus of Jackson's model centers around the idea that African American administrators will stay and develop at PWIs when elements of engagement, retention, and advancement are prevalent" (p. 218).

\section{Strategies for Advancement at PWIs}

Women and minorities in the field of higher education have struggled to obtain support in the form of mentoring in part because of the historical nature of higher education and most workplaces (Tessen, White, \& Webb, 2011). The practice of mentoring has materialized into an institutional strategy by organizations for minorities to attain career promotion, retention, and success in senior leadership roles (Blackwood, 2010). Wilson and Meyer (2012) suggest diversity management, if appropriately incorporated, can increase diversity within an organization. Literature has also identified succession planning as a strategic method for creating a seamless transition for the advancement of minority employees (Rothwell, 2005).

\section{Mentoring}

Mentoring as defined by Dunbar and Kinnersley (2011) is the practice whereby a senior or more experienced individual, direct, coach, counsel, and assist a junior, younger, new, or less experienced employee to help cultivate and develop their leadership 
skills and possible advancement within the institution. Previous literature suggests mentoring relationships provide enormous advantages to individuals who participate (Ballenger, 2010; Jacobson \& Lomotey, 1995; Kram, 1985). However, without the benefits of mentorship, minorities are least likely to advance and will continue to earn less than their White counterparts (Blackwood, 2010; Seanlon, 1997). Mentoring is a vital part of the developmental process, both personal and professional, as it relates to all facets of higher education, e.g., students, faculty, and staff members (Vance, 2016). Research on the effects of mentoring supports the notion of mentoring having a meaningfully and positive impact on the earning and promotion potential of those involved in such relationships, eliminating some of the inequities existing in earnings and career advancement (Hubbard \& Robinson, 1998).

Mentoring, for African American faculty, is an accepted method by which to promote their professional maturation and increase representation in PWIs of higher learning; however, there is not sufficient empirical data in this area to prove this is the case (Tillman, 2001). Now more than ever, institutions are becoming more dependent on mentoring as an instrument to improve socialization, training, and career development (Young, Cady, \& Foxon, 2006). Good mentoring, a wide range of experiences, and the opportunity to participate in leadership programs increase African Americans chances of obtaining executive level positions with colleges and universities (Jackson, 2001; Nelms, 1999). Judson (1999) suggest effective mentorship, in part, contributes to the success of African American administrators.

According to Bogat and Redner (1995), a mentor is an individual who has more expertise and skills then the protégé in a specific field or area, in which the mentor 
facilitates the professional growth of the protégé. The primary functions of mentors are their behavior and psychosocial roles and career development (Kram, 1985). Mentors in their psychosocial role serve as friend, coach, role model, and counselor as well as provide personal support when needed (Kram, 1985). Moreover, role modeling serves as a separate function (Scandura, 1992). Protégé's receive tremendous benefits from the mentoring relationship, and as a result, the protégé receives knowledge and experience from the interactions with the mentor, adding value to the protégé's personal and professional development (Kram, 1985). As it relates to career development, mentors assume the responsibilities of coaching and creating opportunities for positive recognition as well as provide assignments which challenge the protégé to grow as a leader, while serving as a coach (Kram, 1985).

\section{Mentoring Relationship}

According to Searby, Ballenger, and Tripses (2015), mentoring and the mentoring relationship have evolved over the last 30 years. During the early and mid-1980s mentoring typically involved a one-on-one relationship with one protégé being paired with one mentor (Searby et al., 2015). However, current literature has shifted toward the idea of a developmental network of mentors (Searby et al., 2015). This concept involves the protégé having multiple mentors who take an active role in helping the protégé develop and advance (Searby et al., 2015). Dumbar and Kinnersly (2011) contend a healthy and active mentor-protégé relationship hinges on various factors and suggest, mentoring relationships are most successful when both parties involve share similarities, such as backgrounds, values, outlooks, and experiences. Moreover, the literature shows organically developed mentoring relationship tend to be more beneficial than those 
constructed through some type of program or formal process (Dunbar \& Kinnersley, 2011).

The relationship between mentor and protégé is not only beneficial for the protégé but the mentor as well, helping the mentor produce positive results as it relates to the organization's outcomes and intrinsic gratification (Ragins, 1997). According to Ragins (1997), when the mentor and protégé relationship involves people of different backgrounds, diversity outcomes are more likely to to be accomplished. The mentor obtains knowledge, develop cultural competency and skills relating to interacting with persons from diverse groups (Ragins, 1997). Mentors benefit from a diverse relationship because it could lead to the mentor receiving a boost in his or her own career (Ragins,1997). Mentors, as it relates to intrinsic measures, may develop a sense of satisfaction through the fact of knowing they are contributing to the growth and development of a new or young administrator (Ragins, 1997). Moreover, through the mentoring relationship, the mentor may develop a renewed interest in their own job and career as a result of the vibrant and creative energy of their proteges (Ragins, 1997).

Although literature supports the notion of mentoring relationships having a positive influence and significant benefits to all involved; however, African Americans, women, and other minorities still encounter barriers making it challenging for such a relationship to exist (Searby et al., 2015). The number one obstacle facing minority administrators is connecting with mentors and gaining access to support groups and informal networks (Searby et al., 2015). Minorities sometime encounter opposition and lack of support from individuals in leadership positions who have the ability to promote (Searby et al., 2015). But, when the support is there, and promotion occurs, many 
minority administrators continue to be excluded from the "good ole boys" club existing on many college and university campuses (Carr, 2012; Rhode, 2003).

\section{Diversity Management}

The effect diversity has within an organization is maximized when strategically instituted within the organization's mission, vision, and strategic plans (Wilson, 2015). Historically, the task of overseeing diversity among human capital was the responsibility of division and department heads or the human resource department (Sabharwal, 2014). The literature suggests employing the use of diversity management can increase inclusion; moreover, implementing inclusion strategies to change the culture of an organization is critical to the diversity management practice (Sabharwal, 2014). To move organizations past shallow levels of diversity practices to organizational culture change and management, Wyatt-Nichol and Antwi-Boasiako (2012) posit, perception and practices are imperative. Juffer (2001) references the importance of cultural sensitive training and multicultural courses as essential management practices for transforming institutional culture, promoting inclusive campus culture, and minimizing internal and external perspectives.

When analyzing strategies of management and accountability, Bradbury and Kellough (2008) advocate that when viewed from the perspective of representative bureaucracy, strategies can produce a more inclusive leadership team, reflecting the student population, while moving an institution from passive to active representation. According to Flowers and Moore (2008), studies suggest upper management subscribe to an array of management practices to increase the representation of minority leaders in college administration positions. To grow diversity within the leadership pipeline, 
Wilson and Meyer (2013) and Galarrage (2014) suggest the use of succession planning and management as a viable method for access and promoting inclusion for minority groups at the chief executive level. Aligning management and succession planning can help decrease barriers hindering the pipeline of minority non-positional leaders (GrotrianRyan, 2015).

\section{Succession Planning}

Succession planning is a method in which companies can create a seamless transition to field vacancies, especially position of leadership, by identifying potential successors (Kowalewski, Moretti, \& McGee, 2011). Succession planning allows the organization to develop a talent pipeline (Rothwell, 2005). According to Grotrian-Ryans (2005), effective implementation and management of succession plan strategies could enhance diversity, address retirement issues in leadership positions, and prepare the next generation of minority leaders. To achieve the goals of succession planning, Rowthell (2005) suggests a comprehensive plan that includes assessment personnel and position duties, the use of strategies, a commitment to the procedure, evaluation of future employees and positional requirements, and the evaluation of succession planning strategies.

Succession planning is a top-down approach requiring a commitment from upper management to achieve the goals of identifying potential candidates and critical positions within the agency (Orellano, 2018). Strategic planning combined with identifying future leadership vacancies followed by a process outlined for developing possible successor could make for an effortless transition when it is time to fill vacant positions (GrotrianRyans, 2005). Investing and growing replacements is a vital piece to developing an 
effective succession plan to increase diversity at the senior level. According to a presidential study released in $2013,80 \%$ of the $87 \%$ of White male executives working at PWI of higher learning are nearing retirement (ACE, 2013). Gomez (2010) suggests institutions of higher learning should implement succession planning strategies identifying mentors and endorsing the advancement of minorities to address the lack of racial diversity.

\section{Chief Diversity Officer}

Stewart and Brown (2010) advocate to increase the likelihood and stability of diversity within an organization a serious commitment to diversity management is vital. A strategic plan incorporating diversity principles coupled with a firm commitment from the president depicts a vision and mission of equity and inclusion (Owen, 2009). Wilson, Meyers, and McNeal (2012), in their study on institutions' mission, found mission statements sending a concise and robust strategy for inclusion often include diversity language. Reports indicate industries such as academic medicine and healthcare have taken a proactive attitude toward diversity and inclusion by integrating the use of a Chief Diversity Officer (CDO) in conjunction with a company-wide diversity plan, increased diversity within leadership by 45\% (AAMC, 2012). Incorporating a CDO shows an institution is committed to diversity efforts and willing to respond to the need for adequate representation of diversity among administrators, faculty, staff, and students in higher education (Harvey, 2014).

Jackson (2004) contends while CDOs are viewed as upper-level leadership positions and advocates for inclusion and institutional diversity, many of them have limited power and resources to bring about meaningful change. Literature shows, the 
hiring of CDOs at PWI has increased; however, gender diversity among top executives has experienced a significant increase of $43 \%$, while racial diversity decreased about 1.2\% (ACE, 2013). A presidential study produced by ACE (2013) shows minorities, especially African Americans, are underrepresented in leadership positions at PWIs, and of the minorities represented in executive leadership positions, $82 \%$ held positions of diversity manager or $\mathrm{CDO}$, neither of which are a direct pipeline to a president position.

\section{Critical Race Theory}

Critical Race Theory (CRT) is a theoretical framework created in the 1970s by African American, Asian, and Latino scholars and social activists who studied law and legal policies with the purpose of addressing racial suppression, relationships between law and race, and other societal issues ( Howard-Hamilton, 2003). To understand and address issues in the areas of education surrounding racism and discrimination, Delgado and Steffanic (2012) reexamined the work of Derrick Bell, who is credit with being the originator of CRT. Delgado and Stefanic (2012) describe CRT as,

The Critical Race Theory is a collection of activist and scholars interested in studying and transforming the relationship among race, racism, and power. The movement considers many of the same issues that the conventional Civil Rights and ethnic studies discourses take up, but place them in a broader perspective that includes economics, history, context, group-and self -interest, and even feelings and the unconscious. (pp. 2-3)

Delgado and Stefancic (2012) introduced five essential tenets of CRT in which Hiraldo (2010) explains CRT's relationship to higher education. These five tenets are, 
- Ordinariness, suggest addressing or curing racism is challenging because of the lack of acknowledgment (Delgado \& Stefancic, 2012). Hiraldo (2010) referred to this as "colorblindness." the failure to contemplate the longevity of discrimination and bigotry and how they maintained the social inequities in higher education.

- Interest convergence or material determinism, suggests because of the interest in White superiority, there is a lack of motivation to eliminate racism (Delagado \& Stefancic, 2012).

- Social construction, suggests race and races are socially constructed, and individuals with particular physical features are categorized by the commonality of those features as opposed to character, intellect, and ethical behavior (Delagado \& Stefancic, 2012). Hiraldo (2010) suggests social construction in higher education advances the institutional racism affecting diversity efforts on college and university campuses.

- Differential racialization, CRT suggests the dominant group racializes the minority groups in response to the necessities driven by the economy and the workforce (Delagado \& Stefancic, 2012). Hiraldo (2010) describes this as "Whiteness as property," which is attributed to the racism existing in America.

- Voice-of-Color, allow racial minorities a chance to articulate in their own voice their lived experiences with racism (Delagado \& Stefancic, 2012). Hiraldo (2010) explains how voice-of-color could contribute to the investigation of college campuses by allowing minorities the chance to share their experiences of feeling insignificant and powerless. 
According to Zamudio et al. (2011), CRT contest the concept of meritocracy assumes equal access to opportunity and success is granted to all people. Applying the CRT implies race is the principal driver in Amerian culture (Blauner, 2001). While the reality of racism is not a hypothetical problem, Blauner (2001) suggests members of the dominant group would rather embrace a neutral position instead of acknowledging the truth about racism. CRT is a useful concept for investigating power and its relationship to racism within the processes, practices, and policies in the field of higher education (Fujii, 2014).

Fujii (2014) conducted a qualitative study exploring the level of diversity in the community college search process. For this study, Fujii interviewed administrators and faculty members from three different colleges, 12 participants total. The interviews with the 12 participants examined the communication of diversity in the faculty search. The data collected from the study regarding the role of leadership within the colleges concluded race and ethnicity were significant when it came to addressing the underrepresentation of African American faculty and the internal silence surrounding issues of race in educational administration as problematic, irregular, or strained (Rusch \& Horsford 2009). Fujii (2014) further concluded that if authentic discussions for creating fundamental change were to take place, leadership within the colleges would need to accept the notion that racism exists and CRT could be used to facilitate the discussion.

Fujii (2014) presented a narrative supporting the use of CRT as an appropriate theoretical framework and its practicality in addressing the value of diversity and its minimization or eradication of racism in the community college hiring process. Findings 
from Fujii's study revealed that the community colleges'search committees all acknowledged valuing diversity, but their hiring practices suggested the opposite. According to Fujii (2014), CRT is a useful educational tool which allows researchers to engage in meaningful conversations geared toward recognizing barriers, analyzing educational policies and institutional power structures, as well as hiring practices used to maintain the status quo within leadership positions.

Levin, Walker, Haberler, and Jackson-Boothby (2013) conducted a qualitative field study exploring the connection between the lived experiences of minority faculty members in higher education and CRT. Levin et al. elected to use the CRT because it provided a framework appropriate for identifying the drivers of the colleges' policies and norms. The purpose of the study was to "examine double consciousness and explain how it relates to the professional identity of faculty of color" (Levin et al., 2013, p. 315). Double consciousness is a term coined by W.E..B. DuBois, which means the idea of feeling divided into multiple parts and seeing one's self through the lens of others (DuBois, 1903; Levin et al., 2013). Their findings suggest faculty of color were optimistic about change occurring at their respective institutions; nevertheless, the likelihood of change occurring, they felt, was low (Levin et al., 2013). As it relates to double consciousness, faculty members of color acknowledged its present, and some expressed feelings of having to change or alter their identities to keep from feeling excluded (Levin et al., 2013).

\section{Human Capital Theory}

Human capital theory (HCT) is a broad and strategic approach to analyzing a range of human affairs (Tan, 2014). Human resource development professionals, both 
practitioners, and researchers, particularly within the HRD field, focus heavily on the developing of and capitalizing from human talent and skills for the betterment of society (Mclean, 2004). Harbison and Myers (1964) reference HRD's impact in general and its impact on institutions that provide formal education. The relationship between the two allows HRD to move beyond the boundaries of an organization and focus on performance improvement (Harbison \& Myers, 1964). With the evolution of new theories guiding and being guided by practical application in both the organizational and educational arena, the linkage implies a demand to better understand the skills and attitudes associated with workplace setting (Cornacchione \& Daugherty, 2013).

Dae-Bong (2009) categorizes the effects of human capital into three components: individual, organizational, and societal. Becker (1993) argues at the individual level, unlike economic capital, human capital did not depreciate over time, therefore, making the case that the investment process of human capital makes it comparable and complementary to other forms of capital. Weber, similar to Becker suggests attaining credentials in the form of a diploma or degree through an educational system is a definite form of documented skills obtainment that are valued and recognized by society as exchangeable for higher income (Cornacchione \& Daugherty, 2013).

One major theme continues to emerge as an investment in human capital is education (Sweetland, 1996). HCT describes the advancement in training and education as a type of investment in human resources with the contributors - the people — being looked upon as a form of capital (Nafukho, Hairston, \& Brock, 2004). Therefore, HCT infers people financing their own education and training (human capital) act rationally in 
doing so. Stafford, Lundstedt, and Lynn (1984) suggest that when people see that the benefit of a college education out weights the cost, they will invest in education.

From an organizational standpoint, human capital theorizes employees as being equipped with a set of skills that can be leased to employers (Ehrenberg \& Smith, 1997). Human capital seems to be owned by the people and not the organization but is obtained through employment relations and when cultivated through professional development and practice can transform into intellectual capital (Baron \& Armstrong, 2007). It has also been debated that to view employees within a company as an asset was open to manipulation and restricted as human asset accounting; thereby, making it difficult to quantifiably consider the added value of human capital and the rights of workers as free agents (Davenport, 1999). Likewise, human capital at the societal level theorizes the possibility of human capital for equality, human rights and political power on a shared consciousness of societal constituents (Dae-Bong, 2009). As a result, the relationship between social consciousness and human capital is constructed on the inter-relationship resulting in socio-political development (Dae-Bong, 2009).

According to critics of HCT, the HCT model has numerous challenges, including the idea of not accounting for structural or social factors (Dobbs, Sun, \& Roberts, 2008; Walters, 2004). For example, HCT "does not devote enough attention to the fact that some people are socially and culturally better prepared to gain access and succeed within the education system than others" (Walters, 2004, p. 102). Barlett (2007) also suggest HCT does not accurately depict the impact of schooling on economic development without taking into account other educational processes. 


\section{Theory of Representative Bureaucracy}

The theory of representative bureaucracy is the expectation that public administrators who possess the authority to influence public policy represent the people in terms of race, ethnicity, and sex (Bradbury \& Kellough, 2011). Kingsley (1946) during the initial stages of the theory of representative bureaucracy argued the administrative structure should always mirror the character of the social structure of the population, which at the time in Great Britain was class-based and therefore his perspective was it should reflect the dominant class (Meier, 1975). In the United States when representative bureaucracy was first explored as an alternative method for monitoring administrative power, Levitan (1946) defined "representativeness" as to mean every level and branch of government in the United States should be representative of American society.

There are two essential components in which the theory of representative bureaucracy builds upon passive representation and active representation. Salden (1997) defines passive representation or the degree to which a government hires individuals of varied demographic backgrounds lead to active representation, or the development of guidelines reflecting the interest and needs of those individuals. According to Mosher (1982), active representation is when individuals or management are expected to advocate for the interests and needs of those they are supposed to represent. The theory of representative bureaucracy suggests if administrators attitudes reflect the attitudes held by the workforce, the decision made by the administrators will be responsive to the wants and needs the public (Meier \& Nigro, 1976). 
According to Kranz (1976), the following governance consideration could lead to a more racially inclusive and diverse bureaucracy:

- More democratic decision making and better decisions by expanding the number and diversity of views brought to bear on policy-making;

- Improved operations and outputs from decisions and services to the needs of all citizens, particularly minority groups;

- Better human talent development and management decisions;

- An increase, both symbolically and actually, in the legitimacy of public service and other governance institutions; and

- Elevation of social equity and justice to prime administrative values on par with other values in public administration paradigms. (p. 390)

Critics of the theory of representative bureaucracy suggest the theory does not clearly identify which societal group should be represented (Larson, 1973). However, Kingsley (1946) posits the dominant groups in society should be represented within the administration, while Mosher (1982) argues representation should be a diverse representation composed of all groups within society. A significant challenge influencing the link between advocacy and bureaucratic diversity for marginalized people's interests is the influence of administrative socialization (Bradbury \& Kellough, 2011). Rehfuss (1996) argues racial minorities and women share the same management ideology as their White male counterparts, which may work against the augment of direct representation of group interests. 


\section{Summary}

Chapter II presents a review of literature providing a historical look at the political and social issues affecting African Americans and their pursuit of equal access to educational opportunities. Arguably, the most renowned piece of academic legislation to date is Brown v. Board of Education 1954 (McNeal, 2009). According to Prendergast (2002), the Supreme Court ruling in the case of Brown v. Board of Education of Topeka Kansas was the impetus to the increased matriculation of African Americans into PWIs of higher learning in the 1960s. Ria and Critzer (2002) also contend for many African American students the passing of the Higher Education Act of 1965 made education more accessible. Chapter II also provides insight into the effects of Jim Crow law, which in part was the impetus of affirmative action (Allen et al., 2000). Marable (1996) contends affirmative action was never a law nor was it developed logically to address societal discrimination and institutional racism.

The purpose of Chapter II literature review was to provide the credibility required to justify the need for the study (Creswell, 2005). Perrakis et al. (2009) conducted a quantitative study examining institutional diversity and campus administrative diversity in which their findings revealed a need to grow a pool of diverse candidates within the pipeline for administrative positions. One of the narratives in their finding suggests further research is needed to substantiate their hypothesis.

Chapter II also includes a close examination of the relationship between race and higher education. Allen (2001) suggests racism is a system bestowing unearned privileges and power on individuals identifying with the dominant group while discriminating against individuals identifying as people of color. Racism is multifaceted 
and can be categorized in three ways: individual racism, institutional racism, and cultural racism (Jones, 2007).

Previous literature points to mentoring and succession planning as possible strategies for growing the leadership pipeline for African American administrators at PWIS. Mentoring has long been an acceptable method by which to promote professional maturation of African Americans (Tillman, 2001). Judson (1999) suggest different mentorships, in part, contributes to the success of African American administrators. However, succession planning as noted by Kowalewski, Moretti, and McGhee (2011) can help companies create a seamless transition when filling vacancies in leadership.

The review of literature provides insight into the enablers and barriers influencing career advancement for African Americans at PWIs. Ladson-Billings (1998) contends educational institutions like many other organizations and companies in the United States still have forms of racism and discrimination embedded in them. According to King and Watts (2004), African Americans have identified concerns of retaliation as the primary purpose of why upper-level leadership positions have been slow in the Academy. Holmes (2003) references how categorization made based upon racial stereotypes have limited career advancement opportunities for African Americans. Chapter II concludes with sound information about CRT, HCT, and the theory of representative bureaucracy.

Chapter III describes the use of the qualitative method used to explore and identify enablers and barriers influencing African American administrators' career advancement at PWI's of higher learning. Chapter III includes a description and explanation for the study outline, the sampling procedure, and data collection procedure. 
The chapter concludes with a description outlining the steps taken place to ensure trustworthiness and a chapter summary. 


\section{CHAPTER III - METHODOLOGY}

A qualitative approach was used to explore and gain an understanding of enablers and barriers influencing African Americans career advancement into administration positions at PWIs of higher learning. Implementing a qualitative research method, allowed the researcher to gather rich amounts of descriptive data about the lived experiences of the participants, directly from the participants (Merriam \& Tisdell, 2015). The purpose of this research is to explore and identify perceived enablers and barriers contributing to African Americans advancement into administrative positions at PWIs of higher learning.

Recent literature suggests the underrepresentation of African American administrators at PWIs of higher learning is not a new phenomenon (Turner \& Grauerholz, 2017). The increasing growth of racial and ethnic minorities' matriculation into PWIs demands PWIs diversify administration if they are to equip all students to live and compete in a global society (Creighton, 2007). The literature also identifies enablers and barriers relevant to the career advancement of African American administrators at PWIs. This study investigates the perceived enablers and barriers specific to African American administrators at PWIs in the state of Mississippi. The remainder of Chapter III includes a description of the research objectives, research design, population and sample, procedures, instrument, data collection procedures, data analysis, trustworthiness of data, instrumentation, the role of the researcher, and limitations. 


\section{Research Objectives}

This study explores the lived experiences of African American administrators. The following research objectives were developed to explore the enablers and barriers influencing African Americans' advancement at PWIs of higher learning.

RO1 - Describe the demographic characteristics of the participants, including their gender, work experience in higher education, years of experience in their current position, and degree attainment.

$R O 2$ - Explore and identify perceived enablers influencing the advancement of African Americans at PWIs of higher learning.

RO3 - Explore and identify perceived barriers influencing the advancement of African Americans at PWIs of higher learning.

RO4 - Explore African American administrators' perspective toward advancement opportunities for African Americans at PWIs of higher learning.

RO5 - Identify institutional strategies in place at PWIs of higher learning addressing racial diversity.

\section{Research Design}

This study's design was qualitative phenomenological. Creswell (2013) posits qualitative research begins with the assumption of a worldview using theory and the investigation into research problems to provide meaning or insight into an individual or group's perspective about a particular phenomenon. Creswell (2013) suggests a phenomenological approach places emphasis on exploring meanings in which individuals attach to lived experiences. According to Pietkiewicz and Smith (2014), people are products of their experiences; they suggest people are self-interpreting beings, which 
implies they actively engage in creating meaning for the thing relevant in their life. A qualitative phenomenological design is a process in which the researcher has a more involved role in the research (Pietkiewicz \& Smith, 2014). Consequently, affecting the degree to which the researcher obtains access into the participants' lived experiences, and how they interpret each participant's view (Pietkiewicz \& Smith, 2014).

The primary objective of this study is to improve understanding of percieved enablers and barriers influencing career advancement of African Americans in higher education from the perspective of the participants. McMillan (2012) emphasizes qualitative researchers should not insert their viewpoint or preconceived ideas into the study. Instead, when implementing a qualitative approach, the researcher should allow the themes, meanings, and patterns to emerge from the participants and then seek to understand those meanings and how they influenced the behavior of the participants (McMillan, 2012).

\section{Instrumentation}

According to Creswell (2013), researchers use in-depth interviews to collect data for phenomenological studies. Kaplowitz (2001) suggests individuals participating in indepth interviews are more likely to discuss delicate issues and stimulate conversations about a range of topics. The researcher conducted 12 one-on-one interviews using semistructured, open-ended interview questions to collect descriptive narratives about the lived experiences of African American administrators working at PWIs of higher learning in Mississippi.

The interviews consisted of a series of eight semi-structured, open-ended question. The researcher developed the original interview questions by creating a survey 
map aligning the research questions with the five objectives of the study. Phillips, Phillips, and Aaron (2013) describe the process of aligning each question of a research instrument to a research objective as mapping, which is a means to ensure content validity. Table 1 is an illustration of how the interview questions align with the research objectives for this study.

Table 1

Mapping of Research Objectives to Interview Questions

Research Objectives (RO) $\quad$ Interview Questions

RO1 - Describe the demographic characteristics Interview Protocol

of the participants, including their gender, work experience

in higher education, years of experience in their current

position, and degree attainment.

RO2 - Explore and identify perceived enablers influencing the advancement of African Americans at PWIs of higher learning.

RO3 - Explore and identify perceived barriers influencing the advancement of African Americans at PWIs of higher learning. Q8

RO4 - Explore African American administrators' perspective toward advancement opportunities for Q5, Q6, Q8 African Americans at PWIs of higher learning.

RO5 - Identify institutional strategies in place at PWIs of higher learning addressing racial diversity.

Q4, Q5, Q6, Q7,

\section{Role of the Researcher}

When conducting a qualitative study, Greenbank (2013) encourages the researcher to provide authentic information describing the fundamental principles as it relates to his or her study in an effort to bring understanding and clarity to the readers about the underlying influences of the study (Greenbanks, 2013). According to Cresswell 
(2013), the ability of the researcher to dismiss his or her own bias completely during the data collection, data analysis and constructing the conclusion is very difficult, in part due to the interpretative nature of a qualitative design. Given (2016), however, contends there is never an absence of bias in qualitative research, but the presence of it can be a benefit when the qualitative researcher is aware, accepts, comprehends and embraces his or her own bias. The researcher is an African American administrator working at a PWI of higher learning and having maintained a positive relationship with potential research participants increases the possibility members of the target population will participate in the study and feel comfortable answering the questions openly and honestly.

The researcher is the first and currently the only African American administrator at a college which has 30 administrators, nine of which serve on the executive cabinet. The college has three campuses and three satellite sites and a total student population of 5,711 of which $48 \%$ of the students identify as African American, and $48 \%$ identify as Caucasian, and $2 \%$ other and $2 \%$ did not identify. On the campus where the researcher is located, the total student population is 1,126 of which $47 \%$ of the students identify as African American. Of the 72 employees located on the campus, there are only 9 African Americans, one African American administrator, no African American male instructors, four African American female instructors, and four African American support staff members three females and one male. Before becoming an administrator, the researcher was the only African American male instructor on the campus in which he is employed. Therefore, the researcher acknowledges his own bias and will take the necessary steps to implement appropriate validation strategies to ensure the research remains objective. 


\section{Population and Sample}

A research population is a group of individuals or objects having similar features and are considered to be the central focus of the study (Trochim, 2006). In using a phenomenological approach, one of the objectives is making sure each participant's description is fully valued and respected. Therefore sample sizes in phenomenological studies are typically small (Pietkiewicz \& Smith, 2014). The research population for this study was African American administrators who work at PWIs of higher learning in Mississippi. The sample population are members of the target population who are selected to participate in the research (Trochim, 2006). In general, the population for a phenomenological study is homogenous (Pietkiewicz \& Smith, 2014). For this study, the population was mid and upper-level African American administrators who work at predominantly White two-year and four-year public institutions of higher learning in the state of Mississippi. The objective was to understand the participants' perception of the perceived enablers and barriers influencing career advancement of African Americans at PWIs in Mississippi.

\section{Sampling Procedures}

This study employed a snowball (chain) sampling technique, which according to Swanson and Holton (2005), allows the researcher to obtain rich information from people who know people who know people who meet the characteristics of the population under investigation. Dragan and Isaic-Maniu (2013) define snowball sampling as a research method using the social network of people to contact members of a specific population because the potential participants are hidden due to low population numbers. Dragan and Isaic-Maniu (2013) note the concept of "hidden population," is used to define participants 
making up less than $2 \%$ of the population or identify with a group in which there may not be official records. Since there are no official records pinpointing the percentage of African American administrators currently employed at PWIs in Mississippi, it was theorized the targeted population in Mississippi resembles the national population. According to the ACE (2013), the racial and ethnic demographics of senior leaders have remained stagnant, and Africain Americans in chief academic officer (CAO) positions have dropped from $3.7 \%$ to $2.3 \%$.

Snowballing was an appropriate sampling method for this study because no official database was available to obtain information about the target population under investigation. The number of potential participants is low. Snowball sampling technique increased the likelihood the participants in the study meet the criteria, i.e., ethnicity, occupation, and place of employment. Pietkiewiez and Smith (2014) suggest an appropriate number of participants to conduct a phenomenological study totals between six and eight, while Creswell (2013) suggests 5-20. Merriam and Tisdell (2016) suggest there is not a fixed number of participants, but it depends on the questions guiding the research, the information collected, the progress of the analysis, and the resources available to support the investigation. Lincoln and Guba (1985) suggest sampling should continue up to a point in which redundancy or saturation. Saturation is the point in which continuing to interview yields no new information. For this study, the researcher conducted 12 interviews and saturation of data was determined by the researcher and the researcher's chair.

Once the researcher completed the one-on-one interviews and analyzed the data, a focus group was established to collect additional data. The focus group was used as a 
method for triangulation. Triangulation, in qualitative research, denotes the use of numerous methods or data sources to develop a comprehensive understanding of phenomena as well as a strategic method to test validity (Patton, 1999). Merriam and Tisdell (2015) suggest the composition of the focus group originate from the topic to be discussed, and the selection of the participants sampled purposefully. Purposeful sampling allows the researcher to select participants familiar with or knows the most about the topic (Merriam and Tisdell, 2015). The focus group participants for the study consisted of six mid-level and upper-level administrators (i.e., vice-presidents, deans, and directors) employed at two-year PWIs, who have been involved in the hiring process at their college — serving on interview committees responsible for making recommendations for hire.

Merriam and Tisdell (2015) suggest the number of participants-involved in the focus group — total between six and ten. For this study, six participants agreed to participate in the focus group. Since employees in the community college and university system attend meetings and workshops which might allow them to interact, there was a possibility the participants would know each other, and they did. However, studies show no major difference between groups including people who know one another and groups made up of strangers, and the number or quality of ideas each generates (Fern, 1982).

$$
\text { Institutional Review Board (IRB) }
$$

An IRB is a committee created by The University of Southern Mississippi (USM) for the purpose of reviewing and monitoring research involving human subjects. USM's IRB has the authority to approve, require modifications (to secure approval), or 
disapprove research. The USM IRB committee's role is to protect the rights and welfare of human research subjects.

The IRB responsibilities include protecting the rights and welfare of the individual(s) participating in research to ensure minimal risk. The IRB has provision to protect the privacy of the study participants and to maintain the confidentiality of all collected data. This study was submitted and approved by the IRB

\section{Data Collection Procedures}

The focus on data collection in qualitative research is to understand the participants perspective and their reality as it relates to the phenomenon under investigation (Creswell, 2013). For this study, one-on-one interviews were conducted. Merriam and Tisdell (2015) define a research interview as a systematic process in which the interviewer and the interviewee take part in a conversation centered around questions related to a research study. According to Merriam and Tisdell (2015), one-on-one interviews are the most commonly used method of qualitative research. The researcher elicits information directly from the participant. The primary purpose of conducting interviews is to acquire information concerning the thoughts of someone else (Merriam \& Tisdell, 2015). Interviewing is essential when the feelings, behaviors, and the perspectives of how people view their surroundings are not observable (Merriam \& Tisdell, 2015).

Merriam and Tisdell (2015) posit three types of interview processes, which include structured, semistructured and unstructured/informal. This study used semistructured interviews. Semistructured interviews allowed for a combination of more and less structured interview questions, flexibility in how the questions were asked and 
the order in which the questions were asked. Semistructured questions, according to Pietkiewicz and Smith (2014), allow the interviewer and the interviewee to participate in discussions in real time. It also provides opportunity and flexibility for unanticipated topics to arise allowing the interviewer to explore the interviewee's responses in greater detail.

Once the study was approved by The University of Southern Mississippi IRB (see Appendix A), the researcher emailed potential participants (see Appendix B) requesting their participation in the study, explaining the nature of the study and a copy of the consent form (see Appendix C) for their review. The initial email also asked for names and contact information on potential participants who met the requirements of the target population. Participants who were recommended received a similar email to the one sent to the initial group (see Appendix D). The scheduling of interviews began after IRB approval was obtained. All interviews were conducted in a neutral location on either the campus of the interviewer or interviewee, i.e., office - library or conference room. A consent form was signed and collected from each participant on the day of their interview. An interview typically takes one hour to conduct (Pietkiewicz \& Smith, 2014). The 12 interviews conducted ranged from 30 to 70 minutes. Before the interviews, code names were assigned to each participant for confidentiality purposes. Upon consent, the interviews were audio recorded. All of the transcriptions were transcribed by a third party transcription service, Rev.com. Once the audio recordings were transcripted, each participant was emailed (see Appendix E) a copy of their transcript to review for accuracy and to address any errors or misinterpretation of the data. If a response to the email was not received within three days of being sent, the 
researcher assumed the transcript was accurate and began reading the transcript, journaling, and developing codes and themes. Below, Table 2 illustrates the 11-week data collection plan.

Table 2

Data Collection Plan

Week Task

Pre-Study

1

$2-8$

9

10

11
- Gain approval from the USM Institutional Review Board.

- Email information detailing the purpose of the study and requesting participation to face-to-face participants.

- Schedule interviews date, time, and location.

- Begin making entries into reflective journal.

- Conduct one-on-one interviews.

- Send audio data to the transcriptionist.

- Begin reading and reading transcripts for accuracy.

- Send post-interview email to participants detailing the next step and member check.

- Email participants a copy of the transcript to check for accuracy.

- Start analyzing interview transcripts, identifying themes, coding, and comparing transcripts.

- Email invitational letter to focus group participants.

- Conduct a focus group session.

- Analyze the data from the focus group.

- Compare data from focus group to interview data.

- Create a report of finding and key themes.

- Email thank you letters to the participants. 


\section{Data Analysis}

Merriam (1998) describes data analysis as a multifaceted practice involving the moving back and forth between interpretation and description, abstract ideas, and real data. Merriam and Tisdell (2016) note that the researcher in a qualitative study is simultaneously involved in some form of data analysis while he or she is collecting the data. The analysis of the data for this study coincided with the data collection process. IPA seeks to search for the core or basic structure of a phenomenon. Embedded in the IPA approach are various techniques such as bracketings, epoche, horizontalization, imaginative variation, and phenomenological reduction, which are used to analyze experiences (Merriam \& Tisdell, 2016).

Researchers using the IPA data analysis design have some autonomy and flexibility within the guidelines to adapt based on their research objectives (Pietkiewicz \& Smith, 2014). Therefore, this study implemented the IPA design as outlined by Pietkiewicz and Smith. The initial step involved reading and re-reading each transcript and listening to the audio recording. Pietkiewicz and Smith (2014) recommend reviewing the transcript a few times and if the interviews are being recorded listen to it as well. The following step involved the researcher making notes and reflecting on the interviews. During this process the researcher reflected on things such as body language, voice tone, and ways in which he could improve upon his interview techniques the next time, as well as responses made by the participants in which the researcher may have wanted to probe into a little more. Pietkiewicz and Smith (2014) suggest the researcher make notes about his or her observation and reflection about the interview. The next step involves the initial coding process. During the next phase of the data analysis process, 
the researchers transformed his notes from the first interview into emerging themes. Once the themes were developed, the researcher sought relationships and connected themes (clustering). Cresswell (2013) defines themes as large pieces of data that, together, form a familiar concept. This process took place after each interview recording was transcribed. After each interview, the researcher looked for common themes amongst each transcript. Once a minimum of 12 interviews were conducted the researcher looked to determine if any new information arose or if saturation was reached.

Once saturation was reached, and all of the interview data was analyzed, a focus group was assembled to validate the responses from the one-on-one interviews and address the research objectives for the study. IPA requires the researcher to approach each case independently of the other to preserve individuality. Therefore, the researcher conducted an interview, read and re-read the transcript, coded the data, reviewed the data for emerging themes, clustered and organized the emerging themes before beginning the analysis on the next case.

Prior to the start of each interview the researcher reviewed the interview protocol (see Appendix F) with each participant. After which, the researcher began the interviews by asking participants a set of semistructured, open-ended questions (see Appendix G), while recording responses using a hand-held recording device. After the end of each session, a digital copy of the audio recording was sent to a third party transcriptionist company (Rev.com) to have the data transcribed to text. Upon the completion of each interview, the researcher sent participants a post-interview email (see Appendix $H$ ). Once a copy of the transcript was received, the researcher read and reread the transcript while listening to the recording to check for accuracy and to develop a better 
understanding of the interview. During this time the researcher wrote down thoughts and comments. According to Pietkiewicz and Smith (2014), this allows the researcher to reexperience and playback the atmosphere and the setting of the interview, thereby, helping him or her to become submerged in the data. Once the researcher completed this step, the transcript was emailed to the participant to validate the accuracy of the data (member check).

The next step involved the coding of the transcript. The researcher generated the codes manually. According to Merriam and Tisdal (2015), coding manually is more time consuming than using computer-aided software, but it allows the researcher to become more engaged and to develop a deeper understanding of the data. Coding allows the researcher to examine patterns of similarities, causations, correspondences, frequencies, and sequences (Saldana, 2009). Identifying constant themes and codes will reduce the threat of interpretative validity (Saldana, 2009). Coding also assists in helping the researcher develop real meaning and understanding (Miles \& Huberman, 1994). The first round of coding entailed the researcher reading through the document and highlighting relevant or interesting phrases or comments using the right margin to document analysis.

The second round of coding involved the researcher going back and reviewing the first round of coding in an attempt to consolidate the first round of coding looking for categories or themes to identify as emerging themes. The researcher used a different color writing utensil in the left-hand margin to document themes. Once the researcher identified emerging themes, the themes were cut into strips and placed on a larger poster board. This process allowed the researcher to look for patterns and then place them into clusters. 
Once an analysis was completed on all of the one-on-one interview participants, the focus group interview was conducted. The data from the focus group was used to triangulated with the data gathered from the one-on-one interviews to strengthen the trustworthiness of the findings from the research. Focus group participants received an initial email (see Appendix I). At the start of the focus group session, the researcher handed out a demographic form (see Appendix J) for each participant to complete. Afterwards, the researcher reviewed the focus group protocol (see Appendix K) with the group and then had them sign a consent form, which was identical to the consent form signed by the one-on-one interview participants. The participants in the focus group were asked a set of open-ended questions (see Appendix L), and their responses were recorded using a hand-held recording device. The audio recording from the focus group session was sent to the same third party transcriptionist service used for the one-on-one interviews. Once the researcher received the transcribed data, the same manual coding process was used as with the one-on-one interview participants. Once the focus group data was coded and analyzed, the researcher compared the findings of the focus group interview to the findings from the one-on-one interviews to validate the results. Creswell (2013) suggests analyzing data using a qualitative research method requires the organization of data using coding methods to produce themes from the data, and explaining the data verbally or through visual production. Table 3 illustrates the data analysis plan. 
Table 3

Data Analysis Plan

\begin{tabular}{llll}
\hline Objectives & Data Collected & Data Category & Data analysis \\
\hline RO1 & $\begin{array}{l}\text { Gender, work experience } \\
\text { education, years of experience } \\
\text { in their current position, } \\
\text { degree attainment. }\end{array}$ & Nominal/Ordinal & Descriptive Statistic \\
RO2 & $\begin{array}{l}\text { Perceived enablers } \\
\text { influencing advancement }\end{array}$ & Text & $\begin{array}{l}\text { Content analysis } \\
\text { Recurring themes }\end{array}$ \\
RO3 & $\begin{array}{l}\text { Perceived barriers } \\
\text { influencing advancement }\end{array}$ & Text & $\begin{array}{l}\text { Content analysis } \\
\text { Recurring themes }\end{array}$ \\
RO4 & $\begin{array}{l}\text { African American administrators } \\
\text { perspective toward advancement }\end{array}$ & Text & $\begin{array}{l}\text { Content analysis } \\
\text { Recurring themes }\end{array}$ \\
& $\begin{array}{l}\text { Institutional strategies in place } \\
\text { addressing racial diversity. }\end{array}$ & Text & $\begin{array}{l}\text { Content analysis } \\
\text { Recurring themes }\end{array}$ \\
& & &
\end{tabular}

Trustworthiness

According to Roberts (2010), researchers who conduct qualitative studies typically use the term trustworthiness when referring to the validity and reliability of a study. Roberts described it as a credibility factor, which is the process that gives the reader confidence in the investigator's data analysis. For this study, trustworthiness will be used to address internal validity. For accuracy and validity, each interview was recorded on audiotape and transcribed accurately. According to Shank (2002), interviews and data collection conducted in an informal setting are often more trustworthy than those conducted in a more formal setting. Therefore, the researcher deferred to the participants as to the campus, time, and date, the interviews were held. 
Once the interviews were conducted, the researcher used the transcription services Rev.com to convert the audio to text. Member check is critical when it comes to qualifying data and assurance of internal validity (Merriam \& Simpson, 2000). Since the ultimate objective of a qualitative study is to understand the participants perspective with as much accuracy as possible, member check is an appropriate technique to use (Merriam \& Tisdell, 2015). Each participant in this study was emailed a copy of his or her transcript to check for accuracy. Literature suggests multiple strategies be implemented to check for the trustworthiness of the findings (Creswell, 2013). Therefore triangulation and reflective journaling were used along with member check as validation methods.

For triangulation, a focus group was used as an additional data collection method. The focus group participants originated from a different group than those who participated in face-to-face interviews. Implementing this step required the researcher to identify similar themes to validate the findings. Creswells (2013) suggests if the themes are developed based on converging multiple data sources or viewpoints from participants, then the procedure can be viewed as adding to the validity of the research. As a third and final step to clarify any research bias, the researcher kept a reflection journal, during the research process, detailing any personal belief or assumption that could have possibly affected the study. Respectable qualitative research encompasses comments by the researcher about how their background shapes their interpretation of the findings, e.g., culture, gender, history, and experiences (Creswell, 2013).

Coding allows the researcher to examine patterns of similarities, causations, correspondences, frequencies, and sequences (Saldana, 2009). Identifying constant themes and codes will reduce any threats to interpretative validity (Saldana, 2009). 
Coding also assists in helping the researcher develop real meaning and understanding (Miles \& Huberman, 1994). The researcher manually coded the data, searching for patterns of similarities, frequencies, and sequences.

\section{Summary}

Chapter III outlines the research methodology, which was used to collect data about the lived experiences of African American administrators employed at public PWIs of higher learning in the state of Mississippi. Chapter III also provided information on the research and target population for this study and how the participants were selected. In using snowball sampling technique to select the sample population, the researcher collected data from participants who met the selection criteria. Interviews were conducted using semistructured questions. Semistructured interviews according to Pietkiewicz and Smith (2014) allow the interviewer and the interviewee to participate in real-time discussions; it also provides opportunity and flexibility for unanticipated topics to arise allowing the interviewer to explore in greater detail. Lastly, the chapter concluded with an overview of the data analysis process and the steps that were used to guarantee the trustworthiness of the research. The following chapter will report the results collected from the study. 


\section{CHAPTER IV - RESULTS}

The purpose of this study was to explore and identify enablers and barriers contributing to African Americans' advancement into administrative positions at PWIs of higher learning. Specifically, this qualitative interpretative phenomenological investigation was to give voice to the lived experiences of African American administrators at two and four-year public PWI's in Mississippi. The analysis was conducted based on the interpretation of the researcher using the process outlined by Pietkiewicz and Smith (2014).

Chapter IV reports the results collected from semi-structured interviews and reflective journaling, including theme development used to report the findings of the study. The chapter begins with a detailed description of the data analysis process for this

study. The validation strategies are discussed to support the validity and reliability of the data collected. Also included in the chapter is a brief description of the participants involved in the face-to-face and focus group interviews and the demographic tables to allow the readers to gain insight into the participants' unique perspectives. Additionally, the chapter presents findings from the investigation corresponding with the five research objectives.

\section{Data Analysis}

Data analysis is a multifaceted process in which Merriam (1998) describes as the back and forth movement between interpretation and description, abstract ideas, and real data. IPA data analysis design allows the researcher to have some autonomy and flexibility to adapt based on the researcher's objectives (Pietkiewiez \& Smith, 2014). Implementing IPA to analyze data requires the researcher to become immersed in the 
data collected (Larkin \& Thompson, 2012). The researcher implemented the IPA process as outlined by Pietkiewiez and Smith (2014), using general phases in the IPA process:

1. read and reread each transcript

2. make notes about the observation

3. initial coding process

4. transform notes into emergent themes

5. connect themes (clustering)

6. move to the next transcript

7. look for patterns across cases

Employing the IPA analysis process requires the researcher to examine each transcript independently to preserve originality. The initial step requires the researcher to read and reread each transcript several times, which allows the researcher to become familiar with the participant's account of their lived experiences (Smith \& Osborn, 2007). For each case, the researcher read and listened to the audio transcript, simultaneously checking for accuracy. Step two, the researcher reflected on the actual interview and made notes in his journal. Once the researcher checked the transcript for accuracy, participants were emailed a paper copy of the audio transcript to check for accuracy and to validate the transcription (member checking). The third step in the IPA process is the initial coding of the transcripts. The researcher reread the transcript and underlined comments, from the transcript, judged noteworthy or thought-provoking using a black pen to identify initial codes on the right outer margin of the transcript that potentially aligned with $\mathrm{RO} 2, \mathrm{RO} 3, \mathrm{RO} 4$, and RO5. After completing the initial coding process, the 
researcher began the fourth step, which included transforming the notes and initial codes into themes.

Step four required the researcher to review his notes and the initial codes transforming them into emergent themes. The researcher used a red pen to document emerging themes on the outer left margin of the transcript (see Appendix M). The researcher captured emerging themes from the entire transcript, allowing the frequency of keywords and phrases to noticeably stand out.

Step five in the IPA process according to Pietkiewiez and Smith (2012) is to identify similarities between themes emerging from the transcript and categorize them based on similarities and assign each a descriptive label. The researcher grouped similar words and phrases captured on paper (see Appendix N). The researcher developed an emergent theme matrix (see Appendix $\mathrm{O}$ ) to make sure quotes and codes documented in the table accurately reflect the perspective of the participant. The researcher reviewed portions of the transcripts as needed. After completing this process the researcher repeated the process for all cases.

The remaining 11 cases were analyzed using the steps outlined for IPA. The IPA method calls for the researcher to examine each case independently to maintain the uniqueness of each case. The researcher examined each case separately allowing codes and themes to originate from the individual transcripts. The final step in the analysis process was to develop a theme clustering matrix documenting correlation and convergences between themes and cases (see Appendix P). The researcher looked at patterns and themes across cases listing emerging themes in the far left column and individual participants names across the top. Using the individual clusters, the researcher 
used the " $\mathrm{X}$ " symbol to identify common themes. The researcher in consultation with his dissertation chair determined data saturation after completing cross-analyses for the 12 one-on-one interviews.

\section{Trustworthiness}

When checking for trustworthiness, researchers conducting a qualitative study typically apply multiple strategies (Creswell, 2013). Trustworthiness, as described by Roberts (2010), is the credibility factor that gives the reader confidence in the investigator's analysis of the data. To decrease any issues pertaining to the trustworthiness of the study, the researcher implemented three strategies: journaling, member checking, and triangulation.

Journaling is a technique used in qualitative research to offset any research biases. The researcher documented in a journal his reflections on the actual interviews throughout the data collection process. Before each interview was conducted, the researcher informed each participant, notes would be taken during the interview. Following each of the interviews and after listening to the audio recording, the researcher documented additional information. The journal entries included reflections on things such as body language, the overall tone of the interview sessions, responses to the questions, and the relevance of the questions as they related to the objectives of the study.

The second strategy employed to establish trustworthiness was member checking. Since the ultimate goal of a qualitative study is to understand the participants' perspective with as much accuracy as possible (Lincoln \& Guba, 1985), each participant received a copy of their transcript via email. Each participant was informed at the end of their interview, and in their follow-up email about the timeframe (three days) to respond 
confirming the accuracy of the transcript. If the researcher did not receive an email from the participant within three days, the researcher assumed the transcript was accurate and moved to the next phase of the analysis. If a participant identified any inaccuracy, the researcher made the changes.

The final strategy employed to establish trustworthiness was triangulation. Triangulation, according to Patton (1999), tests validity through two or more data collection methods to develop a comprehensive understanding of phenomena. The researcher implemented what Patton (1999) describes as a methodological triangulation, which is the use of more than one option to collect data. After completing all 12 one-onone interviews, the researcher collected data from a focus group. The focus group consisted of six administrators, representing five PWIs, none of whom participated in the one-on-one interviews. Triangulation requires the researcher to identify common themes from different data sources to validate findings (Creswell, 2013). The themes gathered from the focus group were compared to the themes from the one-on-one interviews to identified patterns and common themes. Once the focus group interview was completed, all participants in the study received a final thank you email (see Appendix Q).

\section{Participant Demographics}

RO1 - Describe the demographic characteristics of the participants, including their gender, work experience in higher education, years of experience in their current position, and degree attainment.

The researcher met the goal of the first research objective by obtaining the demographic information of the interview and focus group participants from the interview protocol form and a demographic questionnaire. Twelve African American 
administrators currently working at two and four-year public institutions participated in the interviews. For this research, upper-level refers to individuals who serve in the position of president, vice-president, chancellor, vice-chancellor, associate vice-president, or assistant vice president. The term mid-level represent individuals who serve in the position of dean, director, assistant dean, associate dean, assistant director or associate director.

The interview participants represent 11 of the 19 public two and four-year PWIs in Mississippi, seven community colleges and three universities. The following summaries provide background information about the participants as administrators at their respective institutions. Table 4 provides demographic information on the 12 interview participants. To protect their anonymity, each participant received a pseudonym, and job titles are not included in the demographics. The focus group was used to triangulate data collected from one-on-one interviews. The six focus group members were all employed at two-year public PWIs in Mississippi. The only requirements to participate in the focus group were full-time employment at a public PWI in Mississippi with either responsibilities for hiring or serving on a hiring committee. Table 5 illustrates the demographics of the six focus group participants. 
Table 4

$\stackrel{\infty}{\omega}$ Interview Participant Demographics

\begin{tabular}{|c|c|c|c|c|c|c|c|}
\hline Participant & Gender & $\begin{array}{l}\text { Yrs. Working } \\
\text { In Higher Ed }\end{array}$ & $\begin{array}{l}\text { Yrs. Working } \\
\text { In Higher Ed. } \\
\text { Adm. }\end{array}$ & $\begin{array}{l}\text { Yrs. Working In } \\
\text { Current Position }\end{array}$ & $\begin{array}{l}\text { Degree Attainment At } \\
\text { Start of Current Position }\end{array}$ & $\begin{array}{l}\text { Highest Level of } \\
\text { Degree Attainment }\end{array}$ & Position \\
\hline $1-3 \mathrm{~T}$ & $\mathrm{M}$ & 26 & 19 & 19 & Master & Doctorate & ULA \\
\hline 3-Tina & $\mathrm{F}$ & 10 & 10 & 6 & Specialist & Specialist & ULA \\
\hline 4-Tim & M & 25 & 20 & 3 & Doctorate & Doctorate & ULA \\
\hline 6-Tonya & $\mathrm{F}$ & 12 & 6 & 5 & Master & Master & MLA \\
\hline 7-Sarah & $\mathrm{F}$ & 19 & 10 & 7 & Doctorate & Doctorate & ULA \\
\hline 8-Tiffany & $\mathrm{F}$ & 16 & 3 & 3 & Master & Master & MLA \\
\hline 9-Amy & $\mathrm{F}$ & 19 & 11 & 11 & Master & Doctorate & MLA \\
\hline 10-Ebony & $\mathrm{F}$ & 10 & 5 & 5 & Master & Master & MLA \\
\hline
\end{tabular}

Note. MLA refers to Mid-Level Administrator

ULA refers to Upper-Level Administrator 


\section{Participant 1 - 3T}

3T is an upper-level African American male administrator with 26 years of work experience in higher and 17 years of experience in higher education administration. 3T has served in his current position for 19 years. 3T earned a master's degree prior to being appointed to his current position and later earned a doctorate.

Participant 2 - Thomas

Thomas is a mid-level African American male administrator with 12 years of work experience in higher and seven years of experience in higher education administration. Thomas has served in his current position for five years. Thomas earned a master's degree prior to being appointed to his current position. Thomas is currently, a candidate in a doctoral program.

Participant 3 - Tina

Tina is an upper-level African American female administrator with ten years of work experience in higher education and higher education administration. Tina has served in her current position for six years. Tina earned a specialist before being hired in her current position.

Participant $4-$ Tim

Tim is an upper-level African American male administrator with 25 years of work experience in higher education and 20 years of experience in higher education administration. Tim has served in his current position for three years. Tim earned a doctorate prior to being appointed to his current position. 
Participant 5 - Joyce

Joyce is an upper-level African American female administrator with 23 years of work experience in higher education and 12 years of experience in higher education administration. Joyce has served in her current position for three years. Joyce earned a doctorate prior to employment at her current institution.

Participant 6 - Tonya

Tonya is a mid-level African American female administrator with 12 years of work experience in higher education and six years of experience in higher education administration. Tonya has served in her current position for five years. Tonya earned a master's degree before being hired in her current position.

Participant 7 - Sarah

Sarah is an upper-level African American female administrator with 19 years of work experience in higher education and ten years of experience in higher education administration. Sarah has served in her current position for seven years. Sarah earned a doctorate before becoming employed at her current institution.

Participant 8 - Tiffany

Tiffany is a mid-level African American female administrator with 16 years of work experience in higher education and three years of experience in higher education administration. Tiffany has served in her current position for three years. Tiffany earned her master's degree before being hired in her current position. Tiffany is currently pursuing a doctorate. 
Participant - 9 Amy

Amy is a mid-level African American female administrator with 19 years of work experience in higher education and 11 years of experience in higher education administration. Amy has served in her current position for 11 years. Amy earned a master's degree before being hired in her current position and later earned a doctorate. Participant 10 - Ebony

Ebony is a mid-level African American administrator with ten years of work experience in higher education and five years of experience in higher education administration. Ebony served in her current position for five years. Ebony earned a master's degree before being hired in her current position. Ebony is currently pursuing a doctorate.

Participant 11 - Dennis

Dennis is an upper-level African American male administrator with 28 years of work experience and administrative experience in higher education. Dennis has served in his current position for seven years. Dennis earned a doctorate before becoming employed at his current institution.

Participant 12 - Heather

Heather is a mid-level African American female administrator with 12 years of work experience in higher education and nine years of experience in higher education administration. Heather has served in her current position for two years. Heather earned a master's degree before becoming employed at her current institution and later earned a doctorate. 
Table 5

$\stackrel{\infty}{*}$ Focus Group Participant Demographics

\begin{tabular}{lllllll}
\hline Participants & Gender & Race & $\begin{array}{l}\text { Yrs. Working } \\
\text { In Higher Ed }\end{array}$ & $\begin{array}{l}\text { Yrs. Working In } \\
\text { Current Position }\end{array}$ & $\begin{array}{l}\text { Highest Level of } \\
\text { Degree Attainment }\end{array}$ & Position \\
\hline Participant 1 & M & C & 25 & 6 & Doctorate & MLA \\
Participant 2 & F & C & 21 & 1 & Doctorate & ULA \\
Participant 3 & M & O & 15 & 6 & Master & MLA \\
Participant 4 & M & C & 11 & 5 & Doctorate & MLA \\
Participant 5 & F & C & 9 & 1 & Doctorate & ULA \\
Participant 6 & F & AA & 5 & 5 & Specialist & MLA \\
\hline
\end{tabular}

Note. MLA refers to Mid-Level Administrator

ULA refers to Upper-Level Administrator

AA refers to African American

$\mathrm{C}$ refers Caucasian

$\mathrm{O}$ refers to all other races 


\section{Participant 1}

Participant 1 is a mid-level Caucasian male administrator with 25 years of work experience in higher education. Participant 1 has worked in his current position for six years and has a doctorate.

Participant 2

Participant 2 is an upper-level Caucasian female administrator with 21 years of work experience in higher education. Participant 2 has worked in her current position for one year and has a doctorate.

Participant 3

Participant 3 is a mid-level non-African American, non-Caucasian male administrator with 15 years of work experience in higher education. Participant 3 has worked in his current position for six years and has a master's degree.

Participant 4

Participant 4 is a mid-level Caucasian male administrator with 11 years of work experience in higher education. Participant 4 has worked in his current position for five years and has a doctorate.

\section{Participant 5}

Participant 5 is an upper level Caucasian female administrator with nine years of work experience in higher education. Participant 5 has worked in her current position for one year and has a doctorate. 
Participant 6

Participant 6 is a mid-level African American female administrator with five years of work experience in higher education. Participant 6 has work in her current position for five years and has a specialist degree.

\section{Themes}

Participants in this study provided answers to a range of semi-structured, openended questions about their lived experience as an administrator at a public PWI in Mississippi. The analysis of the data and its subsequent theme development produced eight themes, seven relating to the research objectives for this study. The following themes developed from the transcribed audio interviews and the reflective journal are listed below.

- Theme 1 Good Mentors

- $\quad$ Theme 2 Relationships matter

- Theme 3 The intangibles: What to bring to the table

- Theme 4 Above and beyond expectations

- Theme 5 Challenges influencing advancement

- Theme 6 "The only" or "the first"

- $\quad$ Theme 7 The optimistic future

- Theme 8 Strategies for growth

Themes Associated with Internal and External Enablers RO2 - Explore and identify perceived enablers influencing the advancement of African Americans at PWIs of higher learning. 
The second research objective explored and identified perceived enablers influencing the advancement of African Americans at PWIs of higher learning. Research participants were asked various semi-structured, open-ended questions to gather their perspective on the internal and external enablers influencing their career advancement into administration at their institution. Based on responses from the research participants, four themes were discovered and identified as enablers influencing career advancement (see Figure 2). The perceived internal and external enablers identified in the study were good mentors, relationships matters, the intangibles, and above and beyond expectations. However, Theme Four above and beyond the expectations was discovered to both an enabler and barrier. The appropriate information to support the themes includes excerpts from the participants' transcript.

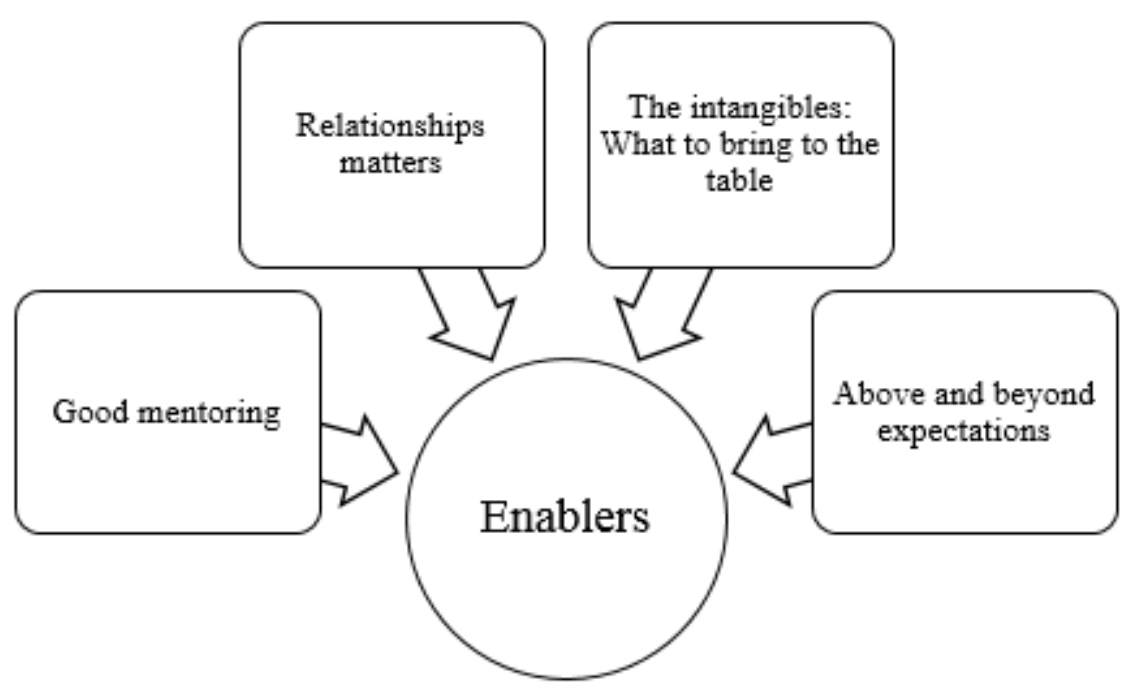

Figure 2. Enablers

Theme 1. Good mentors. When discussing people instrumental to success, nine of the 12 participants interviewed alluded to the impact and role their mentor(s) played in 
their path to becoming administrators. However, only four participants identified people, within their current institution, who served as mentors. Due to the lack of African American administrators at their institution; only one participant reported having an African American mentor. When asked about their professional career in higher education and what gave them the confidence they were ready for a position in administrations, seven participants recognized individuals who had mentored them from previous employment and recalled their experience with their mentor as such:

- I was not planning at all to be involved on campus, but that changed whenever I became an RA [Residential Assistant]. So as I started working as an RA, I met one of my mentors, and my mentor encouraged me to start getting involved on campus.... My former boss, who was also my mentor allowed me the creative rein to be able to do what I wanted to do in terms of program implementation within the constraints of which it could be done within the college. He also gave me the opportunity to sit in on meetings with administrators. And I am thankful. (Amy)

- I think in my 28-year career at this point; I've had mentors that have developed in the most unlikely kind of ways. Some have even been people who have never even gone to college. So I think all of us [African Americans] need to be open to people who genuinely care about us, who understand us, who have sort of seen the way that things work and who are given us really good advice. I think the openness of mentorship from wherever it comes from is helpful and beneficial if it pushes and challenges you. I don't know that the mentor should be your BFF [Best friend forever] that doesn't want to hurt your feelings, because sometimes 
your feelings need to be hurt. Because sometimes you're wrong and sometimes you need for people to tell you that you're wrong so that you will quit doing that, and move on to the things that you ought to be doing. (Dennis)

- I just think being able to talk to other administrators that are in leadership positions. I have different people that I look up to on campus - on the main campus - that if I'm having a situation or if something has come up and I am not sure of exactly how to approach it, I will reach out to them. They are not necessarily my mentors as in we have an official mentor-mentee program. They are mentors to me. I feel like I can talk to them to get advice on how to problem solve. Like, if I come into a situation that I'm not sure how to approach it, okay, let me ask Dr. so and so, because I am sure she has probably dealt with this before. (Ebony)

- I wasn't really interested in being in administration, because you hear about the politics. You hear everything about the downside of being in administration, but after she [Former boss]continued to mentor and push me regarding that, she told me to "think about the difference that you can make as an administrator more so than you can do in the classroom." "Although you're in the classroom, and you're shaping lives, and you're motivating, and you're inspiring students, you can make policies and procedure that also impact these students for the better just as well as you can in the classroom." So she was like, "Think about it from that perspective." So I did! So she was my mentor, and she was shaping me to be that administrator, to take her place when she left ... She begin helping me and 
sharing everything that she had learned and had experienced. She understood the culture. (Tiffany)

- One day I got enough courage to go and introduce myself to one of the nicest men you could ever come across. Him [Mentor] ... and Dr. . of course, the only thing you can say about Dr. . . . is he is too nice, super nice guy, and then I found myself wanting to be like those two men, young African-American males in education. Dr. . . office was right on the third floor, right above my office. I would go and chat with him on a regular basis about different things and so forth. He was a great mentor to me as well as Dr. . . Two great mentors and I have a lot of respect for. Well back when, one of my mentors, early mentors ... people didn't like her, but I learned so much from this little woman, super sweet woman if you get to know her, and one thing I learned, you have to get to know a person for yourself. I heard all these horror stories about going to work for her. "You don't want to work with Ms. . . no, no, no." They called her racist and all kinds of stuff. I found her to be one of the sweetest people you could ever come across. I give her credit for creating a good work environment and for instilling in me a backbone. She instilled in me ... like my daddy, some strong work ethic, because when you are in administrative positions, you can't be scared, because they will run over you. They will run over you. (Tim)

- I think beginning in the classroom was very helpful and working under several strong female administrators who mentored and gave me opportunities for advancement helped. . . My mentors, whether it was talking about a tire or 
talking about relationships in the community, or talking about aspirations, I mean they lead by example, and I aspire to do the same. (Joyce)

- I looked at those mentors that I had that were within the system and at the college in which I served, and it was that selfishness that if they could do this, then I knew that I could this do. There were two [Mentors]; one was the same sex. She was a vice president at that time who is gone on to become a current community college president. She served as a mentor and then it was a male that was also a vice president at that time, who's also gone on to be a community college president. They were not a minority. They were not Black. They were both Caucasia... And so having gone to my dean at that time who later became my mentor, "How do we make this change? What can I do?" And she said, "well, the only way to do that is to position yourself so that you can do that." And so by golly, I started looking at opportunities to further my education to get my $\mathrm{PhD}$, because I had my master's at that time, so I went on to get my $\mathrm{PhD}$ so that I could position myself to do that. Did I think that I would become a dean as quickly as I did? No. (Sarah)

Several participants attributed some of their success to the strong support received from supervisors who mentored them early on in their career stating: The participants provided the following responses:

- I have been very fortunate; I think largely in part to the campus I am located on. I have been under administrators who were very mentor-focused and who were very free in allowing opportunities for me to do external leadership development, pursue higher degrees, and even assisted with some of that. So, I had a lot of 
support, from my very lowest position all the way to this very current position, from the administrators that I worked under. (Tonya)

- Overall, I have had a very positive experience [In administration].... Had a great experience. Had a great mentor in my athletic director, who worked with me and helped molded me to understand the importance of the small things, and kinda guiding me and helping develop me as an administrator. I moved on to a community college in Mississippi, where I had another great mentor in my supervisor, who worked extremely hard to help develop me as a minority in administration at a community college in Mississippi. I think that was one of the best things that ever happened to me is having someone to recognize that this was a trend-setting moment for the institution, and helping me understand how to adapt to the different styles of management that take place on a college campus. I think the thing that helped me the most is that my supervisor trusted me. He gave me instruction; he allowed me to make mistakes. "If you make a mistake, we're gonna stop, we're gonna regroup, and then we're gonna learn from those mistakes, and we're gonna keep going.” Being the first African American, my supervisors understood that you might not understand this culture, and you're gonna probably say some things, or might do some things that might offend or kinda rub people the wrong way ... "And if you make those mistakes because you don't understand the culture, I understand that, and what I'm gonna do is I'm gonna spend time with you to help you understand." (3T)

One participant discussed her perspective on the importance of having a mentor despite not having anyone in higher education to mentor her. Her comment was: 
- I think mentorship is critical, if we are in positions, no matter what level we are. To have a willing mentee or have an inquiring mentee, we should take the opportunity to do that, if we feel like we are capable of providing them what they need to grow. If not, I think we ought to be prepared, through our network, to refer that person to someone that can provide that mentorship. It is just critical [emphisis added]. For me, because I came to the game with a resume, and I came at the peak of my career cycle, as far as my age is concerned, it was hard to formulate mentorships because people say, well she's old enough to know. (Amy) Theme 2. Relationships matter. Of the 12 participants, 10 expressed the importance of developing strong relationships internally and externally. Those internal relationships were identified as being important because "when issues occur, it's important to have trusted people to assist with problem-solving." "Alternatively, there may be times when you need an advocate at the table to speak on your behalf, especially when it comes to promotions." Several of the research participants described their relationships as such:

- So we are very tight-knit, everyone knows everyone by name, even down to some students. A lot of times, I walk through campus, and if someone is visiting or walking with me, they are surprised how many student names I can recall. When you are on a smaller campus, to me that is the greatest benefit. Relationship building is what allows you to influence, not only your students, but your coworkers and your subordinates. (Tonya)

- Prior to my first head coaching job, I worked for a head coach that was very, very old-school, and he taught me the importance of those small things. You know, 
having good relationships, forging good relationships with people and being polite, especially, to everybody. Always treating people with respect, treating people with dignity, regardless of their position ... even if it was the janitor or the cafeteria lady ... respect the personhood of people. I think that helped me with my relationship-building with people. That is one of the things in my first job that ... the culture that I was working in, he [Former supervisor] taught me everybody is important. Everybody is important [emphasis added]. I think that of all the conversations I have with other colleagues that are at the same position that I am at other institutions, spending time off the clock talking about the issues that we have on campus, you can't pay for that. You can't get that in a classroom. Forging those relationships with peers is vital to the success of any administrator ... not just an African American, but any administrator. (3T)

According to the study participants, "it is not always what you know, but who you know that can open up doors leading to advancement." When asked about the importance of networking and cultivating relationships, several of the participants stated:

- There are some relationships that exist that may or may not be an environment that's conducive for growth. ... I think I've been fortunate to have a lot of individuals that have been truly vested and interested in my growth, whether they wanted that to be something that was a notch in their belt to say that "I have helped her get to where she is," or, "I had something to do with that." And then networking. I mean, if you're not a sociable networking individual, out rubbing elbows with individuals, then you're definitely in the wrong position of being an administrator, an African American administrator in this system. There is no 
other way to grow without doing that because it's not always what you know; it's who you know. Get to know as many people as you possibly can in this business, because an opportunity may become available that you are unaware of, and you may become aware of because of someone. (Sarah)

- Relationships are very important. A lot of times even with education and experience sometimes, it is not what you know, it is who you know, and so forth. ... I had a part-time job while I was there [College], it was at the golf course, and I worked there, and I worked there forever, but at the part-time job, I got to know so many people. And the thing is, I got to know the president of the college, and the vice president, and the people in the community. I got to know a lot of people. ... But when the recruiting position became available, I applied for it. The boss at the time ... said she had never seen so many phone calls recommending a person for a job. So all those contacts I made at the golf course called ... and basically I got the job. (Tim)

Other participants acknowledge the importance of developing internal relationships with students and faculty members, and external relationships with community members and sister institutions.

- My relationship with the students brought me to the attention of the administration very early on. My involvement in the community and maintaining that involvement and those relationships, even after I began obtaining administrative roles was very important to me. I had to build those relationships, and go above, and beyond almost assuring individuals that hey we are all on the same team, we all want the same things. (Joyce) 
- So, the premise of my experiences thus far [In administration] and being where I'm at is partnerships on behalf of the students and then building partnerships with faculty to ensure student success and with other constituents of the institution. If your goal or your role is being in administration . . . being dedicated means, you are doing your research, learning things that you do not know ... meeting people in the field that's already successful. Networking with people at your sister institutions to understand some of the problems that they may have gone through. (Thomas)

- Yeah. Advancement of African Americans, a lot of time that advancements, to me, sometimes, it's a little . . . a lot of times it's who you know, and we haven't gotten away from that. And then, it's a practice of, well, okay, well, who's going to advance? Who's not going to advance? Is it going to be an African American? And then, sometimes, it's just by campus, and then, campuses lead to, who's the VP [Vice President] on that campus? Relationships are important. It was two ladies I know in particular, the one that came to visit my program and the one that was my VP at the campus that I am at now. She is no longer there, but then, I had other people speaking on my behalf that I didn't even know about. (Tina) Theme 3. The intangibles: What to bring to the table. When asked about innate qualities African Americans need to advance into administration at a PWI, 11 participants identified strong work ethic. Other participants identified qualities like integrity, confidence, compassion, intrinsic motivation, and understanding of one's self as needed attributes. 
- Transparency. And I say that because as a leader, in order for you to get people to believe in you and to follow your vision that you have to be open and you have to be honest with people ... integrity, not to jeopardize your integrity no matter what. Always do what is right and always go with your gut. Accountability... take ownership of what you're doing. (Tiffany)

- A good work ethic is very important. And I think a good work ethic is something that applies to everybody regardless of race, ethnicity, or gender. But then aside from that, I think just having the courage to take action on the things in which you would have a conviction for is probably the single greatest thing. (Dennis)

- Important attributes that African Americans possess ... determination, strength, having a thick skin. I think all of those are definitely things that you have to have when you are working in higher ed. at a PWI. Because there are not many people like you at the institution. (Ebony)

- Honestly, believe in what is right. . . I I am a firm believer that honesty is the best policy and having a high degree of integrity, and doing what you need to do in order to be successful. (Tim)

- You have to have an innate sense of self. That you have to be very cognizant of who you are and if you are not, you have to in short order develop a strong sense of self, because the environment has a tendency to be . . .you have the tendency to be the minority in those environments, and especially on an administrative level. As an African-American, faculty, staff, and administrator it is well documented that we exist in fractions... so you just have to have a strong sense of self, or you have to quickly develop that. They have to have a sense of patience. Definitely, 
there is patience. They have gotta be adaptable. I mean, we have to be adaptable. Different individuals have different leadership styles and management styles; you have to learn what theirs is and adapt to theirs so that you can be successful and continue to grow and do your job and fulfill your job responsibilities. You have to be a lifelong learner. (Amy)

- Dedication, I would say certainly being dedicated to your craft, being dedicated. If your goal or your role is being in administration in student support, instruction, or student services, being dedicated means you are doing your research, learning things that you do not know ... Assertiveness ... Sometimes, you have to say things that are not going to be well received, but, in being assertive, you have to say what you feel is in the best interest of your students, the best interest of the institution and the best interest of yourself, which, means you might say something where you may be the only person in the room that disagrees with the policy. But, you gotta look at it from the perspective of I am doing it for my students, and I'm doing what I think is best for the institution. (Thomas)

- Intrinsically, I think you have to have a great deal of motivation for why you are doing what you are doing ... so intrinsically you have to be motivated, and I think it translates to other people when you are not focused on the rise ... because people still pay attention and so what is guiding me here is just people noticing my motivation towards helping students, not toward advancing. (Tonya)

- To be honest. When it all goes bad, the only thing that you have is your character and your integrity. I think that is the most important thing or the most important attribute that you can have in this business. People need to be able to feel that 
they can trust you. To have character. To make sure that you keep your integrity. ... Keep your word. Keep your integrity, because when everything fails, it's all you've got. (3T)

When asked about the innate qualities African Americans need to possess when seeking to advance into administration at a PWI, the focus group members identified many of the same attributes identified by the one-on-one interview participants. However, the focus group members believed the attributes identified were necessary for anyone seeking to become an administrator. Several of their responses included:

- A good communicator, well spoken, and the ability to see all sides and have an unbiased opinion of situations. To step back outside of who you are and view the situation from a God's eye view. (Focus Group Member)

- They should be fair, consistent. They should always provide a clear view for those that they are working with and leading. (Focus Group Member)

Theme 4. Above and beyond expectations. When discussing the qualification future African American administrators at PWIs in Mississippi would need, most participants agreed, proper credentialing was necessary. Ten participants believed earning a terminal degree would be critical to increasing the representation of African Americans in the pipeline for leadership positions at PWI's. This belief was evident; all but two of the participants either held terminal degrees or were enrolled in doctoral programs. All but one of the interview participants expressed the belief that just being qualified was not enough for African Americans. Several participants expressed the need for future African American leaders to take advantage of every opportunity even if it 
meant going above and beyond the call of duty, without pay. One of the participants stated:

- Take every opportunity, whether paid or unpaid, to learn. You have to gather yourself around those that are wanting to move forward, those that are not naysayers. You have to be willing to read something more than the latest gossip that's out there. Read those articles that are sent to you. You need to know what's going on in the legislation. You need to know what's going on in higher education. Go to the conferences that has to do with higher education that no one wants to go to in the summertime. Take those classes, that push you and motivate you to move forward. That's the way you're going to be given those opportunities. Take on those projects, write those grants, be the ones to volunteer when no one else wants to volunteer. You have to take that narrow road that the others don't want to go down. That's going to give you those opportunities to move forward. (Tina)

When presented the question about formal and informal training believed to be important when pursuing advancement into administration, participants' expressed the value in obtaining advanced degrees and participating in internal and external educational leadership programs. Participants provided the following comments:

- I went through a doctoral program that was geared specifically toward community college leadership. Because, again, I was in the community college system. I believe in the mission of community college, open access, being able to take students from where they are and move them forward. So I had no aspirations to do anything on the university level research-wise. So I knew that this was where I 
wanted to be. So I enrolled in a program that was geared specifically towards that, and I think that program in addition to some of the programs after that, like Mississippi Community College Fellowship Program, the Mississippi Community College Leadership Academy were very instrumental in my maturation process. (Sarah)

- ... I'm thankful for that. He [Former supervisor/mentor] also believed in going to conferences. So, being exposed to what else is out there allowed me to see something different from what I was always seeing in Mississippi. (Heather)

- I think the formal training is sort of the union card. And I think whether you like it or not, you've got to have that union card and that's your undergraduate degree, your master's degree or your terminal degree. But any notion that the completion of a formal training has prepared you to do the job is really a false idea and one that would likely not lead to the level of success that an individual would otherwise have.... I think the best training and the most beneficial training is the training that you're going to get on the job. And then the work that administrators do, it's evolving, it's fluid. We never know from one day to the next what we're going to be faced with. ... The day to day on the job training, post-formal training is what gets you across the finish line. (Dennis)

- I definitely think the degree program that I did for my Master's degree; I definitely think that had a big impact. I received my Master's degree in Higher Education that was a direct correlation to prepare me for roles in administration. Within that program, of course, you take courses on management, community college, research ... you do all of this ... even in community college teaching, 
you do all of this in preparation to get to that next level. I definitely think that had a big impact on it. (Ebony)

- Education gave me perspective about what we do, and I think that is what I got out of my formal training through my masters. It kinda got you prepared to learn where information is, where I can go out, and I can find information about the college. But, when I went through this $\mathrm{PhD}$ process, it not only helped me maneuver through my job on a day-to-day basis, it helped me to the point of developing a real philosophy that's based on something. That's really based on history. It was based on something that's just deeper than just the interaction that we have on a day-to-day basis with students. I really have a thorough understanding of what my purpose is, and it took me a while to get that. It took me a while to get it, but school, college ... I mean, this $\mathrm{PhD}$ program really helped me get that perspective. I think that if I wouldn't have had that experience of going through the $\mathrm{PhD}$ program in Community College Leadership, I would not have had a real thorough understanding of the focus, the history, and the philosophical views that have not changed in over a hundred years. (3T)

One focus group member alluded to the notion of African Americans having to work twice as hard and being held to a different standard than Whites at her institution. No other member of the group disagreed with her perspective, but one of the members stated: "I hold everybody to the same standards regardless of race, gender, or what have you." Themes Associated with Internal and External Barriers RO3 - Explore and identify perceived barriers influencing the advancement of African Americans at PWIs of higher learning. 
The third research objective explored and identified perceived barriers influencing the advancement of African Americans at PWIs of higher learning. The data analysis yield two themes. Study participants responded to questions about barriers and challenges they encountered at PWI, as well as possible challenges future African American administrators may encounter. Theme 4, above and beyond expectation and Theme 5, challenges influencing advancement were identified as barriers (see Figure 3).

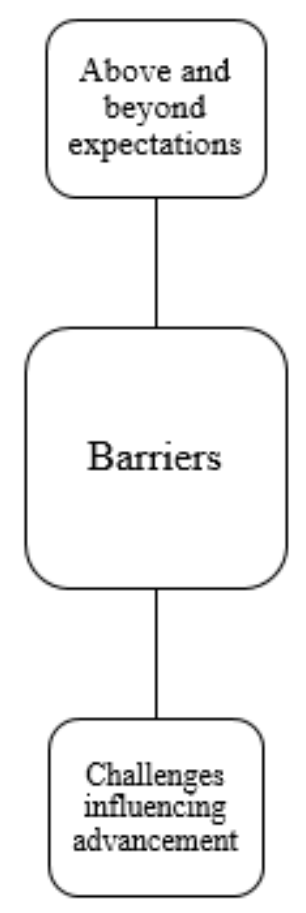

Figure 3. Barriers

Theme 4. Above and beyond expectations. Several participants expressed concerns about African Americans having to work twice as hard and be twice as good as their Caucasian counterparts and stated the following:

- Right, and so, it goes back to, as an African American, you have to have a strong conviction and believe in self and what you're capable of doing, and everything you say and everything you do, you can back it up, and it's a shame that you have 
to ... it's a shame, but then, not, but it's a shame that you have to know. When I speak, and I say something, I have all the factual evidence to back it up because I guarantee you, they are going to check it all. So, whenever I make a statement, it's a fact, and every time I send an email out, it's a fact, because it's going to be checked. So, that's the life I've experienced, and I've lived, but that's helped me to get to the level that I am today. (Tina)

- I think that you have to be qualified, and not just barely qualified. I think that you have to be very, very qualified. Regardless of being a minority or not, people are gonna always want to know, are you qualified for the position ... and that you're a lifelong learner. I think that, that's not just a key to success for an African American or a minority, that's the key to success for anybody who wants to do something great... . people are constantly evaluating you. They're evaluating how you dress, they're evaluating how you talk, the English you speak. They evaluate you on how you write, and that's one thing ... when the reports that you turn in, if your stuff is perfect, they know that you take your job seriously. (3T)

- And so at this stage, you do know that most of your work is looked at longer, scrutinize a little bit more deeply than others work might be. You do have an appreciation for the reality that, your work ethic has to be impeccable, second to nobody else in the department or on campus. I think you do have to have an appreciation for making sure that you've got all the research done. That all of your I's are dotted, all of your T's are crossed that there's no possibility for an error, and whatever it is that you're working on or what you're, sort of, representing. (Dennis) 
- I think as an African American we always have to have more. We have to have more training. We have to have more education. We have to have more experience as opposed to our White counterparts when it comes to applying for higher level positions. And it's only because of, I believe, let me say that, I believe it's only because of race. As a Black woman, especially, I know I have to be overly qualified for the position so that I will have a chance to even be considered for the position. Because if I'm not, as a Black woman, then I probably wouldn't even get an interview. So we always have to have more when it comes to higher level positions. We have to be sure that we have crossed our T's and dotted all I's when it comes to your work history, your work ethics, relationships with people, the way we conducted ourself in the institution if we are looking for advancement. All of those things play a factor. And I don't think they play a factor when it comes to our White counterparts, not as much as it does for us. Because it seems like they're always looking for a way to weed us out. The first thing that comes to mind is we always have to have more. (Tiffany)

- I just feel that we always have to prove ourselves. We always have to strive harder. No one's just going to give that to me just from having years. I feel like that if I don't have the credentials to match. .... She [A White co-woker who was promoted] didn't even have the credentials to match. She had the experience but not experience directly related to what she's doing, but she had the time at the university. Her credentials definitely do not match the job that she's in, but she got that shot. I just don't think that a person such as me, will get that shot. (Ebony) 
Theme 5. Challenges influencing advancement. When addressing the challenges influencing African Americans' desire to advance, some participants perceived internal promotions, who knows who, and stereotypes about African Americans as barriers. Other themes uncovered included perception of the institutions, continuous inconsistency in standards and hiring practices, a lack of African American mentors, and small candidate pool.

- The challenges that they'll face is that sometimes when you got to work, you're not going to make any friends. It's business, and you have to remember that. You be friendly, but it's business, and so, one challenge, and I think I've touched on that too, know your job... Know why you're there. Know you're coming to work to work. Know, sometimes, you might have to stand alone. (Tina)

- You know I think it's important for African Americans especially in the education industry to go in with their eyes wide open. They have to know that what they have to do to attain that mark is going to be something completely different than what their Caucasian or Indian or Hispanic counterpart might have to do. Sadly as minorities, we are not treated equally across the board, it's something about that African American cut that's completely different. The environment can be a barrier if there is inconsistency in how they perceive your value system . . . two of the largest values which really I think it boils down to, whether they think you're competent or not to represent them if they put you on TV or in front of a newspaper reporter or you have to go speak in front of a group of people, are you articulate enough to say what needs to be said and make them look good, or are you going to speak slang, because you're Black. (Tonya) 
- ... Sometimes the biggest threat to your success is in your head. It's in your head. Everybody has shortcomings. All of us as administrators have shortcomings. My shortcomings might not be yours. I think the biggest threat that has been for me is; I think everybody's watching me. And they're watching what I'm doing. Nobody's watching that guy. If I don't come to a meeting . . 'cause, you know, you're the only African American ... if you don't come to the meeting, you think everybody's gonna say, "Well you didn't come to the meeting!" You put this pressure on yourself . . . nobody said anything to me. Nobody said anything to me about anything. If I make a mistake, I'm like, "They're gonna probably run it in the ground because I made a mistake, and the other guys make mistakes and ain't nobody say nothing to them!" And nobody said anything to me. It's like you put this pressure on yourself. You put a lot of pressure on yourself, and some of that pressure is undue, but some of it is just because you know that you're different. You know that you think differently, you've got a different experience than your colleagues have, and you understand that difference. I mean, it's obvious, when we sit at the table, that I'm a little darker than everybody else at the table . . . but you put some undue stress on yourself because you're thinking all the time that, "they're looking at me differently than they look at that guy, or they look at that young lady there." So a lot of it is the stuff that we bring on ourself. (3T)

When discussing barriers influencing career advancement for African Americans, participants alluded to the lack of mentors, especially African American mentors, as a 
challenge influencing advancement. The following excerpts describe the thoughts of several of the study participants.

- I think one of the things that probably addresses, that could be a barrier, is sort of the importance of good mentoring and having a person that identifies an individual early in their career and sort of stays with them and helps to guide that career in such a way that the individual can see the light at the end of the tunnel. And that's often times difficult to do at a university setting because we have so many moving parts on any given day. It's easy to, sort of, get lost in the shuffle as it were. (Dennis)

- There are not many Black mentors that exist within the state. There are not many that exist within the Mississippi community college system. (Sarah)

- I think in the African American community what lacks, my opinion again, is that mentorship. They don't see any role models, and they don't see any mentorship. ... I think it's a strong mentorship too, because I mean, the times when it gets tough, and you think to yourself, "I am not doing this anymore. They don't fuss at him because his emails are wrong, but they're constantly on me." That's where that community, just like anything else, having somebody there to walk beside you and say, " Don't give up. Don't give in. Yeah, this is hard. But because of what you're doing, you're making it easier for the next generation." And then there's going to be more. You're going to multiply. And because of what they do, it's going to be easier for the next one. And that will multiply. (Focus Group Member) 
The participants were asked to discuss the cultural climate at their institution and if the climate promoted racial diversity within its hiring practices. Study participants recognized the inconsistent hiring practices at their institution and attributed them, and the lack of African American representation on hiring committees to the underrepresentation of African Americans at their institution. The participants provided the following perspectives:

- My whole thing is, I truly believe that particularly here in Mississippi, there's more autonomy's to hire people you want than we let on.... When it comes to administrative positions, be consistent in your practices. . . It should be a consistent message for hiring administrators. Not this person can hire one person, but when it's time for this committee, we're gonna go form a hiring committee. Be consistent. Sending a mixed message, to me, it tells people at the institution, we do what we want to when we want to. So, send clear and concise practices for hiring administrators. Let people know what the criteria is so people can prepare for it. (Thomas)

- You gotta think when there are very few individuals, when there are very few minorities that serve on a search committee when there's a vote that's taken, it's a very small vote. And there's implicit bias that exists on search committees. People tend to hire folks that look like them, that act like them, that have some of the same values as they do. (Sarah)

- I'd go back though to the difficulty in getting diverse populations to see themselves coming to Mississippi. Because most people, Black, White, male or female that are really good at what they do that are very successful at what they 
do, have a lot of options. So we sometimes, in education, find ourselves when it comes to strong candidates in a crowded field of other institutions who also want those very strong candidates. And so we have to ask ourselves, what can we do as a university and what can the state of Mississippi do to be more attractive to those people? So I really don't believe I'm naive in believing that there are not any issues on campus, with interview pools and interview committees. I mean, obviously there's always work to be done in that regard. (Dennis)

- So committees appear to be handpicked in our environment ... we're often excluded from that process. As Black administrators, but we don't serve regularly on hiring committees or the hiring committee has no racial diversity, and it may not even have any department diversity.... I don't see how, even though we're administrators, I don't see how we're often excluded from that process when we hold the frontline to the institution. There are no instruments that lend objectivity to the process. It usually is a subjective "how do you feel about it?" And then the voting ranks, even if you are on a committee, you already outnumbered. (Amy) The focus group members were asked the same question as the one-on-one interview participants about the cultural climate and promoting racial diversity within the hiring practice at their institution. One focus group member's response was, "we discussed the notion of making sure to check the diversity box when it comes to interview committees but not because were are being intentional..." The excerpt below provides full detail of the focus group member's verbatim comment.

- Something that we've kind of laughed about in any our hiring ventures. We'll come up with an interview committee and interview team, and we'll check the 
diversity box, because we'll have either the male, female, or the Black, White, whatever makeup we have to have. Whether we're pulling that person in because we feel like they're really going to be instrumental in choosing the right person,. We're going to check the box before we choose somebody, not because we're being intentional about diversifying, but because we're checking the box. (Focus Group Member)

Study participants spoke openly and honestly about race and stereotypes and their influence on African Americans' career advancement at PWIs. Several participants suggested it was more than just stereotypes about African Americans presenting challenges in attracting qualified African Americans to PWIs in Mississippi, it was also the perception that some people have of Mississippi and some of the PWIs in Mississippi.

- I think race is still the barrier, unfortunately. And then especially in the state of Mississippi. I think it is very much so the main barrier ... it's not because there are not enough qualified African Americans. (Tiffany)

- I'd like to believe that we have a culture here that is open and inclusive and transparent. And I think there are a number of things that support that position. I believe that the greater challenge for us, and I would even go so far as to say maybe for other institutions in the state, really is just the opinion and the perception that the state has in the larger country and around the world. And I think that a lot of very talented men and women of many race and ethnicities, somehow view coming to Mississippi as something that's not an advancement to their career, but maybe something that's more of a challenge to come here and be a part of what they perceive the state of Mississippi to be ... We need a little bit of 
help with the national perception of the state where we live and work, because anybody who doesn't believe that that's an issue and that people don't draw conclusions about us and what we stand for in this state, I think that they have missed it by a long shot. (Dennis)

- I think race is more of an issue when it comes to more of the higher level when you go to the cabinet level positions. I think the higher you go up, that's when race, it seems like, play a major role. If you looked at our cabinet today, you would see. I wouldn't have to say a word. Right now, in our cabinet, there's one, one male. (Tina)

The focus group members comments about race and stereotypes supported the commentary made by the one-on-one participants suggesting perceptions of the PWIs and race relations in Mississippi might affect PWIs ability to recruit and hire qualified African Americans. Two focus group members had this to say about the perception of PWIs:

- A lot of times, I think that for instance, when you are searching, and you see positions at a particular campus, particular institution, you look through the qualifications and you say, "I'm qualified. I meet the qualifications." You're going to Google, and you're going to go, and you're going to look at the general makeup of who sits where. And a lot of times, when you see it, there may not be an African American in a CEO position or mid-level, or even executive level. And then you know, you kind of ask around, and there's a perception, "Oh you can try, but you're not going to get selected because they probably already have someone in mind." Which is a lot of times, true. There's already someone in 
mind to promote from within, but you have to advertise it. And so the perception is then there, "Oh, well they didn't want any African Americans anyway." When that might not be true. Because we do have to advertise, you know, for legalities and everything, but we already have someone in mind, and a lot of times, the person that's in mind is part of the system, the clique, and there's the perception.

- But in some areas, these rural areas, I think there's such a stigma tied to it, and how do we let that go? I don't know if we can. Hey, we can say racism's dead. It's not. It still exists on certain levels. I don't think institutions are intentionally being racist. I just think it's the way that things have been done, and that in certain places, change is happening, but it's just happening at a snail's pace

On the subject of racial stereotypes, some participants contend stereotypes about African Americans can influence career advancement opportunities. Study participants provided the following comments:

- I think that sometimes, the stereotype is you can be led to a decision, you don't have the ability to big picture think, to understand all the working variables and parts ... somebody has got to tell you what to do; you have just got to be able to say yes, no. (Tonya)

- You have already established this perception of what it's gonna be or who they're gonna be. It's like, "Okay, well I know I can't work with that person," or, "That won't be good," or, "They attended that institution." "They attended that HBCU." Because, again, there's this stigma that exists with certain races and certain cultures. (Sarah) 
- Outward stereotypes. You know hair or you know they're perceived you as this angry person [Anger Black man or anger Black women] or this not refined person because I'm wearing dreadlocks. Or I have a nose ring, or I'm wearing a dashiki, so I'm angry. Still to this day you have to kind of conform to what is socially acceptable as the professional, as you seek to aspire, unfortunately. (Joyce)

- ... And I think that [Prejudging] comes with, of course, the racial stereotypes that are out there about African Americans and our culture. And unfortunately, that is not the case for every African American. So to put us all in that box, I don't think is unfair without giving us the opportunity to prove ourselves and prove our worth. And I think a lot of times that's what institutions of higher learning will do when it comes to the advancement of Black people. Because they already have that stereotype or their preconceived notion about Black people. One, for the sake of a better example, is we have the spirit of laziness. Our work ethic is not there. We always want to take advantage of doing the wrong thing. (Tiffany)

- For screening applicants, I think there's a name bias based on the ethnocentric names that can show up on applications. I've been on hiring committees where people have snarled at the name of a candidate that ended up being somebody they were going to interview. I have witnessed rankings changing once the final five candidates are selected. I've witnessed those rankings change personally, firsthand. And those rankings couldn't have been based on anything other than the perception of some of these people. (Amy)

- I think it's been across the spectrum. I think that some people have enjoyed tremendous success and tremendous advancement because of their race or 
ethnicity. And I think on the other end of that spectrum, I think that some people have been left out of the conversation simply because of their race and ethnicity. And I think that it's our jobs at the university level to look for and to take action against situations in which the latter of that occurs.... But I think that there are examples of people who have benefited because of their race and ethnicity, who have also been very qualified, in addition to that. But I also believe that there are people who have been marginalized and left out because of it. So it's on both sides. (Dennis)

- ... And you may get to this question, but I was almost told that I was a token that was selected, but I didn't look at it as that. I looked at it as an opportunity that I was given because I had the talent that God had blessed me with to help those along the way. (Tina)

Focus group members discussed the effects of stereotypes on the career advancement of African Americans at their institution and in educational leadership at PWIs in general and stated the following:

- ... The education that you received, where you go to school. You're going to Southern. You're going to a predominantly White university. And I'm not saying this negatively, but there are some people that will look down on you if you were getting your doctorate from Jackson State or Alcorn. And I mean, that's the truth. And so, where you receive your education does affect the quality of education received. ... I'm not saying this negative at all, but you know, years ago in the 40s, 50s, 60s, Black universities, African American universities, their quality of 
education for their teachers, for their administrators was not the same quality as a predominantly White. And I'm not saying that ugly.

- I think partially my experience is that getting over the stereotypes. Of course, we know all about the stereotypes about Asians and African Americans and Caucasians. Unfortunately, in our society, we live in this society. It's very unfortunate, but true, and I don't see that changing in my lifetime or the foreseeable future.... But a lot of times, as an African American, there are hidden stereotypes that I don't think everybody wants to recognize, or may not even realize. But I have found where, if I'm doing something, if I'm submitting something, or if I'm saying something, I need to be extremely sure that I'm crossing every T, dotting every I, and that is not the same standard that everybody is held to.

The study participants recognized the importance of developing internal and external relationships. However, some participants talked about the barriers African Americans face when it comes to hiring people solely on the basis relationships (who knows who). Study participants suggest tradition has created barriers influencing the disparity between African Americans and Caucasians at their institution. Several participants stated:

- We do too much internal inbreeding here. We did too much inbreeding. I call a spade a spade now. We do too much inbreeding, we need to bring some diversity into this place. I think people hire in their comfort zone, they gonna find those that look like them, who they relate to, and maybe individuals they go to the golf course with, they go to the same church and so forth. I think those kind of things; they stay in their comfort zones. Sometimes people don't wanna get out of their 
comfort zones.... We had a guy here who was always hiring people he know, cuz, Billy Bob's nephew, so on and so forth who ain't got a clue, and he won't bring no one in and or was only hiring internally. I'm not saying it all should go external or outside hiring people, but there needs to be a balance. (Tim)

- From my perspective, our institution do a lot of hiring from within. So, it's my opinion with it already being a deficient in the number of people of color there, it's hard to hire people of color when you're just introducing people of color to the climate. I think that goes back to the conversations we should have at our institutions. Should every position be internal? Or, should sometimes it be that we decide that we may go outside ... In my opinion, sometimes it comes down to who someone liked and who people talked about or who this person has made mad or something like that.... I think that the more and the sooner we can get people to have that mindset of I'm not doing diversity for a checkbox, I'm doing it because it's right, the better we'll be. (Thomas).

- Yeah. Advancement of African Americans, a lot of time that advancements, to me, sometimes, it's a little ... a lot of times it's who you know, and we haven't gotten away from that. A lot of times, the budget and hiring from within and promoting from within has kind of stemmed to, okay, who might be losing a job, but then, even at that, who do you know? And then, it's a practice of, well, okay, well, who's going to advance? Who's not going to advance? Is it going to be an African American? And then, sometimes, it's just by campus, and then, campuses lead to, who's the VP [Vice President] on that campus? (Tina) 
- I don't know that we attract those applicants. I think that's part of our problem is that we haven't been able to get past the "Good Ole Boy "system and that we're not attracting. They're not even trying, because, "oh I know I'm not going to get it, so why try...." You just think about promoting from within, people knowing people. I mean, that's carried on for 40 or 50 years, you know. You went to church with this one's grandma. She knows you, and all. (Focus Group Member) "The Only" or "The First"

During the one-on-one interviews, many of the study participants talked about their experience as being either "the only" or "the first" at their institution. Study participants alluded to the pressure, loneliness, and challenges encountered by them as "the only" or "the first." Theme 6, while not connected to the research objectives, was recognized as being a significant finding due to the number of participants who were either the only or first at their institution.

Theme 6. "The only" or "the first." The pressure and anxiety of being " the only" or "the first" were expressed over and over by participants. One of the participants described the pressure of feeling troubled and stress in being the only one, suggesting, at times as if he was called on to speak on behalf of all the African Americans at his institution. Another participant expressed the idea of feeling like she was not being heard and wondering if her peers saw her as just being a token. Additional comments from study participants include:

- I know that I have often found it very difficult how I perceive my institution to see the advancement of African Americans in 2019. I know that hearing just four years ago, five years ago that I was the first Black assistant dean down here blew 
my mind. Blew my mind, [emphisis added] but I was. And so to me that says something about my institution that doesn't make me feel good inside. What is going on that we are still there, what is going on that our mindset is still at that place, at this time. (Tonya)

- The cultural climate here is completely one-sided. It is a predominantly White institution, no doubt. I have very few African American faculty members.... At the administrative level it's probably even more alarming for the lack thereof. And it's not just racial. It's gender. Because I am the only female senior administrator at this college. There are no Black academic instructor. And even in my role, I'm the very first African American to serve in this current role, which was widely publicized ... and being the only Black in the room you walk in to; you have to be ready. You have to always be ready and armed with all of the information that you possibly can be armed with. And in addition to that, the overt racism that has been pervasive in our country here lately has allowed individuals to be more bold and vocal about their opinions and their thoughts. And so at this level that shouldn't be the case. I shouldn't have to deal with that at this point. I shouldn't be questioned about my integrity . . . when you make a statement or have a voice, I feel like I am speaking for all of the others, and I am representing all of the others here at my institution. Because, again, the numbers are small, so you have to be careful ... you become the voice of the race. You become the voice of the people, and you become that vision of what it's supposed to be. (Sarah) 
- ... If I have someone who looks like me [African American counterpart], you already know what I'm coming to the table with. You already know how it feels to be the token. I don't have to explain that concept to you. You already know what it feels like to be in a room where you're the only Black woman, and you're the one that's supposed to make the decisions, but you know that there has already been some conversations that have been had before you got into the room. (Tiffany)

- And remember I am the only one. Only African-Americans executive-level administrator. We have a high percentage of African-Americans students at this college, actually the majority of the students at this college. But, I have to speak for the whole race ... some of them have good intentions, but they don't understand. They don't understand. And some of them don't want to understand. ... I am the only one. I constantly have to prove myself, I constantly have to go above and beyond, and it's frustrating, and I can't lie to you. It's frustrating [emphasis added] when I have gone the long way around, the long way around, then I see one of my White counterparts just starting and goes straight to the top ... I started at the first floor, and I go to the second floor, the third floor, fifth floor, and so forth, and I'm starting at the first floor, and they just go straight to the tenth floor ... And it is with no experience. They get promoted to the same level as I am, making the same amount of money, making as much money as I make, and so forth. That's frustrating. (Tim)

- But for me, I think over 28 years, while that's been the case, I think it's made me, and many people who've been the only one much better as a result of it has made 
us much more intentional. Has made us much more analytical. Has made us much better listeners, better question askers, because that's just the world that we have sort of grown up in and it's just almost become second nature. And so I don't know that I am as sensitive to it as maybe I was 25 years ago when I was just starting . . . because I've been doing it for 28 years now at a very high level, pretty much as the only one. You just, sort of, embrace early what that means, and how to, I don't want to just say how to survive, but how to be successful and thrive and accomplish your career goals in this, in an environment where you're the only one. (Dennis)

- I never really thought about it until you asked the questions. It's kind of like, it's always in the back of your mind, of course, you're working at an institution where not a lot of people in administration look like you. It's actually gotten to be second nature to me now. I was just in a meeting, and I was the only Black girl in the meeting. (Ebony)

\section{Perspectives Toward Advancement Opportunities}

RO4 - Explore African American administrators' perspective toward advancement opportunities for African Americans at PWIs of higher learning.

The fourth research objective explored African American administrators' perspective toward advancement opportunities for African Americans at PWIs. Participants were asked their thoughts regarding African Americans' access to leadership positions and expressed some concerns, but they were optimistic about the future for African Americans at PWIs. Some of the participants suggest future African American 
administrators will not face as many challenges as previous generations or their generation.

Theme 7. The optimistic future. Many participants, when discussing their perspective toward the advancement of African Americans at PWIs, expressed a belief which suggests some of the current members of the dominant culture at their institution do not see diversity as a priority and are unwilling to relinquish control. However, they suggest in certain departments at their institution, change is already occurring, and they are very optimistic about the future for African Americans taking on leadership positions at PWIs in Mississippi. The following comments represent some to the participants' outlook on advancement opportunities.

- I really think that in years to come, I really think that we will be moving ... we're continuing to move in the right direction. On our campus, I feel like we're taking steps. One of the steps was those new positions for diversity and inclusion. I think, continuing to make those steps, continuing to have race at the forefront. A lot of people like to put it on the back.... You need to have those conversations because it's here. It's just the reality. I think bringing those conversations to the forefront and understanding that a more diverse faculty and staff will bring you a more diverse student population. ... I see it moving in the right direction. I think it's going to be growing. I feel like there will be more positions for minorities in higher ed. in the future at PWI's because if not, I just don't see them growing. (Ebony)

- I believe since the new president is here, he has recognized that a shift is needed culturally and he has embraced diversity. He has embraced the perspectives of 
people who don't look like him. So, in short, I think that we are amidst a cultural change. I think we're amidst of a cultural change in diversity. (Heather)

- I really believe that we're having a cultural shift in the country, I really believe that. I think it's not going to be as hard as it has been, I really believe that. ... I won't say it's going to be easy, but I think with all the changes ... the number of minorities, African-Americans, and females who are in Congress and so forth, I really think it's kind of funneling down, and I think it's going to change, I think. I think it's not going to be as easy ... it's not going to be easy, but it's not going to be as difficult as it was when I came up the ranks of higher education. ... In midlevel-administrative-type positions, we already have a pretty high number of African Americans in key positions, as mid-level administrators like deans, and so forth ... there could be more, given the make up the college, but we have a number ... again, on my level, the cabinet level, I'm the only African-American on the cabinet here. Our president is a phenomenal man he gets it, but everybody dont get that, as far as culture promoting, I think he tries to hire minorities, but some people have been in positions a long time, but guess through attrition we my begin to see more African Americans at that level. (Tim)

Strategies Addressing Racial Diversity RO5 - Identify institutional strategies in place at PWIs of higher learning addressing racial diversity.

The fifth and final research objective identified institutional strategies in place at PWIs of higher learning addressing racial diversity. The findings also include possible strategies such as developing mentoring programs, succession planning, and PWIs 
becoming more intentional in recruiting African Americans for position of leadership (see Figure 4). Study participants suggest implementing such strategies could increase the application pool for administrative positions. When asked about specific policies, procedures or strategies in place at their institution to address hiring more minorities, only one of the participants stated having procedures in place, outside of the standard federal discrimination policy, at their institution.

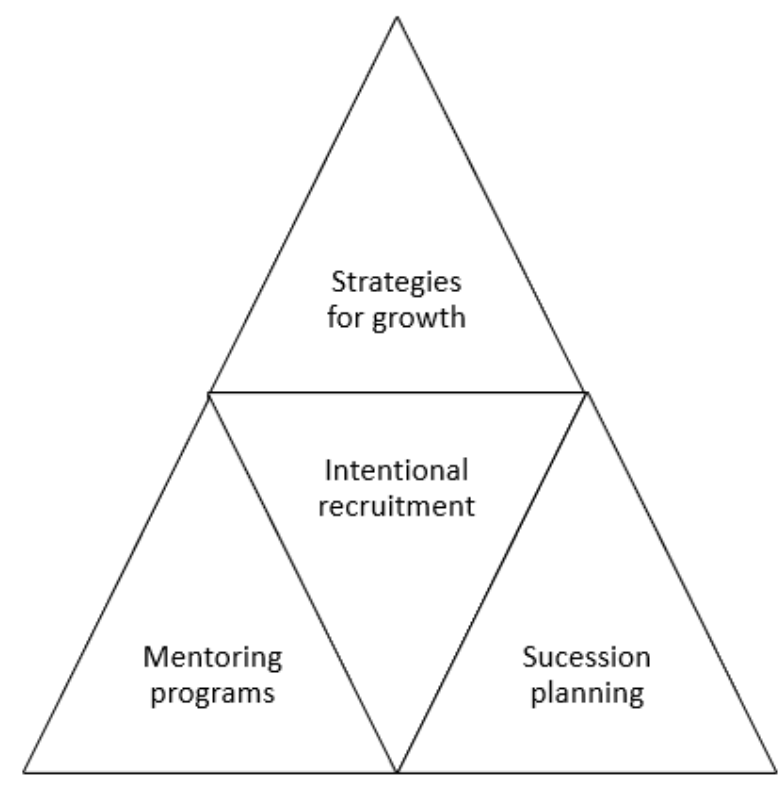

Figure 4. Strategies for Growth

Theme 8. Strategies for growth. Nine participants believed their college administration promotes diversity. When discussing possible strategies, the majority of participants believed their institution's administration needed to be more intentional in diversifying when hiring and stated:

- I think that recruiting-wise we need to focus in on it [Diversity]. It's one thing to have people to apply, and then actually have them hired. It's another thing to recruit. If you know that we do not have enough Black administrators or Black 
faculty, then you have to put extra efforts into recruiting them. And when you recruit, you have to make it marketable. (Heather)

- Well, based upon our statistics, we have not done a really good job of promoting within and attracting more qualified African Americans. There have been a lot that have applied, but we've had a lot of internal candidates that had been there for a while. (3T)

Study participants were asked to talk about strategies in place at their institution that promoted racial diversity within its hiring process. Only one participant acknowledged having a hiring process in place at her institution designed to increase fairness and diversity. Two participants talk about strategies they have incorporated, even though there is no formal process in place.

- Yes, I definitely think that they promote it [Diversity] in the hiring practices. Especially now, I guess I'm very aware of this because we're going through a search process here. We have a new system; you have to actually list in the system the names, the races, the sex, and the ages of the people on the hiring committee. It has to be diverse. You can't have all Caucasians. You can't have all females. You can't have all African Americans. They can't all be over 30... . I definitely think that's really good because this is the first time I've ever known that to happen. I think we moved to this system about three years ago. I think that's really good. You know you're going to get a diverse search committee. You're not going to be looking at somebody who does not look like you [An interviewee/candidate for hire]. Somebody will look like you on that search 
committee.... It shows you that they're taking steps. A lot more will eventually happen. I know they're taking good steps in the right direction. (Ebony)

- Well, there's not a strategic plan to hire more African-American males, but I think the college tries to hire African-American. We can advertise more in those diversity higher education magazines, and so forth that caters to AfricanAmericans. We visit the HBCUs in the state. However, we can advertise in those places more and get the word out more. We can do a better job of doing that, and the one thing that I do personally. (Tim)

- Well, of course, we have the non-discrimination policy that's in place, and we've gotten a lot better. Whenever we go through the hiring process, everyone is given the opportunity, and when you cull the applications or what have you, that's gotten a lot better as well. I say it's gotten a lot better because when I first got there, it was kind of different. But now, what we do, is there's a fair practice, for instance, as far as the interview committee, we try to have equal representation. (Tina)

- Well, one thing that we decided to do is to increase the likelihood of the applicant pool, where people who traditionally would not apply . . . because they didn't know ... we're starting to go in places that we traditionally didn't go. And those places sometimes are HBCUs, so if you really wanna look to diversify your population, you can't just put it in the newspaper or just advertise on your webpage, because that population is very specific that looks at your webpage, people that look at the newspaper, and that's based upon the region. So we have to start looking at different places that we traditionally didn't look at. (3T) 
When asked about hiring strategies aimed at promoting diversity, the focus group members admitted to the absence of any official policies, procedures, or strategies at their institution. However, similar to interview participants, the focus group members too felt as if the $\mathrm{CEO}$ of their respective institution promoted diversity. The participants provide the following perspective:

- There's nothing in writing [Policy for hiring more minorities]. You're right. At my institution again, we have a great president who's promoting this culture. We're told directly to look for minorities. Look for qualified candidates, to begin with, and then look for minorities. (Focus Group Member)

- So the key to some of this is making sure that as we're looking to hire these entrylevel positions to consider diversity at that level, especially if we're going to promote from within and grow those individuals that we bring in on the ground level to that type of leadership position. (Focus Group Member)

- I agree with what you said [Another focus group member] about you know when the new generations of presidents are coming on. I think we're seeing less of that good ole boy system, and more of the intentionally looking for diversity. (Focus Group Member)

\section{Research Objectives and Theme Correlation}

The analysis for this study yielded 23 emergent themes, clustered into seven of the eight overall themes. A display of the participants demographic (see Table 4), along with a brief description of the participants fulfilled RO1. The descriptive narrative and interview excerpts from Themes 1-4 satisfies RO2. Theme 4: Above and beyond expectation and Theme 5: Challenges influencing advancement correlates with RO3. 
Theme 7: The Optimistic future connects to RO4, while Theme 8: Strategies for growth supports RO5. Theme 6: "The only" or "The first" is not attached to any of the ROs but is one that seemed significant throughout the analysis of the study. Table 6 outlines the correlation between the research objectives and themes for the study.

Table 6

Research Objectives and Theme Correlation

\begin{tabular}{ll}
\hline Research Objective (RO) & Themes \\
\hline RO 1 & - Interview Protocol Form and Demographic Form \\
RO 2 & - Theme 1: Good mentors \\
& • Theme 2: Relationships matter \\
& - Theme 3: The intangibles: What to bring to the table \\
& • Theme 4: Above and beyond expectations \\
RO3 & - Theme 5: Challenges influencing advancement \\
RO4 & - Theme 7: The optimistic future \\
RO5 & -Theme 8: Strategies for growth \\
\hline
\end{tabular}

Summary

Chapter IV details the data analysis process used to develop the codes, themes, and results of the study. The chapter also includes sections outlining the steps taken to ensure the trustworthiness of results. The participants' demographics conveyed in a table with a brief description allows the reader to become familiar with each administrator and their role within the educational arena. Excerpts from the interview and focus group transcripts were used to address the objectives for this study. The responses from the participant interviews and reflective journal entries yielded eight themes and 23 emergent themes. Finally, the creation of Table 6 , as a result of the data analysis, displays the 
research objectives and theme correlation. Chapter V discusses the conclusions, interpretations, and recommendations for future research. 


\section{CHAPTER V - CONCLUSION}

This study focused on the lived experiences of African Americans who work at publicly funded PWIs in Mississippi. Chapters I - IV presented background information supporting the need for the research, a literature review, the methodology, and the results from the data collection. Organized in several sections, Chapter V includes a summary of the study, a summary of results, findings, conclusions, and recommendations. Finally, the chapter concludes with recommendations for further research, discussion, and chapter summary.

\section{Summary of the Study}

The purpose of the research was to explore and identify enablers and barriers contributing to African Americans' advancement into administrative positions at PWIs of higher learning. The researcher used a qualitative interpretive approach to collect the data. The following research objectives were developed to guide the study:

RO1 - Describe the demographic characteristics of the participants, including their gender, work experience in higher education, years of experience in their current position, and degree attainment.

$R O 2$ - Explore and identify perceived enablers influencing the advancement of African Americans at PWIs of higher learning.

$R O 3$ - Explore and identify perceived barriers influencing the advancement of African Americans at PWIs of higher learning.

RO4 - Explore African American administrators' perspective toward advancement opportunities for African Americans at PWIs of higher learning.

RO5 - Identify institutional strategies in place at PWIs of higher learning 
addressing racial diversity.

Snowball sampling technique was used to select one-on-one interview participants. Likewise, purposive sampling was used to solicit focus group participants. The one-on-one interview sample consisted of 12 African American mid and upper-level administrators, who were asked semi-structured open-ended questions. The focus group, however, consisted of six community college administrators who were asked semistructured open-ended interview questions.

The data collected was interpreted using the IPA method. The demographics of each participant were collected using the interview protocol form and the focus group demographic form. The IPA process yielded eight themes classified as good mentoring, relationships matter, the intangibles, above and beyond expectations, challenges influencing advancement, "the only" \& "the first," and strategies for growth.

Summary of Results

The participant demographics were collected from participants, which satisfied RO1. Analysis of the interview and focus group transcripts yielded 23 emergent themes, which were categorized into seven of the eight overall themes. Seven of the eight themes supported RO2 - RO5. One of the themes that emerged did not connect with either of the objectives but was relevant throughout the analysis process. Excerpts of the verbatim transcripts from the interviews and focus group were used to support the themes.

Findings, Conclusions, and Recommendations

Finding 1: Having a mentor(s) is critical to the development and advancement of African Americans at PWIs. 
Participants from the study spoke passionately about having a mentor(s) who assisted and inspired them throughout their career. Participants acknowledged the importance of having a mentor regardless of race or gender. In contrast, some participants expressed concerns over not having African Americans in administrative leadership positions available to serve as mentors.

Conclusion. The literature supports the value of mentorship to help future African American administrators navigate their career path and understand the culture and politics at PWIs. Cleveland (2004) suggests formal and informal mentoring taking place offers valuable insight into the politics of the institution as well as the overall campus culture for African Americans. Ragins (1997) also contends mentors benefit from a diverse relationship because it could lead to the mentor receiving a boost in his or her career. Judson (1999) suggests appropriate mentorship, in part, contributes to the success of African American administrators.

Participants in administrative positions in higher education expressed concerns with the lack of African American administrators to serve as mentors. The dearth of African American mentors in administrative positions leaves new, young or aspiring African American administrators without guidance when trying to understand where they fit in a culture dominated by people who are racially and culturally different from them.

Recommendation. Develop an internal mentoring program allowing African American faculty and staff members within the institution, who want to become administrators, to connect with current administrators who can assist in navigating careers. The creation of a mentoring program could also be beneficial in helping aspiring administrators understand the culture and the processes within the institution. The 
relationship between mentor and mentee is not only beneficial for the mentee but the mentor as well. The mentoring relationship could assist the mentor in producing positive results as it relates to the organization's outcomes and the administrator's intrinsic fulfillment (Ragins, 1997).

From a policy perspective, PWIs could recruit top-level administrators to undertake a mentoring relationship with mid-level African American administrators or potential administrators. In schools with no African American mid-level administrators, top-level administrators could identify faculty or staff members who have expressed interest in administration and mentor them. Consequently, this could help to develop a pipeline of potential African American administrators at various institutional levels.

The development of a state and national mentoring program to connect African Americans who aspire to be administrators with other administrators could be beneficial. Dunbar and Kinnersly (2011) contend a healthy and active mentor-mentee relationship hinges on various factors and suggest a mentoring relationship is most successful when both parties involved share similarities, such as backgrounds, values, outlooks, and experiences. However, Ragins (1997) suggests when the mentor and protégé relationship involves people of different backgrounds, diversity outcomes are more likely to to be accomplished, because the mentor obtains knowledge, develop cultural competency and skills relating to interacting with persons from diverse groups.

Finding 2: African American administrators expressed the anxiety of being "the only" or "the first" at their current institution.

When talking about their experience as administrators at their respective institution, participants alluded to the anxiety and the challenges they felt in being "the 
only" or "the first" African American to hold the position. The participants' racial identity is a central part of their background while serving at a PWI. However, the challenge of being an African American administrator at a PWI presents an illusion that they were the voice of all things relating to African Americans and diversity at their institution.

Conclusion. In a study conducted by Rolle, Davis, and Banning (2000), findings suggest African Americans struggle for acceptance into mainstream society. Additional findings support the previous research from Kanter (1993), that African American administrators feel apprehensive about "not measuring up" and "having to prove their leadership abilities" to the organization, continuously. Study participants believe they always have to prove themselves to be accepted, and most times, their ideas are scrutinized or vetted more rigorously than their White counterparts.

Racial tokenism, which originated from Kanter's original theory on tokenism (1993), suggests African Americans assume high profile positions to be an authority on all things relating to African Americans. Study participants expressed concerns over feeling as if when they spoke their voice represented the voice of all African Americans at their institution. Several participants expressed additional pressure to succeed because if they did not, it might minimize opportunities for other African Americans in the future. Jackson and O'Callaghan (2009b) suggest such challenges and pressure can lead to African Americans becoming discouraged and in essence causing them not to pursue upper-level positions.

Recommendation. College and university administrators on all levels could be required to participate in diversity, and inclusion training as a part of their development 
plans. Juffer (2001) references the significance of cultural sensitivity training and multicultural courses as necessary management practices that can transform institutional culture, promote inclusive campus culture, and minimize internal and external perspectives on race and stereotypes.

Finding 3: A lack of formal institutional hiring policies and procedures aimed at increasing diversity attributes to the racial disparity among mid and upper-level administrators at PWIs, creating the perception of institutional racism.

Recruitment and hiring procedures are critical strategies for the progression and hiring of diverse administrators. Study participants from the focus group and one-on-one interviews, suggest the degree in which internal promotions take place, and people hiring individuals in whom they are comfortable with contributes to the lack of diversity among administration and faculty at PWIs. Participants also contribute the lack of diversity on search committees and inconsistent hiring practices as possible factors. Moreover, participants felt their institution could implement intentional practices that lead to a culture of diversity and inclusion. Several participants alluded to the absence of consistent hiring practices as possible barriers for African Americans' advancement at PWIs.

Conclusion. Fujimoto's (2012) finding reveals when it comes to colleges' ethics and hiring practices, job announcements were not advertised in a manner to attract a more diverse pool of applicants. Participants in this study suggest their institution becoming more strategic and change how they advertise and recruit African American administrators and faculty. Furthermore, study participants acknowledge that their institution did not have any policies in place addressing diversity within the school's 
leadership. However, two of the participants alluded to the standard nondiscrimination clause required by the federal government as their school's policy on diversity. Lastly, study participants contend people within the institution tend to hire either people they know or people they feel comfortable with while using the term "good fit."

Recommendation. PWIs need to become more intentional in their advertisement and recruitment of African Americans for leadership positions within their institution. Advertising at HBCUs, state and national conferences, and in educational journals geared toward African Americans and other minorities should be a part of the recruitment strategy. After applications are received a fair and systematic method to determine potential candidates should be in place as a consistent practice throughout the institution. Interview committees should be diverse in terms of race, gender, and age. All interview committee members should receive training and information detailing the roles, responsibilities, and expectations of an interview committee member.

PWIs could look at developing a succession plan so as administrators advance, retire, or move on, qualified African Americans will be ready to assume positions without any serious dropoff in productivity. PWI could develop a plan for upward movement of African American faculty and staff members into administrative positions. Moreover, a plan detailing the guidelines for advancement could be available for internal promotions. Previous literature supports the idea of succession planning and management being a viable method for access and the promotion of inclusion for minority groups at the chief executive level (Galarrage 2014). Aligning management and succession planning can help cut barriers obstructing the pipeline for African American non-positional leaders (Grotrian-Ryan, 2015). 
Finding 4: Proper credentialing, along with internal and external leadership

development opportunities were identified as key factors influencing advancement opportunities for African Americans at PWIs in Mississippi.

All of the study participants expressed the importance for African Americans to have the proper credentials for administrative positions. Study participants stress the importance of participating in internal and/or external higher education leadership development programs. However, several of the participants noted the disparity and barriers African Americans face when pursuing leadership development opportunities.

Conclusion. In discussing the credentials for future African American administrators at PWIs, several of the participants believed it would be imperative that minority candidates have a terminal degree. However, some of the participants believed at the very least a graduate degree along with the proper experience would suffice. Jackson (2001) suggests the idea of African American administrators having the opportunity to be involved in a plethora of leadership opportunities is appealing and could lead to an increased number of African American applicants for leadership positions at PWIs. The leadership opportunities are believed to be vital in preparing African American administrators to advance within their educational institution (Cleveland, 2004).

Recommendation. Exposure to various internal and external leadership development opportunities for African Americans who work at PWIs can prove vital in growing the pipeline for future African American administrators. Upper-level administrators at PWIs could encourage and recommend potential African American leaders to participate in internal and external leadership programs when opportunities 
arise. Harvey (1999) suggests minimal effort from upper management was being put forth to push African Americans to seek senior-level leadership positions, because of the perception that African Americans lack the requisite skills needed to be successful.

Being intentional and being knowledgeable about all integral parts and nuances of an institution is important for African Americans when navigating their career pathway into administration. African Americans who are interested in advancing into leadership positions could let it be known and be intentional in their pursuit. They could seek to enroll in terminal degree programs and identify the positions of interest (e.g., student affairs, academic, admission and enrollment) in which to advance.

\section{Implications of Limitations}

Limitations of a study are factors in which researchers cannot control, but they can affect the study and the interpretation of the results in a significant way (Lunenburg \& Irby, 2008). Several implications of limitations occurred throughout the study. The first limitation is the researcher. The researcher in this study is part of the target population. Therefore, the researcher analyzed the data from the viewpoint of his lived experiences which could have affected his interpretation of the data. However, through reflective journaling, the researcher acknowledged the possible biases, thereby minimizing the biases effect on the methodology and results of the study.

A second limitation was the researcher's inability to acquire representatives from four-year institutions to participate in the focus group, which was a part of the triangulation. In using the purposive sampling technique to solicit participation, administrators at 12 of the 18 PWIs in Mississippi received emails requesting their participation, three four-year institutions and nine two-year institutions. Eight responses 
were received, two declining because of other obligations and six agreeing to participate. However, all of the responses were from two-year PWIs.

The third limitation included the researcher inability to identify and solicit more African American administrators employed at four-year PWIs in Mississippi to participate in the one-on-one interviews. The snowballing method only yielded the identification of eight potential candidates. Of the eight potential candidates receiving an email to participate, only four responded, with three of the four actually participating in the study.

The fourth possible limitation was the inexperience of the researcher in conducting interviews for this qualitative study. Throughout the interview process, the researcher recognized ways in which to improve his interview approach, and after each interview, the researcher reflected and made notes on process improvement. The researcher also exercised caution to ensure questions did not lead participants to a desired response. With each interview, the researcher confidence grew in understanding when to ask follow up questions and prompts requiring deeper responses from the participants.

Lastly, the findings from the study may not be generalizable. Generalizable is the extension of a study's results and conclusions from research conducted on a sample population to the larger population (Creswell, 2013). This study only includes African American administrators currently employed at public PWIs of higher learning in Mississippi.

\section{Recommendations for Further Research}

Future research may investigate the lived experiences of African American administrators employed at private, religious, and proprietary PWIs. The current study 
examines the enablers and barriers influencing African American administrators' career advancement at two and four-year institutions as a single phenomenon. Impending research could seek to compare factors influencing African Americans' career advancement at two and four-year institutions. Furthermore, research exploring the lived experience of African American administrators at HBCUs to the lived experiences of African American administrators at PWIs could be conducted.

A study comparing the paradigm and culture of PWIs and HBCUs, as it relates to the hiring and promotion of African Americans at PWIs and Caucasians at HBCUs. The study could compare and contrast the differences that exist in the recruitment, hiring, and advancement opportunities. Findings from this type of study could lead to the development and implementation of strategies geared toward diversity and inclusion at both PWIs and HBCUs.

Likewise, a study aimed at understanding the perspective of Caucasian administrators and senior leaders as it relates to enablers and barriers influencing the underrepresentation of African American administrators at PWIs could be beneficial. A study of this nature would provide an alternative perspective on the subject and the findings could be used to educate African American administrators and potential administrators on what the dominant culture view as contributing factors.

\section{Discussion}

The participants in this study spoke honestly and passionately about their experience as an African American administrator at a PWI. The interview participants expressed the need and their desire to motivate and cultivate up-and-coming African American higher ed leaders. Each of the participants in this study, both one-on-one 
interviewees and focus group members, expressed their support in conducting a study in Mississippi that addressed this phenomenon. Members of the focus group, which consisted of four Caucasian administrators and two minority administrators, seemed very passionate and sincere in wanting to hire more African Americans and to have their institution truly be a representation, from top to bottom, of the students they serve.

The researcher, through personal lived experiences, identified with many of the responses provided by members of the target population. At times the researcher felt engrossed in the discussion and hinged on every word of some of the participants, because of the similarities of their story and plight. However, the researcher was able to remain objective throughout the interviews. Moreover, when it comes to understanding the enablers and barriers influencing the career advancement of African Americans at PWIs, PWIs will need to become more strategic and intentional in their efforts to grow the pipeline and employ more African Americans into leadership positions. Likewise, African Americans seeking administrative positions at PWI will need to develop an understanding of the enablers and barriers influencing their advancement opportunities in order to effectively navigate their career.

\section{Summary}

This chapter presents a summary of the study, including interpretations of the results. This study focused on the lived experience of African Americans who work at publicly funded PWIs in Mississippi. The purpose of the research was to explore and identify enablers and barriers contributing to African Americans' advancement into administrative positions at PWIs of higher learning. The researcher used a qualitative 
interpretive approach to collect the data. The data collected was interpreted using the IPA method.

This study offers a lens to explore and expand knowledge relating to racial diversity and inclusion at PWIs of higher learning. The personal experiences showcase African American administrators' advancement while exploring the enablers and barriers influencing their career advancement at PWIs. The IPA process yielded eight themes categorized as good mentoring, relationships matter, the intangibles, above and beyond the expectations, challenges influencing advancement, "the only" \& "the first," the optimistic future and lost opportunities.

The researcher's goal is that this study's results, findings, and implications attract interest from senior leaders at PWIs who are serious and determined to bridge the racial gap existing in higher education administration. Furthermore, the creation of a state and national mentoring program in addition to hiring strategies aimed at growing the pipeline of potential African American administrators could lead to PWIs having a workforce that adequately represents its student population. Consequently, increasing African American representation throughout various levels of the institution (e.g., faculty, staff, support staff, administration), which could increase PWIs ability to recruit, retain and graduate more African American students. 


\title{
APPENDIX A - IRB Approval Letter
}

\author{
(RTIffice of \\ 118 COLLEGE DRIVE $\# 5116$ • HATTIESBURG, MS | 601.266 .6756 | WWW.USM.EDU/ORI
}

\section{NOTICE OF INSTITUTIONAL REVIEW BOARD ACTION}

The project below has been reviewed by The University of Southern Mississippi Institutional Review Board in accordance with Federal Drug Administration regulations (21 CFR 26, 111), Department of Health and Human Services regulations (45 CFR Part 46), and University Policy to ensure:

- The risks to subjects are minimized and reasonable in relation to the anticipated benefits.

- The selection of subjects is equitable.

- Informed consent is adequate and appropriately documented.

- Where appropriate, the research plan makes adequate provisions for monitoring the data collected to ensure the safety of the subjects.

- Where appropriate, there are adequate provisions to protect the privacy of subjects and to maintain the confidentiality of all data.

- Appropriate additional safeguards have been included to protect vulnerable subjects.

- Any unanticipated, serious, or continuing problems encountered involving risks to subjects must be reported immediately. Problems should be reported to ORI via the Incident template on Cayuse IRB.

- The period of approval is twelve months. An application for renewal must be submitted for projects exceeding twelve months.

PROTOCOL NUMBER: IRB-18-174

PROJECT TITLE: ENABLERS AND BARRIERS INFLUENCING AFRICAN AMERICAN ADMINISTRATORS' CAREER ADVANCEMENT AT PREDOMINANTLY WHITE INSTITUTIONS OF HIGHER LEARNING

SCHOOL/PROGRAM: School of ISPD, Human Capital Development

RESEARCHER(S): Larry Webster, Hamett Brown

IRB COMMITTEE ACTION: Approved

CATEGORY: Expedited

6. Collection of data from voice, video, digital, or image recordings made for research purposes.

7. Research on individual or group characteristics or behavior (including, but not limited to, research on perception, cognition, motivation, identity, language, communication, cultural beliefs or practices, and social behavior) or research employing survey, interview, oral history, focus group, program evaluation, human factors evaluation, or quality assurance methodologies.

PERIOD OF APPROVAL: January 24, 2019 to January 24, 2020

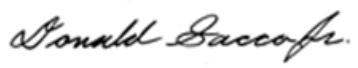

Donald Sacco, Ph.D.

Institutional Review Board Chairperson 
APPENDIX B - Initial Email to Participants

Dear Recipient,

I hope this message finds you in positive spirits and good health. As you may know, I am a Doctoral Candidate in the Human Capital Development Program at The University of Southern Mississippi, where my research focuses on diversity in administration at predominantly White public two and four-year institutions in Mississippi. Specifically, my work intends to critically explore the enablers and barriers that influence the career advancement of African Americans at predominantly White institutions (PWIs) of higher learning.

I am currently collecting data and would like to invite you to participate in an interview about your lived experiences as an administrator at a PWI. If you agree to participate, please email me letting me know if any of the dates and times provided work with your schedule. If none of the dates and times work, please counter with dates and times that may work best for you. The interview process will take between 60-90 minutes or possibly longer depending on the richness of the conversation.

- $\quad$ Possible Days, Dates, Times, and Place

Thanks in advance for your consideration in participating in my study titled: Enablers and Barriers Influencing African American Administrators' Career Advancement at Predominantly White Institutions of Higher Learning. Also, please recommend and provide contact information on other African American administrators, who work at public PWIs of higher learning in Mississippi.

If you should have any questions, concerns, or would like to discuss my topic in greater detail, please don't hesitate to contact me. Attached you will find a copy of the Informed Consent Form.

Sincerely,

Larry C. Webster, Jr.

Doctoral Candidate, University of Southern Mississippi

larry.webster@usm.edu

662.347 .1922

The Institutional Review Board of The University of Southern Mississippi reviewed and approved this project, which ensures research projects involving human subjects follow federal regulations. Direct any questions or concerns about rights as a research participant to the Chair of the IRB at (601) 266-5997 or irb@ usm.edu. Participation in this project is completely voluntary, and participants may withdraw from this study at any time. 
APPENDIX C - Consent Form

\section{INSTITUTIONAL REVIEW BOARD \\ STANDARD (SIGNED) INFORMED CONSENT}

\section{STANDARD (SIGNED) INFORMED CONSENT PROCEDURES}

This completed document must be signed by each consenting research participant.

- The Project Information and Research Description sections of this form should be completed by the Principal Investigator before submitting this form for IRB approval.

- Signed copies of the consent form should be provided to all participants.

\begin{tabular}{|c|c|c|}
\hline Today's date: & & \\
\hline & CT INFORMATION & \\
\hline $\begin{array}{l}\text { Project Title: ENABLERS AND BARRIERS } \\
\text { ADVANCEMENT AT PREDOMINANTLY W }\end{array}$ & $\begin{array}{l}\text { ENCING AFRICAN AME } \\
\text { NSTITUTIONS OF HIGH }\end{array}$ & $\begin{array}{l}\text { 'RICAN ADMINISTRATORS' CAREER } \\
\text { IER LEARNING }\end{array}$ \\
\hline Principal Investigator: Larry C. Webster, Jr. & Phone: 662.347 .1922 & Email: larry.webster@usm.edu \\
\hline Arts and Sciences & Department: Humar & Capital Development \\
\hline & RCH DESCRIPTION & \\
\hline 1. Purpose: & & \\
\hline $\begin{array}{l}\text { The purpose of this research is to explo } \\
\text { Americans advancement into administra }\end{array}$ & $\begin{array}{l}\text { identify enablers and ba } \\
\text { sitions at predominantly }\end{array}$ & $\begin{array}{l}\text { rriers that contribute to African } \\
\text { White institutions of higher learning. }\end{array}$ \\
\hline 2. Description of Study: & & \\
\hline $\begin{array}{l}\text { The study is qualitative and will use one } \\
\text { will last approximately } 60-90 \text { minutes. } \\
\text { or the participants. With your permissio } \\
\text { a copy of your transcript to review and }\end{array}$ & $\begin{array}{l}\text { e interviews and a focus } \\
\text { views will be conducted } \\
\text { terview will be recorded } \\
\text { or accuracy. }\end{array}$ & $\begin{array}{l}\text { group to collect the data. Interviews } \\
\text { on the campus of either the researcher } \\
\text { and transcribed later. You will receive }\end{array}$ \\
\hline 3. Benefits: & & \\
\hline $\begin{array}{l}\text { This study does not offer rewards for pa } \\
\text { the conversation about the developmen } \\
\text { the recruitment and retention of African } \\
\text { learning. }\end{array}$ & $\begin{array}{l}\text { ion. The intellectual ben } \\
\text { mplementation of strateg } \\
\text { an administrators at pre }\end{array}$ & $\begin{array}{l}\text { lefit, however, lends itself to adding to } \\
\text { ies, which could lead to an increase in } \\
\text { dominantly White institutions of higher }\end{array}$ \\
\hline 4. Risks: & & \\
\hline There are no known risks associated wi & study. & \\
\hline 5. Confidentiality: & & \\
\hline $\begin{array}{l}\text { I alone with the members of the researc } \\
\text { will be the only ones with access to the } \\
\text { the participant. The final version of the } \\
\text { pseudonyms to protect your identity. }\end{array}$ & $\begin{array}{l}\text { nittee, Institutional Revie } \\
\text { No presentations or publ } \\
\text { ation and any subseque }\end{array}$ & $\begin{array}{l}\text { ew Board, and the transcription service } \\
\text { ications of the data will identify you as } \\
\text { nt journal publications will use }\end{array}$ \\
\hline
\end{tabular}




\section{Alternative Procedures:}

There are no alternative procedures associated with this study.

\section{Participant's Assurance:}

This project has been reviewed by the Institutional Review Board, which ensures that research projects involving human subjects follow federal regulations.

Any questions or concerns about rights as a research participant should be directed to the Chair of the IRB at 601-266-5997. Participation in this project is completely voluntary, and participants may withdraw from this study at any time without penalty, prejudice, or loss of benefits.

Any questions about the research should be directed to the Principal Investigator using the contact information provided in Project Information Section above.

\section{CONSENT TO PARTICIPATE IN RESEARCH}

Participant's Name:

I hereby consent to participate in this research project. All research procedures and their purpose were explained to me, and I had the opportunity to ask questions about both the procedures and their purpose. I received information about all expected benefits, risks, inconveniences, or discomforts, and I had the opportunity to ask questions about them. I understand my participation in the project is completely voluntary and that I may withdraw from the project at any time without penalty, prejudice, or loss of benefits. I understand the extent to which my personal information will be kept confidential. As the research proceeds, I understand that any new information that emerges and that might be relevant to my willingness to continue my participation will be provided to me.

Questions concerning the research, at any time during or after the project, should be directed to the Principal Investigator with the contact information provided above. This project and this consent form have been reviewed by USM's Institutional Review Board, which ensures that research projects involving human subjects follow federal regulations. Any questions or concerns about rights as a research participant should be directed to the Chair of the Institutional Review Board, The University of Southern Mississippi, 118 College Drive \#5116, Hattiesburg, MS 39406-0001, 601-266-5997.

Research Participant

Date
Person Explaining the Study

Date 


\section{APPENDIX D - Initial Email to Referred Participants}

Greetings. I hope this message finds you in positive spirits and good health.

Dr./Mr./Ms. passed along your contact information to me. I am a Doctoral Candidate in the Human Capital Development Program at The University of Southern Mississippi, where my research focuses on diversity in administration at predominantly White public two and four-year institutions. Specifically, this work intends to critically explore the enablers and barriers that influence the career advancement of African Americans at predominantly White institutions (PWIs) of higher learning.

I am currently collecting data and would like to invite you to participate in an interview about your lived experiences as an administrator at a PWI. If you agree to participate, please email me letting me know if any of the dates and times provided work with your schedule. If none of the dates and times work, please counter with dates and times that work best for you. The interview process will take between 60-90 minutes or possibly longer depending on the richness of the conversation.

- $\quad$ Possible Days, Dates, Times, and Place

Thanks in advance for your consideration in participating in my study titled: Enablers and Barriers Influencing African American Administrators' Career Advancement at Predominantly White Institutions of Higher Learning. Also, please recommend and provide contact information on other African American administrators, who work at public PWIs of higher learning in Mississippi.

If you have any questions, concerns, or would like to discuss my topic in greater detail, please don't hesitate to contact me. Attached you will find a copy of the Informed Consent Form.

Sincerely,

Larry C. Webster, Jr.

Doctoral Candidate, University of Southern Mississippi

larry.webster@usm.edu

662.347 .1922

The Institutional Review Board of The University of Southern Mississippi reviewed and approved this project, which ensures research projects involving human subjects follow federal regulations. Direct any questions or concerns about rights as a research participant to the Chair of the IRB at (601) 266-5997 or irb@usm.edu. Participation in this project is completely voluntary, and participants may withdraw from this study at any time. 


\section{APPENDIX E - Member Check Email}

\section{Dear Participant,}

Thank you for participating in the research study titled: Enablers and Barriers Influencing African American Administrators' Career Advancement at Predominantly White Institutions of Higher Learning. As we discussed, your interview recording has been transcribed, and the paper copy is attached for you to review. Please take some time to read the entire transcript and mark any places that you think are inaccurate, or you would like to change. If you think it will help, I can meet with you to review the document. Please do hesitate to call or email me with a time and place to review the document. If I don't hear back from you within three days (date), I will assume you are satisfied with the transcript, and I will move forward with my work.

Once again, thank you for your continued support.

Sincerely,

Larry C. Webster, Jr.

Doctoral Candidate, University of Southern Mississippi

larry.webster@usm.edu

662.347 .1922

The Institutional Review Board of The University of Southern Mississippi reviewed and approved this project, which ensures research projects involving human subjects follow federal regulations. Direct any questions or concerns about rights as a research participant to the Chair of the IRB at (601) 266-5997 or irb@usm.edu. Participation in this project is completely voluntary, and participants may withdraw from this study at any time. 
APPENDIX F - One-on-One Interview Protocol

Enablers and Barriers Influencing African American Administrators' Career

Advancement at Predominantly White Institutions of Higher Learning

Date:

Place:

Interviewer:

Interviewee

Position Title

Pseudonym

Start Time:

End Time:

1. Prior to the start of the meeting

a. Check to make sure notepads and pens are available to capture non-verbal details and high points that may need additional explaining.

b. Check digital recorder for operation.

c. Make sure to retrieve a signed copy of the interview form.

d. Review study criteria and demographic

Gender: Female Male

How many years have you been working in higher education?

How many years have you been working in higher education administration?

How many years of experience do you have in your current position?

What is your highest level of degree attainment?

What was your highest level of degree attainment when you started working in your current position?

\section{Interview Guide}

Hello __ I appreciate you taking the time to meet with me. I am Larry Webster, a PhD candidate conducting this research.

The goal of this research investigation is to explore and identify enablers and barriers influencing African American administrators' career advancement at predominantly White institutions (PWIs) of higher learning in Mississippi.

These questions will focus on your lived experiences as an administrator at a PWI of higher learning in hopes of understanding what enablers and barriers influence the career advancement of African Americans at public PWIs in Mississippi. 
The interview session will last approximately 60-90 minutes. With your agreement, I would like to record our conversation to ensure I accurately capture your perceptions. At times, I may be writing notes during the interview. The recordings are for transcription and analysis only and will not be released in any publications or reports. I am the only person who will have access to your responses and your name. Your name will not be associated with anything that is said today. All information received from you will be strictly confidential. You will be identified in the research by a pseudonym. Only summarized data will be presented at meetings or in publications and none of the information obtained today will make it possible for anyone to identify you.

The interview questions are designed to evoke responses about your lived experiences as an administrator at a PWI of higher learning in Mississippi. I want you to provide honest and accurate accounts of your experiences and personal feelings; however, should you feel uncomfortable with any of the questions, feel free to skip questions.

Your participation in this study is completely voluntary. You are free to withdraw at any time, for whatever reason. The data collected today will be transcribed by a third party transcription company, Rev Transcription Services. Once the transcript is verified for accuracy, I will contact the transcription agency requesting them to delete all the files and recordings associated with this interview.

Before we begin, please read and sign the Informed Consent Form. I will give you a copy for your records, and I will keep a copy for my records.

3. Start the recording:

a. Verbal identification of the recording: Date, time, place

Interviewer's name:

Interviewee's name:

b. Ask semistructured, open-ended interview questions.

c. Use prompts, and deeper questions as needed to assist the interviewee in answering the questions and to help the discussion refocus should the conversation go in a different direction.

4. After the interview:

a. Explain that a contracting service will transcribe the interview and that a paper copy of the transcript will be emailed to them for validation. 
b. Explain the importance of "member-checking."

c. Request the participant to respond to the validation request within three days of receiving a copy of the transcript.

5. At the conclusion of the meeting

a. Thank the participant once again for their support to the research project.

b. Ask participants if they would like a copy of the results from the study once it has been finalized and approved by the university.

c. Answer any remaining questions. 


\section{APPENDIX G - One-on-One Interview Questions}

1. Tell me about your professional career in higher education.

Possible prompt: How did those positions/experiences prepare you for the position that you have today?

Possible prompt: What about those experiences gave you the confidence or belief that you were ready for a position in administration?

2. What attributes, learned or innate, do you think are important for African Americans to possess if they want to become an administrator in higher education?

3. Tell me about any formal or informal training that you believe prepared you to become an administrator?

Possible prompt: Are there any training or workshops that maybe you didn't have an opportunity to participate in but you believe would be beneficial for future African American administrators. Why?

4. Tell me about the cultural climate at your institution.

Possible prompt: Do you believe the climate promotes racial diversity within its hiring practices and the advancement of African Americans into administration positions?

5. Tell me about the strategies in place at your institution that promote racial diversity within its hiring process.

Possible prompt: In addition to the strategies that are in place are there any additional strategies you would like to implement or see implemented?

Possible prompt: If there are none, talk about strategies you would like to see implemented that would promote the hiring and career advancement of African Americans.

6. Talk to me about the role that race has played on the hiring and career advancement of African Americans at your institution. 
Possible prompt: What role if any do you believe racial stereotypes have influenced the hiring or advancement of African Americans at your institution?

Possible prompt: Tell me about the challenges, if any, that you have faced as an African American administrator at a PWI of higher learning.

7. What are your thoughts regarding African Americans access to leadership positions, at PWIs, that have the power to affect policy and change throughout the institution?

Possible prompt: What barriers do you think contribute to the racial inequality in higher education leadership?

8. Understanding the purpose of this study, is there anything else you would like to add? 


\section{APPENDIX H - Post Interview Email}

Dear Participant,

Thank you for participating in my research study titled: Enablers and Barriers Influencing African American Administrators' Career Advancement at Predominantly White Institutions of Higher Learning. As we discussed, your interview recording will be transcribed into a paper copy, and once available, I will email you a copy to review for accuracy. Thank you once again for your participation and support. If you should have any questions or concerns, please don't hesitate to contact me.

\section{Sincerely,}

Larry C. Webster, Jr.

Doctoral Candidate, University of Southern Mississippi

larry.webster@usm.edu

662.347 .1922

The Institutional Review Board of The University of Southern Mississippi reviewed and approved this project, which ensures research projects involving human subjects follow federal regulations. Direct any questions or concerns about rights as a research participant to the Chair of the IRB at (601) 266-5997 or irb@ usm.edu. Participation in this project is completely voluntary, and participants may withdraw from this study at any time. 


\section{APPENDIX I - Focus Group Email}

Dear Participant,

I hope this message finds you in positive spirits and good health. As you may know, I am a Doctoral Candidate in the Human Capital Development Program at The University of Southern Mississippi, where my research focuses on diversity in administration at predominantly White public two and four-year institutions. Specifically, my work intends to critically explore the enablers and barriers that influence the career advancement of African Americans at predominantly White institutions (PWIs) of higher learning.

I am currently collecting data and would like to invite you to participate in a focus group session that explores and identify those enablers and barriers that affect the career advancement of African Americans at PWIs in Mississippi. Below, you will find the date, time, and place of the focus group session. The focus group session will take between 60-90 minutes. If you agree to participate, please email me back accepting my invitation.

- $\quad$ Day, Date, Time, and Place

Thanks in advance for your consideration in participating in my study titled: Enablers and Barriers Influencing African American Administrators' Career Advancement at Predominantly White Institutions of Higher Learning.

If you have any questions, concerns, or want to discuss my topic in greater detail, please don't hesitate to contact me.

Sincerely,

Larry C. Webster, Jr.

Doctoral Candidate, University of Southern Mississippi

larry.webster@usm.edu

662.347 .1922

The Institutional Review Board of The University of Southern Mississippi reviewed and approved this project, which ensures research projects involving human subjects follow federal regulations. Direct any questions or concerns about rights as a research participant to the Chair of the IRB at (601) 266-5997 or irb@ usm.edu. Participation in this project is completely voluntary, and participants may withdraw from this study at any time. 


\section{APPENDIX J - Focus Group Demographic Form}

1. Gender: Female Male

2. Race/Ethnicity:

3. How many years have you been working at your institution?

4. How would you classify your position at your institution? Faculty, Staff, ___ Administrator ___ Support Staff

5. What is your job title?

6. How many hiring committee have you served on at your institution? _ $1-5, \ldots 6-10, \ldots$ more than 10

7. Are you directly responsible for making the recommendation for hire? 


\section{APPENDIX K - Focus Group Protocol}

Enablers and Barriers Influencing African American Administrators' Career

Advancement at Predominantly White Institutions of Higher Learning

Date:

Place:

Interviewer:

1. Prior to the start of the meeting

a. Collect a signed copy of the consent form.

b. Check digital recorder for operation.

c. Check to make sure notepads and pens are available to capture non-verbal details and high points that may need additional explaining.

2. Interview Guide

Hello everyone. I appreciate you taking the time to meet with me. I am Larry Webster, a PhD candidate conducting this research.

The goal of this research investigation is to explore and identify enablers and barriers influencing African American administrators' career advancement at predominantly White institutions of higher learning.

The questions asked today will focus on your personal experiences and perspectives as someone who works at a PWI of higher learning and has served on a hiring/interview committee, in which your duty was to evaluate candidates for possible employment. The findings from this study may be used to assist administrators at PWIs of higher learning understanding the enablers and barriers that influence the career advancement of African Americans at PWIs of higher learning in Mississippi.

The focus group session will last approximately 60-90 minutes. With the group's agreement, I would like to record our conversation to ensure I accurately capture the group's perceptions. At times, I may be writing notes during the interview. The recordings are for transcription and analysis purposes only and will not be released in any publication or report. I am the only person who will have access to your responses and your names. Your names will not be associated with anything that is said today. 
The interview questions are about your experience as a committee member who was responsible for interviewing and making recommendations for employment at a PWI of higher learning. I want you to provide honest and accurate accounts of your experiences and personal feelings; however, should you feel uncomfortable with any of the questions, feel free to skip questions.

All information received from you will be strictly confidential. You will be identified in the research by the term "focus group." Only summarized data will be presented at meetings or in publications and none of the information obtained today will make it possible for anyone to identify you.

Your participation in this study is completely voluntary. You are free to withdraw at any time, for whatever reason. The data collected today will be transcribed by a third party transcription company, Rev Transcription Services

Before we begin, I want each of you to please read and sign the Informed Consent Form. I will give you a copy for your records, and I will keep a copy for my records. Also, will each one of you complete a demographic form and signed the list agreeing to allow me to record this session.

3. Start the recording:

a. Verbal identification of the recording: Date, time, place

b. Ask semistructured, open-ended interview questions.

c. Use prompts, and deeper questions as needed to assist the members of the focus group in answering the questions and to help the discussion refocus should the conversation go in a different direction.

4. After the interview:

a. Make sure each participant has a copy of his/her Informed Consent Form.

b. Explain the importance of the focus group and that the data will be used as a part of the validation strategy for the current research, which seeks to investigate the lived experiences of African American administrators who work at PWIs.

At the conclusion of the meeting thank the participants once again for their support of the research and answer any remaining questions 


\section{APPENDIX L - Focus Group Interview Questions}

1. Describe what you believe to be important administrative/leadership skills for an administrator.

2. In looking at your institution, do you feel African Americans are appropriately represented in administrative positions, i.e., vice president, assistant vice president, associate vice president, deans, directors?

Possible prompt: If yes, what factors do you believe have contributed to the racial equality within the administrative ranks at your institution?

Possible prompt: If no, what factors do believe have contributed to the underrepresentation?

3. Studies indicate that African Americans make up about $2.7 \%$ of all Chief Academic Officers at PWIs and less than $8 \%$ of all administrators at public colleges and universities. What are your thoughts regarding African Americans access to leadership positions, at PWIs, that have the power to affect policy and change throughout the institution?

Possible prompt: What barriers do you think contribute to the racial inequality in higher education leadership?

4. Tell me about the cultural climate at your institution.

Possible prompt: Do you believe the climate promotes racial diversity within its hiring practices and the advancement of African Americans into administration positions.

5. Tell me about the strategies in place at your institution that promote racial diversity within its hiring process.

Possible prompt: In addition to the strategies that are in place are there any additional strategies you would like to implement or see implemented?

Possible prompt: If there are none, talk about strategies you would like to see implemented that would promote the hiring and career advancement of African Americans. 
6. Tell me about the role that race has played on the hiring and career advancement of African Americans at your institution.

Possible prompt: What role if any do you believe racial stereotypes have influenced the hiring or advancement of African Americans at your institution?

7. Think about the last time you served on a hiring committee at your institution, were there any African American candidates?

Possible prompt: If so, what were the discussions like surrounding the decision to recommend for hire or not to recommend for hire?

Possible prompt: If none were interviewed what do believe led to the absence?

Understanding the purpose of this study is there anything else you would like to add? 


\section{APPENDIX M - Transcript Analysis Exerpt}

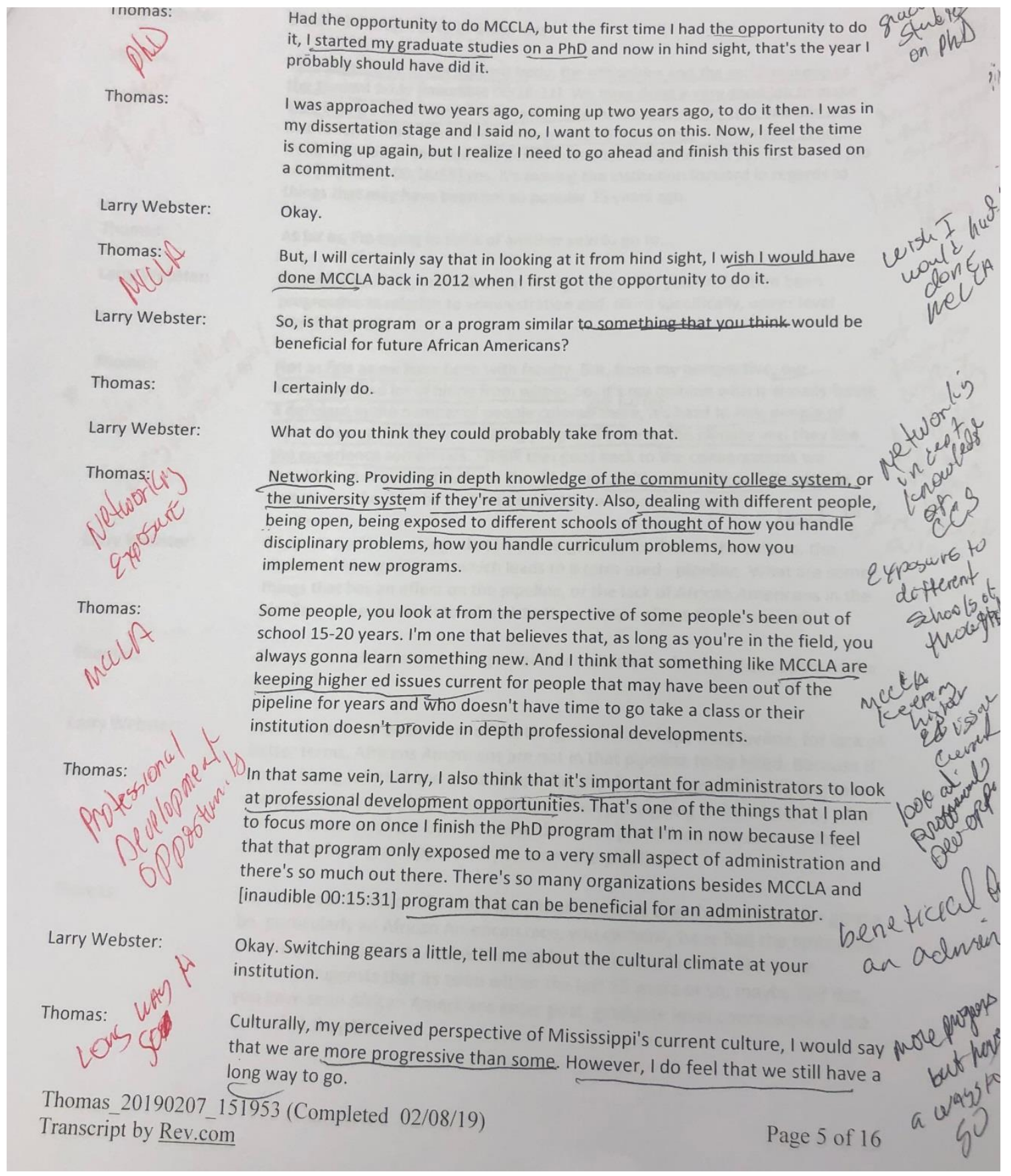


APPENDIX N - Coding Board

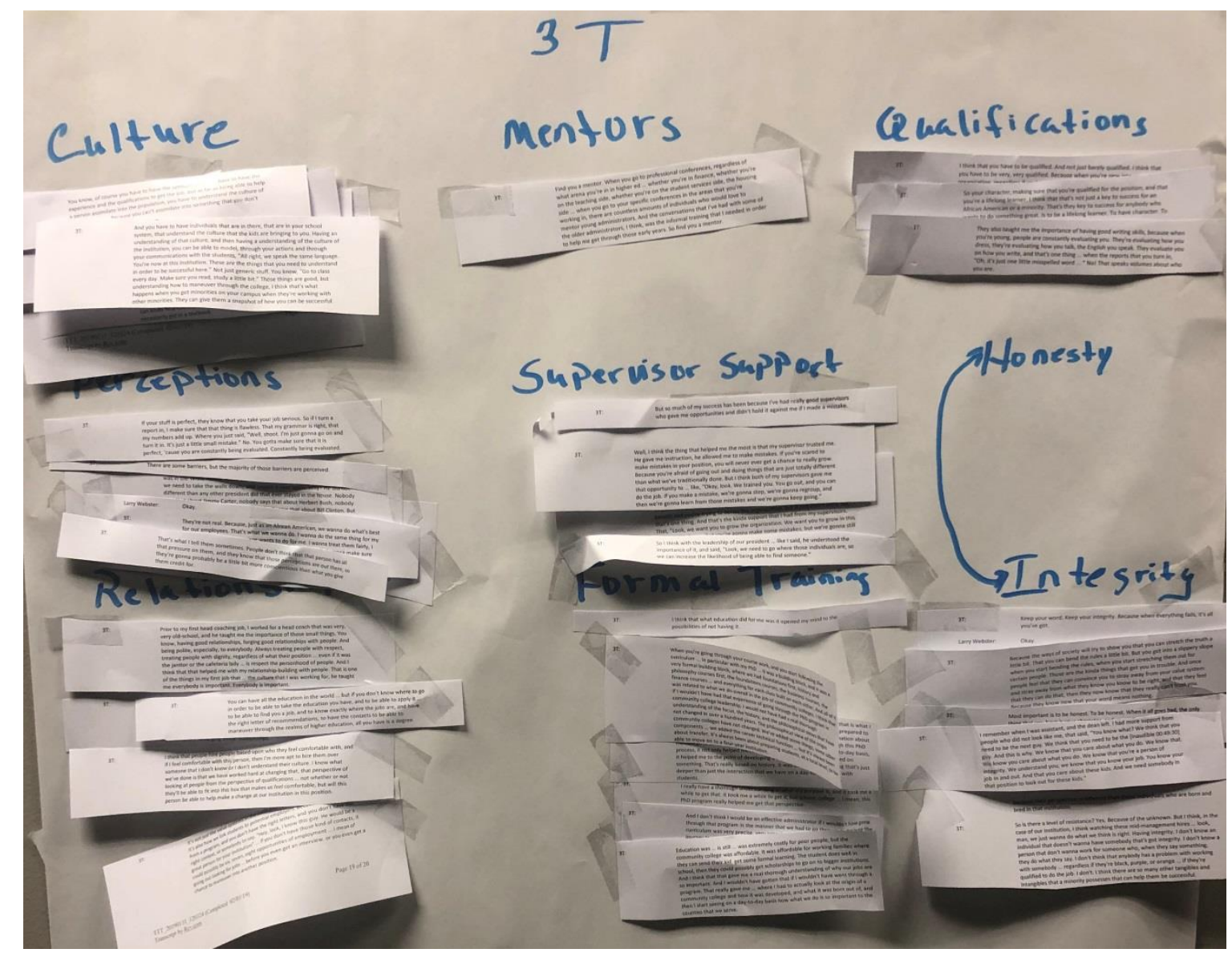


RO2: Perceived Enablers

\begin{tabular}{|c|c|c|c|c|c|c|c|c|c|c|c|c|}
\hline Emergent Themes & $3 \mathrm{~T}$ & Thomas & Tina & Tim & Joyce & Tonya & Sarah & Tiffany & Amy & Ebony & Dennis & Heather \\
\hline Mentoring & $\mathrm{X}$ & $\mathrm{X}$ & $\mathrm{X}$ & $\mathrm{X}$ & $\mathrm{X}$ & $\mathrm{X}$ & $\mathrm{X}$ & $\mathrm{X}$ & $\mathrm{X}$ & $\mathrm{X}$ & $\mathrm{X}$ & $\mathrm{X}$ \\
\hline $\begin{array}{l}\text { Support from } \\
\text { Administration }\end{array}$ & $\mathrm{X}$ & & $\mathrm{X}$ & $\mathrm{X}$ & & $\mathrm{X}$ & $\mathrm{X}$ & $\mathrm{X}$ & & $\mathrm{X}$ & & $\mathrm{X}$ \\
\hline Relationships/Networking & $\mathrm{X}$ & $\mathrm{X}$ & $\mathrm{X}$ & $\mathrm{X}$ & $\mathrm{X}$ & $\mathrm{X}$ & $\mathrm{X}$ & $\mathrm{X}$ & $\mathrm{X}$ & $\mathrm{X}$ & $\mathrm{X}$ & $\mathrm{X}$ \\
\hline $\begin{array}{l}\text { Proper Credentialing and } \\
\text { More }\end{array}$ & $\mathrm{X}$ & $\mathrm{X}$ & $\mathrm{X}$ & $X$ & $\mathrm{X}$ & $\mathrm{X}$ & $\mathrm{X}$ & $X$ & $\mathrm{X}$ & $\mathrm{X}$ & $X$ & $X$ \\
\hline $\begin{array}{l}\text { Leadership Development } \\
\text { Opportunities }\end{array}$ & & $\mathrm{X}$ & $\mathrm{X}$ & $\mathrm{X}$ & $\mathrm{X}$ & $\mathrm{X}$ & $\mathrm{X}$ & $\mathrm{X}$ & $\mathrm{X}$ & $\mathrm{X}$ & $\mathrm{X}$ & $\mathrm{X}$ \\
\hline Understanding of Self & $\mathrm{X}$ & $\mathrm{X}$ & $\mathrm{X}$ & $\mathrm{X}$ & & $\mathrm{X}$ & & $\mathrm{X}$ & $\mathrm{X}$ & & $\mathrm{X}$ & $\mathrm{X}$ \\
\hline Strong Work Ethics & $\mathrm{X}$ & & $\mathrm{X}$ & $\mathrm{X}$ & $\mathrm{X}$ & $\mathrm{X}$ & $\mathrm{X}$ & $\mathrm{X}$ & & & & \\
\hline $\begin{array}{l}\text { Good Communication } \\
\text { Skills }\end{array}$ & $\mathrm{X}$ & & $\mathrm{X}$ & $\mathrm{X}$ & & $\mathrm{X}$ & $\mathrm{X}$ & $\mathrm{X}$ & & & & \\
\hline
\end{tabular}


RO3: Perceived Barriers

\begin{tabular}{|c|c|c|c|c|c|c|c|c|c|c|c|c|}
\hline Emergent Themes & $3 \mathrm{~T}$ & Thomas & Tina & Tim & Joyce & Tonya & Sarah & Tiffany & Amy & Ebony & Dennis & Heather \\
\hline Internal Hires & $\mathrm{X}$ & $\mathrm{X}$ & $\mathrm{X}$ & $\mathrm{X}$ & & $\mathrm{X}$ & & $\mathrm{X}$ & & & & $\mathrm{X}$ \\
\hline Who Knows Who & & $\mathrm{X}$ & $\mathrm{X}$ & $\mathrm{X}$ & & & & $\mathrm{X}$ & & & & \\
\hline $\begin{array}{l}\text { Lack of African } \\
\text { Americans on Search } \\
\text { Committees }\end{array}$ & & & & $\mathrm{X}$ & $\mathrm{X}$ & & $X$ & & $\mathrm{X}$ & & & $\mathrm{X}$ \\
\hline Stuck in Tradition & & $\mathrm{X}$ & $\mathrm{X}$ & $\mathrm{X}$ & $\mathrm{X}$ & $\mathrm{X}$ & & & $\mathrm{X}$ & & & \\
\hline $\begin{array}{l}\text { Institution and State } \\
\text { Perception }\end{array}$ & & $\mathrm{X}$ & $\mathrm{X}$ & $\mathrm{X}$ & & & $\mathrm{X}$ & & $\mathrm{X}$ & & & $\mathrm{X}$ \\
\hline Serotypes & $X$ & $\mathrm{X}$ & & $\mathrm{X}$ & $\mathrm{X}$ & & $\mathrm{X}$ & $X$ & $\mathrm{X}$ & $X$ & $X$ & $X$ \\
\hline $\begin{array}{l}\text { Inconsistent Hiring } \\
\text { Practices }\end{array}$ & $\mathrm{X}$ & $\mathrm{X}$ & $X$ & $\mathrm{X}$ & & & & & $\mathrm{X}$ & & & \\
\hline Lack of Black Mentors & & $\mathrm{X}$ & $\mathrm{X}$ & & & $\mathrm{X}$ & $\mathrm{X}$ & & $\mathrm{X}$ & & $\mathrm{X}$ & $\mathrm{X}$ \\
\hline $\begin{array}{l}\text { Has to Work Twice as } \\
\text { Hard/Prove Self }\end{array}$ & $\mathrm{X}$ & $\mathrm{X}$ & $\mathrm{X}$ & $\mathrm{X}$ & $\mathrm{X}$ & $\mathrm{X}$ & $\mathrm{X}$ & & $\mathrm{X}$ & $X$ & $\mathrm{X}$ & $\mathrm{X}$ \\
\hline
\end{tabular}


RO4: Perspectives Toward Advancement

\begin{tabular}{|c|c|c|c|c|c|c|c|c|c|c|c|c|}
\hline Emergent Themes & $3 \mathrm{~T}$ & Thomas & Tina & Tim & Joyce & Tonya & Sarah & Tiffany & Amy & Ebony & Dennis & Heather \\
\hline $\begin{array}{l}\text { Optimistic About the } \\
\text { Future }\end{array}$ & $\mathrm{X}$ & $\mathrm{X}$ & & $\mathrm{X}$ & & $\mathrm{X}$ & & $\mathrm{X}$ & & $\mathrm{X}$ & $\mathrm{X}$ & $\mathrm{X}$ \\
\hline $\begin{array}{l}\text { Already Seeing Some } \\
\text { Change }\end{array}$ & $X$ & & & $\mathrm{X}$ & & $X$ & $\mathrm{X}$ & & & $X$ & & \\
\hline $\begin{array}{l}\text { Diversity is not a } \\
\text { Priority }\end{array}$ & & & $\mathrm{X}$ & $\mathrm{X}$ & & $\mathrm{X}$ & $\mathrm{X}$ & & $\mathrm{X}$ & $\mathrm{X}$ & & \\
\hline
\end{tabular}

RO5: Institutional strategies to Address Diversity

\begin{tabular}{|l|cccccccccccc}
\hline Emergent Themes & 3T & Thomas & Tina & Tim & Joyce & Tonya & Sarah & Tiffany & Amy & Ebony & Dennis & Heather \\
\hline $\begin{array}{l}\text { No Formal Strategy } \\
\text { or Policy }\end{array}$ & $\mathrm{X}$ & $\mathrm{X}$ & $\mathrm{X}$ & $\mathrm{X}$ & & $\mathrm{X}$ & $\mathrm{X}$ & $\mathrm{X}$ & $\mathrm{X}$ & & \\
$\begin{array}{l}\text { Upper Management } \\
\text { Promotes Diversity }\end{array}$ & $\mathrm{X}$ & $\mathrm{X}$ & $\mathrm{X}$ & $\mathrm{X}$ & & $\mathrm{X}$ & $\mathrm{X}$ & $\mathrm{X}$ & & $\mathrm{X}$ & $\mathrm{X}$ & $\mathrm{X}$ \\
Be Intentional & $\mathrm{X}$ & $\mathrm{X}$ & & $\mathrm{X}$ & $\mathrm{X}$ & $\mathrm{X}$ & $\mathrm{X}$ & $\mathrm{X}$ & $\mathrm{X}$ & $\mathrm{X}$ & \\
\hline
\end{tabular}




\section{APPENDIX P - Theme Clustering Matrix}

\section{Theme 1 Good Mentors}

Theme 2 Relationships matter

Theme 3 The intangibles: What to bring to the table

Theme 4 Above and beyond expectations

Theme 5 Challenges influencing advancement

Theme 6 "The only" or "The first"

Theme 7 The optimistic future

Theme 8 Strategies for growth

\begin{tabular}{|c|c|c|c|c|}
\hline Emergent Themes & Theme 1 & Theme 2 & Theme 3 & Theme 4 \\
\hline Mentoring & $\mathrm{X}$ & & & \\
\hline $\begin{array}{l}\text { Support from } \\
\text { Administration }\end{array}$ & & $\mathrm{X}$ & & \\
\hline Relationships/Networking & & $\mathrm{X}$ & & \\
\hline Understanding of Self & & & $\mathrm{X}$ & \\
\hline Strong Work Ethics & & & $\mathrm{X}$ & \\
\hline Good Communication Skills & & & $\mathrm{X}$ & \\
\hline $\begin{array}{l}\text { Proper Credentialing and } \\
\text { More }\end{array}$ & & & & $\mathrm{X}$ \\
\hline $\begin{array}{l}\text { Leadership Development } \\
\text { Opportunities }\end{array}$ & & & & $\mathrm{X}$ \\
\hline $\begin{array}{l}\text { Has to Work Twice as } \\
\text { Hard/Prove Self }\end{array}$ & & & & $\mathrm{X}$ \\
\hline
\end{tabular}




\begin{tabular}{|c|c|c|c|c|}
\hline Emergent Themes & Theme 5 & Theme 6 & Theme 7 & Theme 8 \\
\hline Internal Hires & $\mathrm{X}$ & & & \\
\hline Who Knows Who & $\mathrm{X}$ & & & \\
\hline $\begin{array}{l}\text { Lack of African Americans } \\
\text { on Search Committees }\end{array}$ & $\mathrm{X}$ & & & \\
\hline Stuck in Tradition & $X$ & & & \\
\hline $\begin{array}{l}\text { Institution and State } \\
\text { Perception } \\
\text { Serotypes }\end{array}$ & $\mathrm{X}$ & & & \\
\hline $\begin{array}{l}\text { Inconsistent Hiring } \\
\text { Practices }\end{array}$ & $\mathrm{X}$ & & & \\
\hline Lack of Black Mentors & $\mathrm{X}$ & & & \\
\hline $\begin{array}{l}\text { Has to Work Twice as } \\
\text { Hard/Prove Self }\end{array}$ & $X$ & & & \\
\hline Optimistic About the Future & & & $\mathrm{X}$ & \\
\hline Diversity is not a Priority & & & $\mathrm{X}$ & \\
\hline $\begin{array}{l}\text { Already Seeing Some } \\
\text { Change }\end{array}$ & & & $\mathrm{X}$ & \\
\hline $\begin{array}{l}\text { No Formal Strategy or } \\
\text { Policy }\end{array}$ & & & & $\mathrm{X}$ \\
\hline Be Intentional & & & & $X$ \\
\hline $\begin{array}{l}\text { Upper Management } \\
\text { Promotes Diversity }\end{array}$ & & & & $\mathrm{X}$ \\
\hline
\end{tabular}




\section{APPENDIX Q - Final Thank You Letter}

\section{Dear Participant}

Thank you for participating in my research study titled: Enablers and Barriers Influencing African American Administrators' Career Advancement at Predominantly White Institutions of Higher Learning. The stories, descriptions, and input you provided of your experiences will no doubt continue to add to the scholarship relating to the enablers and barriers influencing the career advancement of African Americans at PWIs. Your continued support throughout this project was greatly valued. Please don't hesitate to contact me if you have any further questions.

Sincerely,

Larry C. Webster, Jr.

Doctoral Candidate, University of Southern Mississippi

larry.webster@usm.edu

662.347 .1922

The Institutional Review Board of The University of Southern Mississippi reviewed and approved this project, which ensures research projects involving human subjects follow federal regulations. Direct any questions or concerns about rights as a research participant to the Chair of the IRB at (601) 266-5997 or irb@usm.edu. Participation in this project is completely voluntary, and participants may withdraw from this study at any time. 


\section{REFERENCES}

Abraham, A. A., \& Jacobs, R. W. (2006). African Americans enrolling and receiving degrees in graduate/professional degree programs. Metropolitan Universities, 17(2), 22-32. Retrieved from http://www.cumuonline.org/

Aguirre, A. R., \& Martinez, R.O. (2006). Diversity leadership in higher education. ASHE Higher Education Report, 32(3), 1-113. doi:10.1002/aehe.3203

Alexander, M. (2010). The new Jim Crow: Mass incarceration in the age of colorblindness. New York, NY: New Press.

Alexander, T. (2010). Roots of leadership: Analysis of the narratives from African American women leaders in higher education. International Journal of Learning, 17(17), 193-204. doi:10.18848/1447-9494/CGP/v17i04/46973

Alger, J. (1999). When color-blind is color-bland: Ensuring faculty diversity in higher education. Stanford Law and Policy Review, 10(2), 191-204. Retrieved from https://law.stanford.edu/

Allen, R. L. (2001). The globalization of White supremacy: Toward a critical discourse on the racialization of the world. Educational Theory, 51(4), 467-486. doi:10.1111/j.1741-5446.2001.00467.x

Allen, W. R. (1992). The color of success: African American college student outcomes at predominantly White and historically Black public colleges and universities. Harvard Education Review, 62(1), 26-45. doi:10.17763/haer.62.1.wv5627665007v701

Allen, W. R., Epps, E. G., Guillory, E. A., Shue, S. A., \& Bonous-Hammarth, M. (2000). The Black academic: Faculty status among African Americans in U.S. higher 
education. Journal of Negro Education, 69(1), 112-127. Retrieved from https:// http://www.journalnegroed.org/

Allen, W. R., Jewell, J. O., Griffin, K. A., \& Wolf, D. S. (2007). Historically Black colleges and universities: Honoring the past, engaging the present, touch the future. Journal of Negro Education, 76(3), 263-280. Retrieved from http:// www.journalnegroed.org/

Allen, W. R., Teranishi, R., Dinwiddie, G., \& Gonzales, G. (2000). Knocking at freedom's door: Race, equity and affirmative action in U.S. higher education. The Journal of Negro Education, 69(1-2), 3-11. doi:10.2307/3343241

American Association of Community Colleges [AACC]. (2013). Competencies for community college leader (2nd ed.). Retrieved from https://www.aacc.nche.edu/wpcontent/uploads/2017/09/AACC_Core_Competenc ies_web.pdf

American Association of Community Colleges [AACC]. (2015). CEO characteristics. Retrieved from https://www.aacc.nche.edu/

American Council on Education [ACE]. (2013). By the number: As presidential diversity stalls, looking into the future of leadership. Retrieved from https://www.acenet.edu/the-presidency/columns-and-features/Pages/By-theNumbers-As-Presidential-Diversity-Stalls.aspx

American Council on Education [ACE]. (2017). American college presidents study 20162017. Retrieved from https://www.acenet.edu/news-room/Pages/AmericanCollege-President-Study.aspx 
Apfelbaum, E. P., Sommers, S. R., \& Norton, M. I. (2008). Seeing race and seeming racist? Evaluating strategic colorblindness in social interaction. Journal of Personality and Social Psychology, 95(4), 918-932. doi:10.1037/a0011990

Association of American Colleges and Universities. (2007). http://archive.aacu.org/

Ballard, A. B. (1973). Academic's records of benign neglect. Change: The Magazine of Higher Learning, 5(2), 27-33. doi:10.1080/00091383.1973.10568474

Ballenger, J. (2010). Female's access to higher education leadership: Cultural and structural barriers. Forum on Public Policy Online. A Journal of the Oxford Round Table, 2010(5), 1-20. Retrieved from http://forumonpublicpolicy.com/vol2010no5/womencareers2010.html

Baron, A., \& Armstrong, M. (2007). Human Capital Management. LaVergne, TN: Kogan Page.

Bartlett, L. (2007). Human capital or human connections? The cultural meanings of education in Brazil. Teachers College Records, 109(7), 1613-1636. Retrieved from http://www.tcrecord.org

Barrows, E. P. (1836). A view of the American slavery questions. Retrieved from https://archive.org/details/ASPC0008112500

Becker, G. S. (1993). Human capital: A theoretical and empirical analysis, with special reference to education. Chicago, IL: University of Chicago Press.

Beckwith, L. B., Carter, D. R., \& Peters, T. (2016). The underrepresentation of African American women in executive leadership: What's getting in the way. Journal of Business Studies Quarterly, 7(4), 115-134. Retrieved from www.jbsq.org 
Beilke, J. R. (1997). The changing emphasis of the Rosenwald Fellowship Program. The Journal of Negro Education, 66(1), 3-15. doi:10.2307/2967247

Betts, K., Urias, D., Chavez, J., \& Betts, B. (2009). Higher education and shifting U.S. demographics: Need for visible administrative career paths, professional development, succession planning \& commitment to diversity. Academic Leadership Empirical Research, 7(2), 1-9. Retrieved from https://scholars.fhsu.edu/

Birch, A. H. (2007). The concept and theories of modern democracy (3rd ed.). New York, NY: Routledge.

Bisbee, D. C. (2007). Looking for leaders: Current practices in leadership identification in higher education. Planning and Changing, 38(1/2), 77-88. Retrieved from https://education.illinoisstate.edu/

Blackwood, J. (2010). The influence of mentoring on female administrators and leaders in California community colleges (Doctoral dissertation). Retrieved from ProQuest Dissertations and Theses database. (UMI No.756466787)

Blauner, B. (2001). Still the big news: Racial oppression in America. Philadelphia, PA: Temple University Press.

Bogat, G. A., \& Redner, R. L. (1985). How mentoring affects the professional development of women in psychology. Professional Psychology: Research and Practice, 16(6), 651-859. doi:10.1037/0735-7028.16.6.851

Bonilla-Silva, E. (2003). Racism without racists. Lanham, MD: Rowman \& Littlefield. Bradbury, M. D., \& Kellough, J. E. (2008). Representative bureaucracy: Exploring the potential for active representation in local government. Journal of Public 
Administration Research and Theory, 18(4), 697-714.

doi:10.1093/jopart/mum033

Bradbury, M., \& Kellough, E. (2011). Representative bureaucracy: Assessing the evidence on active representation. American Review of Public Administration, 41(2), 157-167. doi:10.1177/0275074010367823

Brief, A. P., Buttram, R. T., Reizenstein, R. M., Pugh, S. D., Callahan, J. D., McCline, R. L., \& Vaslow, J. B. (1997). Beyond good intentions: The next step towards racial equality in the American workplace. The Academy of Management Executive, 11(4), 59-72. doi:10.5465/ame.1997.9712024839

Brief, A. P., \& Hayes, E. L. (1997). The continuing "American dilemma": Studying racism in organizations. Journal of Organizational Behavior, 89-105. Retrieved from https://www.wiley.com/en-us/Journal+of+Organizational+Behavior

Brown, C. M. (2007). Still not equal: Expanding educational opportunity in society. New York, NY. Peter Lang.

Brown, M. C., Richard, R., \& Donahoo, S. (2004). The changing roles of HBCUs: Vistas on dual missions, desegregation, and diversity. In M. C. Brown \& K. Freeman (Eds.), Black colleges: New perspective on policy and practice (pp. 3-28).

Westport, CT: Praeger.

Burck, C. (2005). Comparing qualitative research methodologies for systemic research: The use of ground theory, discourse analysis and narrative analysis. Journal of Family Therapy, 27(3), 237-262. doi:10.1111/j.1467-6427.2005. 00314.x 
Burke, B., Cropper, A., \& Harrison, P. (2000). Real or imagined - Black women's experiences in the academy. Community, Work, and Family, 3(3), 297-310. doi:10.1080/13668800020006811

Byrd-Chichester, J. (2000). The federal courts and claims of racial discrimination in higher education. The Journal of Negro Education, 69(1/2), 12-27. Retrieved from https:// http://www.journalnegroed.org/

Caplow, T., \& McGee, R. (2001). The academic marketplace (2nd ed.). Garden City, NY: Routledge.

Carbado, D. W., \& Gulati, M. (2003). The law and economics of critical race theory. Yale Law Review, 112(7), 1757-1828. Retrieved from https://www.yalelawjournal.org

Carr, C. S. (2012). Professional development: A paradigm designed for females. In G. Brown, B. Irby, \& S. Jackson (Eds.), Female leaders advancing careers (pp. 119136). Charlotte, NC: Information Age Publishing.

Chen, J. M., \& Hamilton, D. L. (2015). Understanding diversity: The importance of social acceptance. Personality and Social Psychology Bulletin, 41(4), 586-598. doi:10.1177/0146167215573495

Chesler, M., Lewis, A., \& Crowfoot, J. E. (2005). Challenging racism in higher education: Promoting justice. Lanham, MD: Rowman \& Littlefield.

Civil Rights Act of 1964, Pub.L. 88-352, 78 Stat. 241 (1964).

Chronicle of Higher Education. (2014). Almanac (LX, 45),

Cleveland, D. (Ed.). (2004). A long way to go: Conversations about race by African American faculty and graduate students in higher education. New York, NY: Peter Lang. 
Constantine, M. G., Smith, L., Redington, R. M., \& Owens, D. (2008). Racial microaggressions against Black counseling and counseling psychology faculty: A central challenge in the multicultural counseling movement. Journal of Counseling \& Development, 86(3), 348-355. doi:10.1002/j.1556-6678. 2008.tb000519.x

Corbin, J. M., \& Strauss, A. L. (2008). Basics of qualitative research: Techniques and procedures for developing ground theory (3rd ed.). Thousand Oaks, CA: Sage.

Cornacchione, E., \& Daugherty, J. (2013). Trends in opportunity cost in U.S.

postsecondary education: A national HRD and human capital theory analysis. New Horizons in Adult Education \& Human Resource Development, 25(2), 62-82. doi:10.1002/nha.20017

Cornileus, T. H. (2012). “I'm a Black man and I'm doing this job very well”: How African American professional men negotiate the impact of racism on their career development. The Journal of African American Studies, 17(4), 444-460. doi:10.1007/s12111-012-9225-2

Creighton, L. M. (2007). Factors affecting the graduation rates of university students from underrepresented populations. International Electronic Journal for Leadership in Learning, 11(7). Retrieved from http://iejll.synergiesprairies.ca/iejll/

Creswell, J. W. (2005). Educational research: Planning, conducting, and evaluating quantitative and qualitative research. Upper Saddle River, NJ: Pearson.

Creswell, J. W. (2013). Qualitative inquiry and research design: Choosing among five approaches (3rd ed.). Thousand Oaks, CA: Sage. 
Dae-Bong, K. (2009). Human capital and school success. The 3rd OECD World Forum on "Statistics" Knowledge and Policy. Retrieved from http://www.oecd.org/

Davis, F. J. (1991). Who is Black? One nations definition: Frontline. Retrieved from https://www.pbs.org/wgbh/pages/frontline/shows/jefferson/mixed/onedrop.html

Davis, J. E. (1994). College in Black and White: Campus environment and academic achievement of African American males. The Journal of Negro Education, 63(4), 620-633. doi:10.2307/2967299

Davis, P. C. (1989). Law as microaggression. Yale Law Journal, 98(8), 1559-1577. doi:10.2307/796605

Delgado, R., \& Stafancic, J. (2012). Critical race theory: An introduction. New York, NY: New York University Press.

DeSousa, J. (2001). Reexamining the educational pipeline for African-American students. In L. Jones (Ed.), Retaining African Americans in higher education: Challenging paradigms for retaining students, faculty and administrators (pp. 2144). Sterling, VA: Stylus Publishing.

Dobbs, R. L., Sun, J. Y., \& Roberts, P. B. (2008). Human capital and screening theories: Implications for human resource development. Advances in Developing Human Resources, 10(6), 788-801. doi:10.1177/1523422308325761

Dockery, D. B. (2015). The experiences of African American males in leadership positions at predominantly White institutions of higher learning (Doctoral dissertation). Retrieved from ProQuest. Dissertations and Theses database. (UMI No. 10003436) 
Dragan, I. R., \& Isaic-Maniu, A. (2013). Snowball sampling completion. Journal of Studies in Social Sciences. 5(2), 160-177. Retrieved from http://infinitypress.info/

DuBois, W. E. B. (1903). The souls of Black folks. Oxford: Oxford University Press

Dunbar, D. R., \& Kinnersley, R. T. (2011). Mentoring female administrators toward leadership success. Delta Kappa Gamma Bulletin, 77(3), 17-24. Retrieved from www.deltakappagamma.org

Eastland, T. (1997). Ending affirmative action: The case for colorblind justice. New York, NY: Harper Collins.

Egerton, J. (1974). Adam v. Richardson: Can separate be equal? Change, 6(10), 29-36. doi:10.1080/00091383.1974.10568794

Ehrenberg, R. G., \& Smith, R. S. (1997). Modern labour economics: Theory and public policy. New York, NY: Harper Collins.

Evans, A., \& Chun, E. B. (2007). The theoretical framework: Psychosocial oppression and diversity. ASHE Higher Education Report, 33(1), 1-139. doi:10.1002/aehe.3301

Feagin, J. R., \& Sikes, M. P. (1994). Living with racism: The Black middle-class experience. Boston, MA: Beacon Press.

Fleming, J. (1984). Blacks in college: A comparative study of student success in Black and White institutions. San Francisco, CA: Jossey-Bass.

Fujii, S. J. (2014). Diversity, communication, and leadership in the community college faculty search process. Community College Journal of Research and Practice, 38(10), 903-916. doi:10.1080/10668926.2012.725387 
Flowers, L. A., \& Moore, J. L. (2008). Unraveling the composition of academic leadership in higher education: Exploring administrative diversity at 2-year and 4year institutions. Journal of Thought, 40(3), 71-81. doi:10.2307/jthought.43.34.71

Fries-Brit, S., \& Turner, B. (2002). Uneven stories: Successful Black collegians at a Black and White campus. The Review of Higher Education, 25(3), 315-330. doi:10.1353/rhe.2002.0012

Fujimoto, E. O. (2012). Hiring diverse faculty members in community colleges: A case study in ethical decision making. Community College Review, 40(3), 255-274. doi:10.1177/0091552112450069

Galarraga, F. (2014). Diversity at work: The practice of inclusion. Journal of Psychological Issues in Organizational Culture, 5(1), 73-80. doi:10.1002/jpoc.21132

Gardner, L., Barrett, T. G., \& Pearson, I. C. (2014). African American administrators at PWIs: Enablers of and barriers to career success. Journal of Diversity in Higher Education, 7(4), 235-251. doi:10.1037/a0038317

Gasman, M., \& Abiola, U. (2016). Colorism within the historically Black colleges and universities (HBCUs). Theory Into Practice, 55(1), 39-45. doi:10.1080/00405841.2016.1119018

Gasman, M., Abiola, U., \& Travers, C. (2015). Diversity and senior leadership at elite institutions of higher education. Journal of Diversity in Higher Education, 8(1), 1. doi:10.1037/a0038872 
Gasman, M., Baez, B., Drezner, N. D., Sedgwick, K., Tudico, C., \& Schmid, J. M. (2007). Historically Black colleges and universities: Recent trends. Academe, 93, 69-78. Retrieved from http://repository.upenn.edu/gse_pubs/46

Gasman, M., \& Tudico, C. (Eds.). (2009). Historically Black colleges and universities: Triumphs, troubles, and taboos. New York, NY: Palgrave Macmillan.

Given, L. (2016). 100 questions (and answers) about qualitative research. Newbury Park, CA: Sage.

Glazer, N. (2000). Society needs affirmative action in higher education. Affirmative Action. Retrieved from http://archive.wilsonquarterly.com/inessence/reconsidering-affirmative-action

Greenbank, P. (2003). The role of values in educational research: The case for reflexivity. British Educational Research Journal, 29(6), 791-801. doi:10.1080/0141192032000137303

Grotrian-Ryan, S. (2015). Mentoring functions and their application to the American Council on Education (ACE) Fellows leadership development program. International Journal of Evidence Based Coaching and Mentoring, 13(1), 87-105. Retrieved from http://ijebcm.brookes.ac.uk/

Harbison, F., \& Myers, C. A. (1964). Education, manpower, and economic growth: Strategies of human resource development. New York, NY: McGraw-Hill. Harris, J. V. (1992). African-American conception of literacy: A historical perspective. Theory into Practice, 31(4), 276-286. doi:10.1080/00405849209543554

Harvey, W. B. (1999). Grass roots and glass ceilings. Albany, NY: State University of New York Press. 
Harvey, W. B. (2014). Chief diversity officers and the wonderful world of academe. Journal of Diversity in Higher Education, 7(2), 92-100. doi:10.1037/a0036721

Hebel, S. (2001). A settlement and more division in Mississippi. Chronicle of Higher Education, 47(34), A23-A24. Retrieved from https://www.chronicle.com

Higgs, S. A. (2014). The Obama effect: A study of African American leadership in the community college (Doctoral dissertation). Retrieved from ProQuest Dissertations and Theses database. (UMI No. 3646846)

Hiraldo, P. (2010). The role of critical race theory in higher education. The Vermont Connection, 31, 53-59. Retrieved from https://www.uvm.edu/ vtconn/

Holmes, S. (2003). Black female administrators speak out: Narratives on race and gender in higher education. National Association of Student Affairs Professionals Journal, 6(1), 45-66. Retrieved from https://www.nasap.net/

Holmes, S. L. (2004). An overview of African American college presidents: A game of two steps backward, and standing still. Journal of Negro Education, 73(1), 21-39. doi: $10.2307 / 3211257$

Howard-Hamilton, M. (2003). Theoretical framework for African American women. New Direction for Student Services, 104, 19-27. doi:10.1002/ss.104

Hubbard, S. S., \& Robinson, J. P. (1998). Mentoring: A catalyst for advancement in administration. Journal of Career Development, 24(4), 289-299. doi:10.1177/089484539802400402

Humphreys, J. (2006). Economic impact of the nation's historically Black colleges and universities - technical report. Retrieved from https://nces.ed.gov/ 
Jackson, J. F. (2001). A new test for diversity: Retaining African American administrators at predominantly White institutions. In L. Jones (Ed.), Retaining African Americans in Higher Education: Challenging Paradigms for Retaining Students, Faculty, and Administrators (pp. 93-109). Sterling, VA: Stylus.

Jackson, J. F. (2004). Engaging, retaining, and advancing African Americans in executive level positions: A descriptive and trend analysis of academic administrators in higher and postsecondary education. Journal of Negro Education, 73(1), 4-20. doi: $10.2307 / 3211256$

Jackson, J. F. L., \& O’Callaghan, E. M. (2009a). Ethnic and racial administrative diversity: Understanding work life realities and experiences in higher education. ASHE Higher Education Report, 35(3). doi:10.1002/ache.3503

Jackson, F. L., \& O’ Callaghan, E. M. (2009b). Factors influencing engagement, retention and advancement for administrators of color. In ASHE Higher Education Report, 35(3), 47-64. San Francisco, CA: Jossey-Bass.

Jackson, K. (1991). Black faculty in academia. In W. A. Smith, P. G. Altbach, \& K. Lomotely (Eds.), The racial crisis in American higher education, (pp. 135-148). Albany, NY: State University of New York Press.

Jacobson, A. K., \& Lomotey, K. (1995). African American women in educational administration: The importance of mentors and sponsors. The Journal of Negro Education, 64(4), 409-422. doi:10.2307/2967264

Jones, W. A. (2007). Living with a majority-minority mindset. Diverse Issues in Higher Education, 24(15), 29. Retrieved from http://diverseeducation.com/article 
Judson, H. (1999). A meaningful contribution. In W. B. Harvey (Ed.), Grass roots and glass ceilings: African American administrators in predominantly White colleges and universities (pp. 83-111). Albany, NY: SUNY Press.

Juffer, J. (2001). The limits of culture: Latino studies, diversity management, and the corporate university. Nepantala: Views from South, 31(1), 127-140. Retrieved from https://muse.jhu.edu/article/

Kanter, R. M. (1993). Men and women of the corporation (2nd ed.). New York, NY: Basic Books.

Kaplin, W. A., \& Lee, B. A. (1997). A legal guide for student affairs professionals (3rd ed.). San Francisco, CA: Jossey-Bass.

Kaplin, W. A., \& Lee, B. A. (2014). The law of higher education (5th ed.). San Francisco, CA: Jossey-Bass.

Kaplowitz, M. D. (2001). Assessing mangrove products and services at the local level: The use of focus groups and individual interviews. Landscape and Urban Planning, 56, 53-60. doi:10.1016/S0169-2046(01)00170-0

Kayes, P. E. (2006). New paradigms for diversifying faculty and staff in higher education: Uncovering cultural biases in the search and hiring process. Multicultural Education, 14(2), 65-69. Retrieved from http://www.caddogap.com/ Kelly, B. T., Gayles, J. G., \& Williams, C. D. (2017). Recruitment without retention: Acritical case of Black faculty unrest. The Journal of Negro Education, 86(4), 305-317. doi:10.7709/jnegroeducation.86.3.0305 
King, J. F., \& Gomez, G. G. (2008). On the pathway to the presidency: Characteristics of higher education's senior leadership [Report]. Retrieved from https://www.acenet.edu/

King, K. L., \& Watts, I. E. (2004). Assertiveness or the drive to succeed? Surviving at a predominantly White university. In D. Cleveland (Ed.), A Long Way to Go: Conversations About Race by African American Faculty and Graduate Students (pp. 110-119). New York, NY: Peter Lang.

Kingsley, J. D. (1946). Representative bureaucracy: An interpretation of the British civil service. The American Historical Review, 52(1), 129-132. doi:10.2307/1845094

Kowalewski, S., Moretti, L., \& McGee, D. (2011). Succession planning: Evidence from best companies in New York. International Journal of Management and Marketing Research, 4(2), 99-108. Retrieved from https://www.theibrf.com/ijmmr.htm

Kram, K. E. (1985). Mentoring at work. Glenview, IL: Scott Foreman \& Co.

Kranz, H. (1976). The participatory bureaucracy: Women and minorities in a more representative public service. Lexington, MA: Lexington Books.

Ladson-Billings, G. (1998). Just what is critical race theory and what's it doing in a nice field like education? International Journal of Qualitative Studies in Education, 11(1), 7-24. doi:10.1080/095183998236863

Ladson-Billings, G., \& Donner, J. (2005). The moral activist role of critical race theory scholarship. In N. K. Denzin \& Y. S. Lincoln (Eds.), The SAGE handbook of qualitative research (pp. 279-301). Thousand Oaks, CA: Sage. 
Larkin, M., \& Thompson, A. (2012). Interpretative phenomenological analysis. In A. Thompson \& D. Harper (Eds.), Qualitative research methods in mental health and psychotherapy: A guide for students and practitioners, (pp. 99-116). doi:10.1002/9781119973249

Larson, A. D. (1973). Representative bureaucracy and administrative responsibility: A reassessment. Midwest Journal of Public Administration, 7(1), 79-89.

LeMelle, T. J. (2002). The HBCU: Yesterday, today and tomorrow. Education, 123(1), 190-197. Retrieved from https://www.projectinnovation.com/

Levin, J. S., Walker, L., Haberler, Z., \& Jackson-Boothby, A. (2013, October 30). The divided self: The double consciousness of faculty of color in community colleges. Community College Review. doi:101177/0091552113504454

Levitan, D. M. (1946). The responsibility of administrative officials in a democratic society. Political Science Quarterly, 61(4), 562-598. doi:10.2307/2144373

Lincoln, Y. S., \& Guba, E. G. (1985). Naturalistic inquiry. Thousand Oaks, CA: Sage.

Lopez, I. H. (2006). Race, law and society. Oxford, MA: Blackwell Publishing.

Lords, E. (2002). Keeping Jim Crow alive: A Ferris State University museum aims to use the pain of racist and offensive material to educate and foster racial healing. Black Issues - Diverse Issues in Higher Education, 19(8), 28-31. Retrieved from https://diverseeducation.com/

Lunenburg, F. C., \& Irby, B. J. (2008). Writing a successful thesis or dissertation: Tips and strategies for students in the social and behavioral sciences. Thousand Oaks, CA: Corwin. 
Lynn, M., \& Adams, M. (2002). Introductory overview to the special issue critical race theory and education: Recent development in the field. Equity \& Excellence in Education, 35(2), 87-92. doi:10.1080/713845285

Lynn, M., Benigno, G., Williams, D. A., Park, G., \& Mitchell, C. (2006). Critical theories of race, class and gender in urban education. Encounter, 19(2), 17-25. Retrieved from www.ferris.edu/jimcrow.

Lynn, M., \& Parker, L. (2006). Critical race studies in education: Examining a decade of research on U.S. schools. The Urban Review, 38(4), 257-290. doi:10.1007/s11256-006-0035-5

Marable, M. (1996). Stay on the path to racial equality. In G. E. Curry (Ed.), The affirmative action debate. Reading, MA: Addison-Wesley.

Marable, M. (2008). Blacks in higher education: An endangered species. Retrieved from http://www.nathanielturner.com/blacksinhighereducation.htm

Martin, A. L. (2014). Fifty years after integration: Have we overcome?. Journal of Higher Education Management, 29(1), 4-15. Retrieved from http://www.ijhem.com/

McLean, G. N. (2004). National human resource development: What in the world is it? Advances in Developing Human Resources, 6(3), 269-275. doi:10.1177/1523422304266086

McMillian, J. H. (2012). Educational research: Fundamentals for the consumer (6th ed.). Boston, MA: Pearson.

McNeal, L. R. (2009). Re-segregation of public education now and after the Brown v. Board of Education. Education and Urban Society, 41(5), 562-574. 
doi:10.1177.0013124509333578

Meier, K. J. (1975). Representative bureaucracy: An empirical analysis. The American Political Science Review, 69(2), 526-542. doi:10.2307/1959084

Meier, K. J., \& Nigro, L. (1976). Representative bureaucracy and policy preferences: A study in the attitudes of federal executives. Public Administration Review, 36(4), 458-469. doi:10.2307/974854

Meier, K. J., \& Smith, K. (1994). Representative democracy and representative bureaucracy: Examining the top-down and bottom-up linkages. Social Science Quarterly, 75, 790-803. Retrieved from http://socialsciencequarterly.org/

Menzel, D., \& White, H. (2011). The state of public administration: Issues, challenges, and opportunities. Armonk, NY: M.E. Sharpe.

Merriam, S. B. (1998). Case study research in education: A qualitative approach. San Francisco, CA: Jossey-Bass.

Merriam, S. B., \& Simpson, E. L. (2000). A guide to research for educators and trainers of adults (2nd ed.). Malabar, FL: Krieger.

Merriam, S. B., \& Tisdell, E. (2015). Qualitative research: A guide to design and implementation (4th ed.). San Fransico, CA: Jossey-Bass.

Miles, M. B., \& Huberman, A. M. (1994). Qualitative data analysis (2nd ed.). Thousand Oaks, CA: Saga.

Mosher, F. C. (1982). Democracy and the public service (2nd ed.). New York, NY: Oxford University Press. 
Nafukho, F. M., Hairston, N. R., \& Brooks, K. (2004). Human capital theory: Implications for human resource development. Human Resource Development International, 7(4), 545-551. doi:10.1080/1367886042000299843

National Center for Educational Statistics [NCES]. (2016). Retrieved from https://nces.ed.gov/ipeds/

National Science Foundation. (2015). Doctorate recipients from U.S. universities: 2014. Retrieved from http://www.nsf.gov/statistics/2016/nsf16300/report.cfm

Nelms, C. (1999). From cotton picker to university CEO. In W. B. Harvey (Ed.), Grass root and glass ceilings: African American administrators in predominantly White colleges and universities (pp. 39-56). Albany, NY: SUNY Press.

Orellano, T. (2018). Succession planning as a key to effective managerial transition process in corporate organizations. American Journal of Management Science and Engineering, 3(2), 1-6. doi:10.11648/j.ajmse.20180301.11

Owen, D. S. (2009). Privileged social identities and diversity leadership in higher education. The Review of Higher Education, 32(2), 185-207. Retrieved from https://www.press.jhu.edu/journals/review-higher-education

Palmer, R. T. (2008). Promoting HBCUs. Diverse Issues in Higher Education, 24(26). Retrieved from https://diverseeducation.com/

Palmer, R. T., Davis, J. R., \& Maramba, D. C. (2011). The impact of family support on the success of Black men at an historically Black university: Affirming the revision of Tinto's theory. Journal of College Student Development, 52(5), 577597. doi:10.1353/csd.2011.0066 
Palmer, R. T., Davis, J. R., Moore, J. L., \& Hilton, A. A. (2010). A nation at risk: Increasing college participation and persistence among African American males to stimulate U.S. global competitiveness. Journal of African American Males In Education. 1(2), 105-124. Retrieved from http://www.journalofafricanamericanmales.com

Palmer, R. T., \& Gasman, M. (2008). "It takes a village to raise a child": The role of social capital in promoting academic success for African American men at Black colleges. Journal of College Student Development, 49(1), 52-70. doi:10.1353/csd.2008.0002

Parker, L., \& Villalpando, O. (2007). A racialized perspective on education leadership: Critical race theory in educational administration. Educational Administration Quarterly, 43, 519-524. doi:10.1177/0010013161X07307795

Patton, M. Q. (1999). Enhancing the quality and credibility of qualitative analysis. Health Sciences Research, 34, 1189-1208. Retrieved from https:/www.ncbi.nlm.nih.gov/

Perna, L. W., Gerald, D., Baun, E., \& Milem, J. (2007, March). The status of equity for black faculty and administrators in public higher education in the south. Research in Higher Education, 48(2). doi:10.1007/s1162-006-9041-4

Perrakis, A., Campbell, D. M., \& Antonaros, M. (2009). Diversifying the community college CEO pipeline. Community College Enterprise, 15(1), 7-19. Retrieved from https://schoolcraft.edu/cce/community-college-enterprise

Pewewardy, C., \& Frey, B. (2002). Surveying the landscape: Perceptions of multicultural support services and racial climate at a predominantly White university. The 
Journal of Negro Education, 71(1/2), 77-98. Retrieved from

http://www.journalnegroed.org/

Phillips, P. P., Phillips, J. J., \& Arron, B. (2013). Survey basics. Alexandria, VA: ASTD

Press.

Pierce, C. M., Carew, J. V., Pierce-Gonzales, D., \& Willis, D. (1977, November 1). An experiment in racism: TV commercials. Education and Urban Society, 10(1), 6187. doi:10.1177/001312457701000105

Pietkiewicz, I., \& Smith, J. (2014). A practical guide to using interpretative phenomenological analysis in qualitative research psychology. Psychological Journal, 18(2), 361-369. doi:10:14691/CPPJ.20.1.7

Prendergast, C. (2002). The economy of literacy: How the Supreme Court stalled the civil rights movement. Harvard Educational Review, 72(2), 206-230.

doi:10.17763/haer.72.2.18112t70x6klx6j0

Purdie-Vaughns, V., Steele, C. M., Davies, P. G., Ditlmann, R., \& Crosby, J. R. (2008). Social identity contingencies: How diversity cues signal threat or safety for African Americans in mainstream institutions. Journal of Personality and Social Psychology, 94(4), 615-630. doi:10.1037/0022-3514.94.4.615

Quezada, R. L., \& Louque, A. (2004). The absence of diversity in the academy: Faculty of color in educational administration programs. Education, 125(2), 213. Retrieved from https://www.projectinnovation.com/

Ragins, B. R. (1997). Diversified mentoring relationships in organizations: A power perspective. Academy of Management Review, 22(2), 482-521. doi:10.2307/259331 
Rai, K. B., \& Critzer, J. W. (2000). Affirmative action and the university: Race, ethnicity, and gender in higher education employment. Lincoln, NE: University of Nebraska Press.

Rehfuss, J. A. (1986). A representative bureaucracy? Women and minority executives in California career services. Public Administration Review, 46(5), 454-460. doi:10.2307/975785

Reyes, X. A., \& Rios, D. (2005). Dialoguing the Latina experience in higher education. Journal of Hispanic Higher Education, 4(4), 377-391. doi:10.1177/1538192705280079

Rhodes, D. L. (2003). The difference “difference” makes: Female and leadership. Stanford, CA: Stanford University Press.

Riggs, J. (2009). Leadership for tomorrow's community colleges. The Community College Enterprise, 15(2), 27-38. Retrieved from http://www.schoolcraft.edu/ccE/

Roberts, C. M. (2010). The dissertation journey: a practical and comprehensive guide to planning, writing, and defending your dissertation (2nd ed.). Thousand Oaks, CA: Corwin.

Robinson, P. A., Byrd, D., Louis, D. A., \& Bonner, F. A. (2013). Enhancing faculty diversity at community colleges: A practical solution for advancing the completion agenda. Focus on Colleges, Universities, and Schools, 7(1), 1-11. Retrieved from http://www.nationalforum.com/Journals/FOCUS/FOCUS.htm Robinson-Neal, A. (2009). Exploring diversity in higher education management: History, trends, and implications for community colleges. International Electronic Journal 
for Leadership in Learning, 13(4), 1-18. Retrieved from https://www.learntechlib.org

Rolle, K. A., Davis, T. G., \& Banning, J. H. (2000). African American administrators' experiences in predominantly White colleges and universities. Community College Journal of Research and Practice, 24, 79-94.

doi:10.1080/106689200264222

Rosenberg, G. (2004). The 1964 Civil Rights Act: The crucial role of social movements in the enactment and implementation of anti-discrimination law. Saint Louis University Law Journal, 49(1147), 1147-1153. Retrieved from https://www.slu.edu/law/law-journal/

Rothwell, W. J. (2005). Effective succession planning: Ensuring leadership continuity and building talent from within (3rd ed.). New York, NY: American Management Association.

Rudolph, F. (1990). The American college and university: A history. Athens, GA: University of Georgia Press.

Rusch, E. A., \& Horsford, S. D. (2009). Changing hearts and minds: The quest for open talk about race in educational leadership. International Journal of Educational Management, 23, 302-313. doi:10.1108/09513540910957408

Sabharwal, M. (2014). Is diversity management sufficient? Organizational inclusion to further performance. Public Personnel Management, 43(2), 197-217. https://doi:org/10.1177/0091026014522202

Saldana, J. (2009). The coding manual for qualitative researchers. Thousand Oaks, CA: Sage. 
Scandura, T. A. (1992). Mentorship and career mobility: An empirical investigation. Journal of Organizational Behavior, 13(2), 169-174. doi:10.1002/job.4030130206

Schultz, T. W. (1961). Investment in human capital. American Economic Review, 51(1), 1-17. Retrieved from https://www.aeaweb.org/

Schultz, T. W. (1981). Investing in people: The economics of population quality. Los Angeles, CA: University of California Press.

Searby, L., Ballenger, J., \& Tripses, J. (2015). Climbing the ladder, holding the ladder: The mentoring experiences of higher education female leaders. Advancing Women in Leadership, 35, 98-107. doi:10.18738/awl.v35i0.141

Sears, D. O., Van Laar, C., Carrillo, M., \& Kosterman, R. (1997). Is it really racism? The origin of white Americans' opposition to race-targeted policies. Public Opinion Quarterly, 61(1), 16-53. doi:10.1086/297785

Selden, S. C. (1997). The promise of representative bureaucracy: Diversity and responsiveness in a government agency. New York, NY: Routledge.

Seltzer, R. (2017, June 20). The slowly diversifying presidency. Retrieved from https://www.insidehighered.com/news/

Shank, G. D. (2002). Qualitative research: A personal skills approach. Upper Saddle River, NJ: Merrill Prentice Hall.

Shuman, A. (2006). Entitlement and empathy in personal narrative. Narrative Inquiry, 16(1), 148-155. doi.10.1075/ni.16.1.19shu

Slater, R. B. (1994). The Blacks who first entered the world of White higher education. Journal of Blacks in Higher Education, 4, 47-56. doi:10.2307/2963372 
Smith, J. A., \& Osborn, M. (2007). Interpretative phenomenological analysis. In J. A. Smith (Ed.), Qualitative psychology - A practical guide to research methods (pp. 53-80). Retrieved from http://med-fomfamilymedresearch.sites.olt.ubc.ca/files/2012/03/IPA_Smith_Osborne21632.pdf Spearman, J., \& Harrison, L. (2010). Real role models: Successful African Americans beyond pop culture. Austin: University of Texas Press

Stafford, K. L., Lundstedt, S. B., \& Lynn, A. D. (1984). Social and economic factors affecting participation in higher education. The Journal of Higher Education, 55(5), 590-608. doi:10.2307/1981824

Steele, C. (2003). Race and the schooling of Black Americans. In S. Plous (Ed.), Understanding prejudice and discrimination (pp. 98-107). New York, NY: McGraw-Hill.

Stefkovich, J., \& Leas, T. (1994). A legal history of desegregation in higher education. Journal of Negro Education, 63, 406-420. doi:10.2307/2967191

Stewart, G. L., \& Brown, K. G. (2010). Human resource management: Linking strategy to practice (2nd ed.). Hoboken, NJ: Wiley.

Sue, D. W. (2013). Race talk: The psychology of racial dialogues. American Psychologist, 68(8), 663-672. doi:10.1037/a0033681

Sue, D. W., Capodilupo, C. M., \& Holder, A. M. (2008). Racial microaggressions in the life experience of Black Americans. Professional Psychology: Research and Practice, 39, 329-336. doi.10.1037/0735-7028.39.3.329

Sue, D. W., Capodilupo, C. M., Torino, G. C., Bucceri, J. M., Holder, A. M., Nadal, K. L., \& Esquilin, M. E. (2007). Racial microaggressions in everyday life: 
Implications for clinical practice. American Psychologist, 62, 271-286.

doi:10.1037/0003-066X.62.4.271

Sue, D. W., Lin, A. I., Torino, G. C., Capodilupo, C. M., \& Rivera, D. P. (2009). Racial microaggressions and difficult dialogues on race in the classroom. Cultural Diversity and Ethnic Minority Psychology, 15(2), 183-190. doi:10.1037/a0014191.

Sum, P. E., Lights, S. A., \& King, R. F. (2004). Race, reform, and desegregation in Mississippi higher education: Historically Black institutions after United States v. Fordice. Law \& Social Inquiry, 29, 403-435. doi:10.1111/j.17474469.2004.tb00341.x

Swanson, R. A., \& Holton, E. F. (2005). Research in organizations: Foundations and methods of inquiry. San Francisco, CA: Berrett-Koehler.

Sweetland, S. R. (1996). Human capital theory: Foundations of a field of inquiry. Review of Educational Research, 66(3), 341-359. doi:10.2307/1170527

Tan, E. (2014). Human capital theory: A holistic criticism. Review of Educational Research, 84(3), 411-445. doi:10.3102/0034654314532696

Tessens, L., White, K., \& Web, C. (2011). Senior women in higher education institutions: Perceived development needs and support. Journal of Higher Education Policy and Management, 33(6), 653-665. doi:10.1080/1360080X.2011.621191

The tradition of White presidents at Black colleges. (1997). The Journal of Blacks in Higher Education, 16, 93-99. doi:10.2307/2962918 
Tillman, L. C. (2001, June). Mentoring African American faculty in predominantly white institutions. Research in Higher Education, 42(3), 295-325.

doi:10.1023/A\%3A1018822006485

Tomar, D. (2018). The history of historically Black colleges. Retrieved from https://thebestschools.org/magazine/historically-black-colleges/

Trochim, W. M. (2006). The research methods knowledge base (2nd ed.). Retrieved from https://socialresearchmethods.net/kb/

Turner, C., \& Grauerholz, L. (2017). Introducing the invisible man. Black male professionals in higher education. Humboldt Journal of Social Relations, 39, 212227. Retrieved from https://digitalcommons.humboldt.edu/hjsr

Turrentine, C. J., \& Conley, V. M. (2001). Two measure of the diversity of the labor pool for entry level student affairs positions. NASP Journal, 39, 84-102. doi:10.2202/1949-6605.1161

Underrepresentation. (n.d.) In Merriam-Webster.com. Retrieved February 14, 2018, from https://www.merriam-webster.com/dictionary/underrepresentation

U.S. Department of Education. (2018). White House Initiative on Historically Black Colleges and Universities. Retrieved from https://sites.ed.gov/whhbcu/onehundred-and-five-historically-black-colleges-and-universities/

Vance, M. C. (2016). The importance of mentoring for higher ed leadership. Retrieved from https://www.higheredjobs.com/Articles/articleDisplay.cfm?ID=1077

Wagner, A. (2006). Measuring up internationally: Developing skills and knowledge for the global knowledge economy. (Report \#06-7). Retrieved from http://www.highereducation.org/reports/reports.shtml 
Walters, D. (2004). The relationship between postsecondary education and skills: Comparing credentialism with human capital. The Canadian Journal of Higher Education, 34(2), 97-124. Retrieved from http://journals.sfu.ca/cjhe/index.php/cjhe/article/view/183458

Washington, V., \& Harvey, W. (1989). Affirmative rhetoric, negative action: AfricanAmerican and Hispanic faculty at predominantly White institutions. Retrieved from ERIC database. (ED316075)

White, J. L., \& Cones, J. H. (2013). Black man emerging: Facing the past and seizing future in America. New York, NY: Routledge.

Whittaker, J. A., Montgomery, B. L., \& Acosta, V. G. (2015 July 15). Retention of underrepresented minority faculty: Strategic initiatives for institutional value proposition based on perspectives from a range of academic institutions. Journal of Undergraduate Neuroscience Education, 13(3), 136-145. Retrieved form https://www.ncbi.nlm.nih.gov/

Williams, H. (2001). The data speaks: No rest for the weary. In L. Jones (Ed.), Making it on broken promises (pp. 15-30). Sterling, VA: Stylus Publishing, LLC.

Williams, J. C. (2005). The glass ceiling and the maternal wall in academia. Directions for Higher Education, 2005(130), 91-105. doi:10.1002/he.181

Wilson, H. A. (1998). Does affirmative action for Blacks harm Whites? Some evidence from the higher education arena. Western Journal of Black Studies, 22(4), 218225. Retrieved from https://education.wsu.edu/wjbs/

Wilson, J. L. (2015). Maximizing impact: Purposefully incorporating diversity efforts within postsecondary system wide and institutional strategic plans. Planning for 
Higher Education, 43(2), 15-23. Retrieved from

https://www.questia.com/library/p436211/

Wilson, J. L., \& Meyer, K. A. (2013). The treatment and use of best practices for diversity in position announcements for new presidents. Innovative Higher Education, 38(2), 91-104. doi:10.1007/s10755-012-9227-y

Wilson, J. L., Meyer, K. A., \& McNeal, L. (2012). Mission and diversity statements: What they do and do not say. Innovative Higher Education, 37(2), 125-139. doi:10.1007/s10755-011-9194-8

Wyatt-Nichol, H., \& Antwi-Boasiako, K. B. (2012). Diversity management: Development, practices, and perceptions among state and local government agencies. Public Personnel Management, 41(4), 749-772. doi:10.1177/009102601204100409

Wolfe, B. L. (2010). When being black isn't enough: Experiences and persistence strategies of six African American administrators at a PWI (Doctoral dissertation). Retrieved from ProQuest Dissertations and Theses database. (UMI No. 3446190).

Yosso, T. J. (2005). Whose culture has capital? A critical race theory discussion of community cultural wealth. Race Ethnicity and Education, 8(1), 69. doi:10.1080/1361332052000341006

Zamudio, M. M., Russell, C., Rios, F. A., \& Bridgeman, J. L. (2011). Critical race theory matters: Education and ideology. New York, NY: Routledge.

Young, A. M., Cady, S., \& Foxon, M. J. (2006, June). Demystifying gender differences in mentoring: Theoretical perspectives and challenges for future research on 
gender and mentoring. Human Resource Development Review, 5(2), 148-175. doi: $10.1177 / 153448306287140$

Yull, D. (2014, October 1). Race has always mattered: An intergeneration look at race, space, place, and educational experiences of Blacks. Educational Research International. 2014, 1-13. doi.10.1155/2014/683035 